Chemical Technology

Division

ANL-98/27

Chemical Technology

Division

Chemical Technology

Division

Chemical Technology

Division

Chemical Technology

Division

Chemical Technology

Division

Chemical Technology

Division

Chemical Technology

Division

Chemical Technology

Division

Chemical Technology

Division

Chemical Technology

Division

by W. L. Ebert, E. C. Buck, J. S. Luo, S.-W. Tam, and J. K. Bates

Chemical Technology

Division

Chemical Technology

Division

Chemical Technology

Division

Chemical Technology

Division

Chemical Technology

Division

Chemical Technology

Division

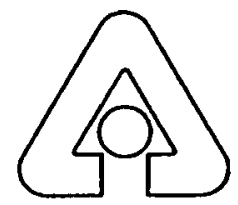

Argonne National Laboratory, Argonne, Illinois 60439

operated by The University of Chicago

for the United States Department of Energy under Contract W-31-109-Eng-38

Chemical Technology

Division

Chemical Technology

Division

Chemical Technology

Division

Chemical Technology

Division 
Argonne National Laboratory, with facilities in the states of Illinois and Idaho, is owned by the United States government, and operated by The University of Chicago under the provisions of a contract with the Department of Energy.

\section{DISCLAIMER}

This report was prepared as an account of work sponsored by an agency of the United States Government. Neither the United States Government nor any agency thereof, nor any of their employees, makes any warranty, express or implied, or assumes any legal liability or responsibility for the accuracy, completeness, or usefulness of any information, apparatus, product, or process disclosed, or represents that its use would not infringe privately owned rights. Reference herein to any specific commercial product, process, or service by trade name, trademark, manufacturer, or otherwise, does not necessarily constitute or imply its endorsement, recommendation, or favoring by the United States Government or any agency thereof. The views and opinions of authors expressed herein do not necessarily state or reflect those of the United States Government or any agency thereof.

Reproduced from the best available copy.

Available to DOE and DOE contractors from the

Office of Scientific and Technical Information

P.O. Box 62

Oak Ridge, TN 37831

Prices available from (423) 576-8401

Available to the public from the National Technical Information Service

U.S. Department of Commerce 5285 Port Royal Road

Springfield, VA 22161 


\section{DISCLAIMER}

Portions of this document may be illegible in electronic image products. Images are produced from the best available original document. 


\section{ANL-98/27 \\ ARGONNE NATIONAL LABORATORY \\ 9700 South Cass Avenue \\ Argonne, Illinois 60439-4837}

\section{CORROSION BEHAVIOR OF ENVIRONMENTAL ASSESSMENT GLASS IN PRODUCT CONSISTENCY TESTS OF EXTENDED DURATION}

by

W. L. Ebert, E. C. Buck, J. S. Luo, S.-W. Tam and J. K. Bates

Chemical Technology Division

September 1998 



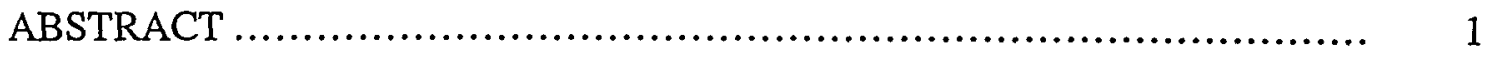

I. INTRODUCTION AND BACKGROUND ............................. 2

II. EXPERIMENTAL .................................................... 4

III. RESULTS ........................................................... 7

A. Test Results .................................................. 7

B. Solution Results ............................................... 7

C. Solids Results ........................................................ 9

IV. DISCUSSION ................................................... 12

A. Measured Dissolution Rates.......................................... 16

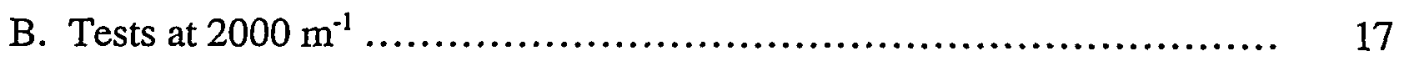

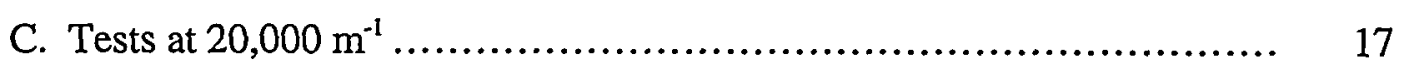

D. Comparison of Stage III Behavior of EA and Other DWPF Glasses ...... 18

V. CONCLUSIONS ................................................... 23

VI. ACKNOWLEDGMENTS ......................................... 24

VII. REFERENCES ................................................. 25

TABLES.......................................................... 27

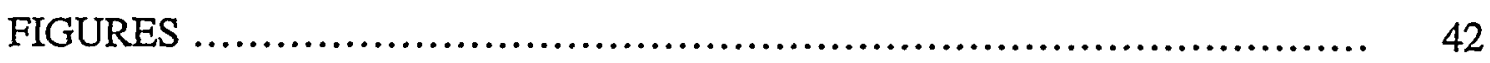

APPENDICES ........................................................... 56 


\title{
CORROSION BEHAVIOR OF ENVIRONMENTAL ASSESSMENT GLASS IN PRODUCT CONSISTENCY TESTS OF EXTENDED DURATION
}

\author{
W. L. Ebert, E. C. Buck, J. S. Luo, S.-W. Tam and J. K. Bates
}

\begin{abstract}
We have conducted static dissolution tests to study the corrosion behavior of the Environmental Assessment (EA) glass, which is the benchmark glass for high-level waste glasses being produced at U.S. Department of Energy facilities. These tests were conducted to evaluate the behavior of the EA glass under the same long-term and accelerated test conditions that are being used to evaluate the corrosion of waste glasses. Tests were conducted at $90^{\circ} \mathrm{C}$ in a tuff groundwater solution at glass surface area/solution volume (S/V) ratios of about 2000 and $20,000 \mathrm{~m}^{-1}$. The glass dissolved at three distinct dissolution rates in tests conducted at $2000 \mathrm{~m}^{-1}$. Based on the release of boron, dissolution within the first seven days occurred at a rate of about $0.65 \mathrm{~g} /\left(\mathrm{m}^{2} \cdot \mathrm{d}\right)$. The rate between seven and 70 days decreased to $0.009 \mathrm{~g} /\left(\mathrm{m}^{2} \cdot \mathrm{d}\right)$. An increase in the dissolution rate occurred at longer times after the precipitation of zeolite phases analcime, gmelinite, and an aluminum silicate phase. The dissolution rate after phase formation was about $0.18 \mathrm{~g} /\left(\mathrm{m}^{2} \cdot \mathrm{d}\right)$. The formation of the same zeolite alteration phases occurred after about 20 days in tests at $20,000 \mathrm{~m}^{-}$ ${ }^{1}$. The average dissolution rate over the first 20 days was $0.5 \mathrm{~g} /\left(\mathrm{m}^{2} \cdot \mathrm{d}\right)$ and the rate after phase formation was about $0.20 \mathrm{~g} /\left(\mathrm{m}^{2} \cdot \mathrm{d}\right)$. An intermediate stage with a lower rate was not observed in tests at $20,000 \mathrm{~m}^{-1}$. The corrosion behavior of EA glass is similar to that observed for other highlevel waste glasses reacted under the same test conditions. The dissolution rate of EA glass is higher than that of other high-level waste glasses both in 7-day tests and after alteration phases form.
\end{abstract}




\section{INTRODUCTION AND BACKGROUND}

High-level radioactive wastes stored at U.S. Department of Energy (DOE) facilities at Savannah River, SC; West Valley, NY; and Hanford, WA, will be immobilized in glass waste forms that will eventually be sent to a federal repository for disposal. The DOE has established waste acceptance product specifications (WAPS) for waste glasses produced at these facilities to facilitate the transfer between organizations responsible for immobilizing the waste and disposing the waste products [DOE-1993]. The WAPS require that the resistance of high-level radioactive waste glasses to dissolution exceed that of a benchmark glass, which is the Environmental Assessment (EA) glass, when assessed by using the Product Consistency Test-Method A (PCT-A) [ASTM-1994]. Although the PCT-A by itself is not currently presumed to provide insight into the long-term durability of a waste glass in a disposal environment, DOE is studying that relationship. It remains to be demonstrated that requiring a waste glass to be more durable than EA glass in PCT-A ensures that the glass will have acceptable longterm durability. The work described in this report and other work being conducted at ANL has been designed to gain a mechanistic understanding of glass corrosion behavior that can be used to predict performance in a disposal system.

We have used several different test methods to characterize the behavior of reference glasses representative of waste forms produced at the Defense Waste Processing Facility (DWPF) at the Savannah River Site and at the West Valley Demonstration Project (WVDP) at the West Valley Site at advanced stages of corrosion relevant to long disposal times. By "advanced stages of corrosion," we mean that very long exposure times would be required under disposal conditions to attain the same solution compositions and extents of surface alteration that are attained in these laboratory tests after only a few days. Those tests have shown that, while the dissolution rates of all glasses decrease initially as the concentrations of glass components in the contacting solution increase, the dissolution rates of many glasses increase upon the formation of certain alteration phases [EBERT-1993A, -1993B, FENG-1993, EBERT1990]. Although work remains to determine the mechanism by which phase formation affects the glass dissolution rate, it appears that some alteration phases act as thermodynamically stable sinks for dissolved silica and decrease the relative stability of the glass in the system.

An understanding of the long-term corrosion behavior of the EA glass is important because the response of that glass in PCT-A is used as the benchmark for waste glasses. The tests discussed in this report provide insight into the relationship between the relative behaviors of EA glass and waste glasses in short-term consistency tests and their long-term behaviors relevant to disposal. Specifically, demonstration that the corrosion behavior of the EA glass is sufficiently similar to that of anticipated waste glasses will provide added confidence that the product consistency requirement for highlevel waste glasses is relevant to their performance in a disposal system.

In this report, we discuss the results of static dissolution tests that were conducted for long time periods and at high glass surface area/solution volume $(\mathrm{S} / \mathrm{V})$ ratios to study the corrosion behavior of EA glass at advanced stages of corrosion. The test method used has been standardized as PCT-B [ASTM-1994]. Tests were conducted at two different $\mathrm{S} / \mathrm{V}$ ratios (approximately 2000 and $20,000 \mathrm{~m}^{-1}$ ) to characterize the glass corrosion behavior under conditions in which dissolved glass components accumulate in solution at different rates. The formation of alteration phases is expected to occur after different test durations, since different amounts of glass must dissolve to saturate the solutions. The same test conditions have been used to characterize other DWPF reference glasses, so test results can be directly compared. In addition, tests were conducted at $20,000 \mathrm{~m}^{-1}$ using 
two different size fractions of crushed glass to study the effects of particle size on the long-term corrosion behavior. These were conducted to determine if the increase in the dissolution rate that occurs coincidentally with the formation of certain alteration phases is affected by the size of the glass grains. 


\section{EXPERIMENTAL}

Crushed EA glass was supplied by the Savannah River Technology Center (SRTC) from a large batch fabricated by Corning Glass Works. Glass from that batch will be used for analyzing the product consistency of glass produced in all DWPF campaigns [PLODINEC-1991]. We measured the glass composition by first dissolving a small aliquot of glass in a mixture of nitric and hydrochloric acids at $90^{\circ} \mathrm{C}$ for several days then analyzing the resulting solution with inductively coupled plasma-mass spectrometry (ICP-MS). The composition measured at ANL is given in Table 1. The compositions measured at SRTC and by Corning Engineering Laboratory Services (CELS) when the EA glass was produced is included for comparison [JANTZEN-1993]. The measured compositions are in good agreement. The mass fractions of key cations in the EA glass that were used to normalize solution results are given in the table as $f(i)$, where i represents the cation of the listed oxide.

The glass received from SRTC was further crushed and sieved to isolate the -100 $+200(74-140 \mu \mathrm{m})$ and $-200+325(43-74 \mu \mathrm{m})$ mesh size fractions for testing. The crushed and sieved glass was washed to remove fines following the methodology specified in the PCT procedure and allowed to dry. The glass was translucent and amber in color. Glass particles of each size fraction were surveyed with a scanning electron microscope (SEM) to characterize their size and shape and to verify that the fines had been removed. Figures $1 \mathrm{a}$ and $1 \mathrm{~b}$ display photomicrographs of representative particles in the $-100+200$ mesh and $-200+325$ mesh size range. There are two typical particle shapes in both size fractions: rods and chunks. The compositions of particles of each shape were the same, as measured with energy dispersive X-ray spectroscopy (EDS) in an SEM. On the basis of SEM analysis, the crushed glass in each size fraction is estimated to consist of about $97 \%$ chunks and $3 \%$ rods by mass for each size fraction.

While the PCT procedure does not require knowledge of the surface area of the glass, the surface area must be known to calculate the dissolution rate and to compare the rates in tests conducted with different size fractions of crushed glass and at different $S / V$ ratios. The PCT procedure does recommend a method for calculating the specific surface area for crushed glass; we followed that procedure. We measured the density of the crushed glass by water displacement to be $2.65 \mathrm{~g} / \mathrm{cm}^{3}$. The specific surface areas of the two size fractions were estimated geometrically. In both size fractions, the rods were about $20 \mu \mathrm{m}$ in diameter and their average length was about $400 \mu \mathrm{m}$; therefore, the average specific surface area was calculated to be about $0.072 \mathrm{~m}^{2} / \mathrm{g}$ for the rods in both size fractions. The average specific surface areas of the chunks in each size fraction were estimated by assuming they were spheres with a diameter equal to the arithmetic average of the two sieve sizes. The specific surface areas of the glass chunks were calculated to be 0.019 and $0.038 \mathrm{~m}^{2} / \mathrm{g}$ for the $-100+200$ and $-200+325$ mesh fractions, respectively. From the estimated amounts of rods and chunks, the overall specific surface areas of the crushed glass were estimated to be 0.020 and $0.039 \mathrm{~m}^{2} / \mathrm{g}$ for the $-100+200$ and -200 +325 mesh size fractions, respectively.

Tests were conducted with the $-100+200$ mesh fraction at glass/water mass ratios of $1: 10$ and $1: 1$ to achieve $S / V$ ratios of about 2000 and $20,000 \mathrm{~m}^{-1}$, and with the -200 +325 mesh fraction at glass:water mass ratios of $1: 2$ to achieve an $S / V$ ratio of about $20,000 \mathrm{~m}^{-1}$. Tests were conducted in a tuff groundwater solution at $90^{\circ} \mathrm{C}$ for reaction times between 7 and 600 days. The groundwater solution was prepared by reacting groundwater from well J-13 on the Nevada Test Site with pulverized tuff ( $<100$ mesh) for 28 days at $90^{\circ} \mathrm{C}$. The resulting solution was allowed to cool to room temperature and then filtered with a $100-\mathrm{nm}$ pore size filter. The filtrate is referred to as EJ-13 water and 
its composition is given in Table 2. Water prepared by the same procedure has been used in tests with DWPF and WVDP reference glasses conducted previously [BATES-1992; EBERT-1996A]. Tests at $2000 \mathrm{~m}^{-1}$ were also conducted for 7 days using demineralized water for comparison with PCT-A results obtained by other workers. Two sets of triplicate PCT-A were conducted at different times. The first set was conducted with about $1 \mathrm{~g}$ glass and $10 \mathrm{~g}$ demineralized water. The second set of tests was conducted about three months later using glass from the same batch of crushed glass that was used in the first set of PCT-A. The second set of PCT-A was conducted with about $1.5 \mathrm{~g}$ glass and $15 \mathrm{~g}$ demineralized water in each test.

All tests were conducted in Type 304L stainless steel reaction vessels that had a volume of about $22 \mathrm{~mL}$. Appropriate amounts of glass and water were weighed into the vessels at the glass/water mass ratios needed to achieve the desired $\mathrm{S} / \mathrm{V}$ ratio. After the glass and EJ-13 water or demineralized water were weighed into the reaction vessels, the vessel was held at an angle of about $45^{\circ}$ and rotated slowly to ensure that all the glass was wetted and no air bubbles remained attached to the glass. The crushed glass was completely submerged in all tests; the amount of solution covering the glass varied between about 1 and $3 \mathrm{~cm}$, depending on the $S / V$ ratio of the test. The amount of air in the vessel varied with the test conditions. We estimate that tests conducted at $2000 \mathrm{~m}^{-1}$ contained about $12 \mathrm{~mL}$ of air, and that tests conducted at $20,000 \mathrm{~m}^{-1}$ with the $-100+200$ and $-200+325$ mesh glass contained about 15 and $16 \mathrm{~mL}$ of air, respectively. (The amount of air in the vessel may become important if carbon dioxide is consumed during the formation of carbonate alteration phases.) Vessels were sealed with Teflon gaskets and compression fittings, weighed, and then placed in an oven that had previously been set at $90^{\circ} \mathrm{C}$. The oven temperature was measured with a thermometer that was traceable to the National Institute of Standards and Technology (NIST) prior to testing and was continuously monitored using a Type $\mathrm{K}$ thermocouple throughout the testing program. The oven temperature and thermocouple read-out were verified with the thermometer semiannually, and remained within the $\pm 2^{\circ} \mathrm{C}$ tolerance specified in the PCT procedure throughout the testing period, except for brief periods (typically less than five minutes) after the oven was opened to remove test vessels for termination.

The test duration was measured from the time the vessel was placed in the oven until it was removed. The time required for the vessel, water, and glass to reach the test temperature is assumed to be negligible relative to the test duration. The durations of most of the tests were selected to match durations of tests with other glasses to permit direct comparison. The durations of some tests were not specified beforehand. These are referred to as "to be determined (TBD)" tests in the test matrix. They were run to allow data to be collected at test durations that were intermediate to or longer than tests with scheduled durations. Six tests were run in addition to the original test matrix: EA-91, EA-92, EA-93, EA-94, EA-95, and EA-96. These were conducted with the $-100+200$ mesh fraction to determine when alteration phases first formed at $20,000 \mathrm{~m}^{-1}$ since phases had already formed within the shorted duration originally scheduled (56 days).

At the end of the test duration, the vessel was removed from the oven, weighed, and opened immediately. Aliquots of the leachate solution were taken for $\mathrm{pH}$ and carbon analyses. The remaining leachate was then filtered through a $450-\mathrm{nm}$ pore size cartridge filter to remove any suspended glass particles; the filter and syringe were preheated to $90^{\circ} \mathrm{C}$ to avoid cooling the solution during filtration. All aliquots were taken while the leachate was near the test temperature to avoid thermally induced precipitation, but were allowed to cool to room temperature before analysis. An aliquot of the filtrate solution was taken for anion analysis. The solutions from two tests were further filtered through an Amicon CF50A filter (estimated pore size is $6 \mathrm{~nm}$ ) with the use of a centrifuge. These solutions were analyzed to distinguish the amounts of cations that were dissolved from 
material present in suspended colloids. All aliquots taken for cation analysis were acidified with a few drops of ultrapure concentrated nitric acid. Most of the aliquots were diluted with demineralized water prior to acidification.

The solution $\mathrm{pH}$ values were measured after the solutions cooled to room temperature but within two hours of test termination. The $\mathrm{pH}$ was measured with a combination electrode; the $\mathrm{pH}$ values were not adjusted for either sodium or temperature effects. The $\mathrm{pH}$ values measured at room temperature are assumed to be about one unit higher than the $\mathrm{pH}$ value at the test temperature of $90^{\circ} \mathrm{C}$; the sodium effect is discussed later. The total carbon and organic (nonpurgeable) carbon contents of most leachates were measured with a Dohrman ${ }^{\circledR}$ carbon analyzer. The total amount of carbon was measured by analyzing the solution without treatment. The nonpurgeable carbon content was measured by acidifying the sample with phosphoric acid then sparging with nitrogen gas. The purgeable carbon content, which includes inorganic carbon and organics removed by sparging, was calculated by difference. Aliquots of the filtrate solutions from some tests were analyzed for anions with ion chromatography (IC) and aliquots of all leachates were analyzed for cations with either inductively coupled plasma-mass spectroscopy (ICP-MS) or inductively coupled plasma-atomic emission spectroscopy (ICP-AES). Samples of the reacted solids were removed from the vessels and allowed to dry in air. The solids from some tests were analyzed with optical microscopy, SEM with associated EDS, and analytical transmission electron microscopy (AEM) with EDS and selected area electron diffraction (SAED). Alteration phases formed in some tests were located by viewing the reacted solids with an optical microscope and isolating altered glass and alteration phases using small particle handling techniques. The isolated material was analyzed with SEM/EDS, AEM, and X-ray diffraction (XRD). The XRD was done by fixing several crystallites onto a lightly greased glass filament and then analyzing in a powder camera using the Debye-Scherre method. Alteration phases were identified by chemical composition and comparison of the crystal planar distances (dspacings) measured in the XRD spectra and with SAED with the X-ray patterns of standard minerals. 


\section{RESULTS}

\section{A. Test Results}

The data for test execution are given in Appendix I. These include the measured glass, water, and vessel masses, the $S / V$ ratio, mass changes, dilutions that were made prior to submittal of solutions for analysis, etc. These data were used in the calculation of the solution concentrations, normalized mass losses, and dissolution rates. Only two significant figures are reported for the S/V ratios used in the calculations to match the uncertainty in the specific surface area of the crushed glass. For PCT-A results to be considered as valid, the mass loss during the test cannot exceed 5\% of the mass of water added to the test. The mass losses in the tests are well below this limit, and all tests were valid. For some tests, not enough leachate solution could be recovered to measure both the $\mathrm{pH}$ and cation concentrations. Aliquots were not analyzed for $\mathrm{pH}$ for tests EA-49, EA-52, EA-53, or EA-54. An appreciable amount of the water had been incorporated into alteration phases in those tests.

\section{B. Solution Results}

The solution cation results are presented in Appendix II for tests following PCT-A and in Appendix 3 for tests following PCT-B. In Appendix II, the analytical results for solutions from tests EA-21, EA-22, and EA-23 analyzed with both ICP-AES and ICP-MS are presented for some components. Other solutions are analyzed with one or the other technique. The cation results were used as the primary measure of the extent of glass corrosion in each test and were used to calculate the glass dissolution rate. The measured concentration was first corrected for the dilution made prior to sample submittal. That dilution was made to provide enough solution for analysis. The dilution factor for each solution was calculated by dividing the mass of leachate in the aliquot by the sum of the masses of the aliquot, demineralized water, and concentrated nitric acid that was added. The filtrate solutions from filtration through the $6-\mathrm{nm}$ pore size filters are referred to as F50 solutions in the spreadsheets in Appendices I, II, and III.

The extent of glass corrosion was calculated from the measured concentrations in solutions filtered through the $450-\mathrm{nm}$ pore size filters in terms of the normalized mass loss, NL(i):

$$
\mathrm{NL}(\mathrm{i})=\left(\mathrm{C}_{\mathrm{i}}-\mathrm{C}_{\mathrm{i}}^{\circ}\right) /[(\mathrm{S} / \mathrm{V}) \bullet \mathrm{f}(\mathrm{i})]
$$

where $\mathrm{C}_{\mathrm{i}}$ and $\mathrm{C}_{\mathrm{i}}{ }^{\circ}$ are the concentrations of species $\mathrm{i}$ measured in the leachate solution and in the initial leachant solution, respectively; $S$ and V are the initial glass surface area and solution volume; and $f(i)$ is the mass fraction of species $i$ in the glass. The normalized mass loss gives the mass of glass required to dissolve stoichiometrically to generate the measured solution concentration of the species i. If the glass dissolves stoichiometrically, the calculated value of NL(i) will be the same when calculated based on each glass components. Differences in the values of NL(i) may indicate that the glass is not dissolving stoichiometrically or that some components are not released entirely into solution as the glass corrodes, but are instead retained on the glass surface as insoluble residue, sorbed onto the test vessel, or incorporated into alteration phases. The normalized mass losses are calculated with the solution concentrations of some of the other glass components in Appendix II. However, only those calculated with the solution concentrations of $\mathrm{B}, \mathrm{Li}, \mathrm{Na}$, and $\mathrm{Si}$ were used to evaluate the dissolution rate. This is because other components are present in only very low concentrations, such that the 
analytical errors are expected to be higher, and because some components are sparingly soluble.

We consider first the results of the 7-day tests at $2000 \mathrm{~m}^{-1}$ in demineralized water, which are the test conditions specified for PCT-A. The results of two sets of triplicate tests conducted as part of this Task at different times are given in Table 3 . The results within each set of triplicate tests are in good agreement, but the agreement between the two set is poor. The results of PCT-A are presented both as the measured concentrations and as normalized concentrations. The normalized concentrations are calculated by dividing the measured solution concentration of a components by the mass fraction of that component in the glass. The mass fractions of $\mathrm{B}, \mathrm{Li}, \mathrm{Na}$, and $\mathrm{Si}$ used for these calculations are given in Table 1. The normalized mass losses calculated from the average results are: $\mathrm{NL}(\mathrm{B})=7.6 \mathrm{~g} / \mathrm{m}^{2}, \mathrm{NL}(\mathrm{Li})=3.9 \mathrm{~g} / \mathrm{m}^{2}, \mathrm{NL}(\mathrm{Na})=6.2 \mathrm{~g} / \mathrm{m}^{2}$, and $\mathrm{NL}(\mathrm{Si})=1.9 \mathrm{~g} / \mathrm{m}^{2}$. The normalized mass loss value based on silicon is significantly lower than those based on the alkalis or boron. This is because most of the silicon released from the glass is incorporated into the layer of clay that forms on the glass (see below). A small amount of sodium (and probably lithium) is also contained in the clay. Boron is not to be incorporated into the clay, so that NL(B) provides the best measure of the extent of glass dissolution. The average dissolution rate over the 7 days test duration is $1.1 \mathrm{~g} /\left(\mathrm{m}^{2} \cdot \mathrm{d}\right)$ based on the release of boron.

The complete results of PCT-B conducted with EJ-13 water are presented in Appendix II. The results are summarized in Table 4 where, in most cases, the average values of duplicate tests are given. Also included in the table is whether or not alteration phases other than clay were observed to have formed; clay had formed in all tests. The results of solid analyses are discussed below. The normalized mass loss values based on the release of $\mathrm{B}, \mathrm{Na}, \mathrm{Li}$, and $\mathrm{Si}$ in tests conducted at $2000 \mathrm{~m}^{-1}$ in EJ-13 water are plotted against the reaction time in Figure 2. The $\mathrm{pH}$ values are also plotted. After an initial increase from the leachant $\mathrm{pH}$ of about 8.2 to a $\mathrm{pH}$ of about 11.6 after 7 days, the solution $\mathrm{pH}$ remains nearly constant. The NL(i) values based on $\mathrm{B}$ and $\mathrm{Na}$ are greater than those based on $\mathrm{Li}$ and Si. For a given element $\mathrm{i}$, the NL(i) values are similar at 7, 30, and 70 days. A significant increase in the value of NL(Na) occurs between 70 and 313 days, while a significant increase in the value of NL(B) occurs between 313 and 470 days.

The normalized mass loss values based on the release of $\mathrm{B}, \mathrm{Li}, \mathrm{Na}$, and $\mathrm{Si}$ in tests at $20,000 \mathrm{~m}^{-1}$ with the $-100+200$ mesh fraction are plotted against the reaction time in Fig. 3. The solution $\mathrm{pH}$ values increase through 181 days, but decrease at longer reaction times. The normalized mass losses based on $\mathrm{B}$ and $\mathrm{Na}$ are greater than those based on $\mathrm{Li}$ and $\mathrm{Si}$. The increase in the NL(B) values slows with time in tests with each size fraction. This is due, in part, to the fact that the values of NL(B) plotted in Figure 3 were calculated with the initial surface area whereas the surface area of the glass decreases as the glass dissolves. The effect of the decrease in the surface area as the glass dissolves is discussed later.

The measured $\mathrm{pH}$ values and calculated $\mathrm{NL}(\mathrm{i})$ values for tests at $20,000 \mathrm{~m}^{-1}$ with the $-200+325$ mesh size fraction are shown in Figure 4 . They follow the same trends seen in the results of tests with the $-100+200$ mesh fraction, although the values for each test duration are slightly less than those for corresponding tests with the $-100+200$ mesh size fractions. While part of the difference may be due to a systematic error in estimating the initial surface areas of each size fraction, most of the difference is probably due to fact that the surface area of the $-200+325$ mesh glass decreases faster than that of the $-100+200$ mesh glass. 
The results of carbon analysis and IC analysis for anions are given in Appendix IV; not all of the solutions were analyzed for anions and carbon. Both the total dissolved carbon and the nonpurgeable carbon contents were measured. The purgable carbon content was calculated by difference. The amounts of carbon and anions in the EJ-13 water used in tests with test numbers of 24 and higher is given at the bottom of each table. (Tests EA-21, EA-22, EA-23, EA-21X, EA-22X, and EA-23X were conducted with demineralized water.) Although the glass was not analyzed for carbon, these results show that a small amount of carbon was released as the glass dissolved. Likewise, the concentrations of anions in the glass were not reported, but tests results show several anions to be released as the glass dissolves, although there is significant scatter in the measured concentrations. The carbon and anion concentrations are only significantly higher then the background concentrations in EJ-13 only in tests affected by the formation of alteration phases. Dissolution of large amounts of glass in those tests resulted in the release of small amounts of $\mathrm{Cl}^{-}, \mathrm{HPO}_{4}{ }^{2-}$, and $\mathrm{SO}_{4}{ }^{2-}$ into solution. For example, after 182 days, the concentrations of $\mathrm{Cl}^{-}, \mathrm{HPO}_{4}^{2-}$, and $\mathrm{SO}_{4}{ }^{2-}$ were about 60,110 , and $180 \mathrm{mg} / \mathrm{L}$, respectively, in tests conducted with the $-100+200$ mesh glass at 20,000 $\mathrm{m}^{-1}$. In tests conducted at $2000 \mathrm{~m}^{-1}$, the concentrations of $\mathrm{Cl}^{-}$and $\mathrm{SO}_{4}^{2-}$ remained near the background levels of the EJ-13 leachant (11 and $30 \mathrm{mg} / \mathrm{L}$, respectively) in all tests, although the concentration of $\mathrm{HPO}_{4}{ }^{2-}$ increased to about $7 \mathrm{mg} / \mathrm{L}$ after 313 days. While the presence of these anions in the leachate solutions is not expected to directly affect the glass dissolution rate, their presence may have a secondary effect by affecting the solution $\mathrm{pH}$. In actual waste glasses, some anions will act as complexants and affect the solution chemistries of released actinides.

The concentrations of anions in the EA glass can be estimated by assuming they are released stoichiometrically with boron as the glass dissolves and are not incorporated into alteration phases. By comparing the anion concentrations listed above for the 182day tests at $20,000 \mathrm{~m}^{-1}$ (after background subtraction for the amounts in the EJ-13 water) with the concentration of boron in the same test, the amounts of $\mathrm{Cl}, \mathrm{P}_{2} \mathrm{O}_{5}$, and $\mathrm{SO}_{3}$ in the glass are calculated to be $0.01,0.02$ and 0.04 mass $\%$, respectively. These concentrations are well below the solubility limits of $\mathrm{Cl}, \mathrm{P}$, and $\mathrm{S}$ in borosilicate waste glasses. The average amount of total carbon in the 182-day tests is about $75 \mathrm{mg} / \mathrm{L}$, which gives an estimated concentration in the glass of about 0.01 mass \% elemental carbon.

\section{Solids Results}

Examination of the reacted glass with an optical microscope revealed the formation of a chalky white layer on the glass grains and the formation of discrete alteration phases separate from the glass. Altered glass grains were examined with an SEM to characterize the composition and morphology of the altered material. Figure 5a shows a photomicrograph of the outer surface of a grain of EA glass from a test in which it had reacted at $20,000 \mathrm{~m}^{-1}$ for 98 days. The altered surface is comprised of two distinct layers: a thin outer surface that has a beady appearance and a thick inner layer, which is partially separated from the underlying glass. The layer surrounding the core of glass has a uniform thickness. Figure $5 \mathrm{~b}$ displays a high-magnification image of the outer layer.

Altered glass from some tests was fixed in an epoxy resin and polished cross sections were be prepared for SEM/EDS analysis. The photomicrograph in Figure 5c shows cross section views of several grains. The unreacted glass is seen to be surrounded by a crust of altered glass about $6 \mu \mathrm{m}$ thick. The outer layer that was shown in Figure $5 \mathrm{~b}$ is too thin to be distinguished from the inner layer in the cross sections. The compositions of the unreacted glass and layer (the average of three analyses of each) measured with EDS are summarized in Table 5. The glass composition measured with EDS has been modified by including the concentrations of trace components to facilitate 
direct comparison with the composition determined by wet analysis (given in Table 1). The measured concentrations of major components as measured with EDS are in good agreement with the values from Table 1 . The concentrations of $\mathrm{B}$ and $\mathrm{Li}$ in the layer can not be measured with EDS. Instead, those concentrations were estimated based on their known concentrations in the glass and the amounts measured to be in solution. The $\mathrm{NL}(\mathrm{Li})$ values in all tests were only slightly higher than the $\mathrm{NL}(\mathrm{Si})$ values, which indicates that lithium was almost completely retained in the layers. The boron concentrations measured in the long-term tests indicate that boron was almost completely depleted from the layers. Therefore, the layer compositions measured with EDS were adjusted by adding the $\mathrm{Li}_{2} \mathrm{O}$ content of the glass and excluding the $\mathrm{B}_{2} \mathrm{O}_{3}$ content of the glass from the normalized total oxide content of the layer. Relative to the unreacted glass, the layer is depleted in $\mathrm{Al}, \mathrm{B}$, and $\mathrm{Na}$ and enriched in $\mathrm{Fe}, \mathrm{K}, \mathrm{Mg}, \mathrm{Mn}$, and $\mathrm{Si}$. The enrichment of some sparingly soluble elements (e.g., $\mathrm{Mn}$ and $\mathrm{Fe}$ ) in the layer is due to their accumulation as the glass dissolves.

Three morphologically distinct alteration phases formed within 56 days in tests at $20,000 \mathrm{~m}^{-1}$ with both size fractions: a translucent, spherical phase (referred to as phase 1); a transparent phase comprised of layered, hexagonal plates (referred to as phase 2); and a translucent, bulbous phase (referred to as phase 3). Most of the crystallites had precipitated separate from the reacted glass and had formed a layer of sediment on top of the reacted glass in the test vessels. Both the size and abundance of these alteration phases increased with the reaction time. Figures 6a-6c display SEM photomicrographs of these phases. Representative phases were isolated and analyzed with SEM/EDS, AEM, and XRD. The compositions determined with EDS and the d-spacings measured with XRD and AEM/SAED are summarized in Table 6. The phases formed in these tests are compared to naturally occurring minerals to provide insight into properties such as their solubilities and tendencies to incorporate other elements, including radionuclides. While the composition and structure of these phases are expected to differ slightly from those of natural minerals because they incorporate trace amounts of elements from the leachate solutions that are not present in nature, correlation of phases formed in these tests with naturally occurring minerals provides a convenient means of labeling the phases.

The morphologies, compositions, and d-spacings of phases 1,2 , and 3 are consistent with those of a naturally occurring sodium aluminum silicate hydrate $\left[\mathrm{Na}_{5.7} \mathrm{Al}_{5.7} \mathrm{Si}_{10.3} \mathrm{O}_{32} \cdot 12 \mathrm{H}_{2} \mathrm{O}\right]$, analcime $\left[\mathrm{NaAlSi} \mathrm{O}_{6} \cdot \mathrm{H}_{2} \mathrm{O}\right]$, and gmelinite $\left[\mathrm{Na}_{2} \mathrm{Al}_{2} \mathrm{Si}_{4} \mathrm{O}_{12} \cdot \mathrm{H}_{2} \mathrm{O}\right.$ ], respectively. In Table 6 , the compositions of the phases measured with EDS have been normalized such that the silicon content of each phase is the same as the silicon content of the mineral phases with which it is compared. The compositions have not been adjusted to attain charge balance in these formulae, and phases 1,2 , and 3 are slightly deficient in positive charge because trace amounts of other cations have been neglected in the composition analysis. The d-spacings measured with AEM/SAED are also included in Table 6. Because the SAED analyses are performed on thin sections, not all planes are sampled and SAED diffraction patterns often lack peaks that are very strong in the corresponding XRD spectra.

It cannot be ascertained precisely when each phase first nucleated because of the very small size of the newly nucleated phases, their immature morphologies, and their sparse distribution in the crushed glass. Figure 6d shows SEM photomicrographs of solids from a 22-day test conducted at $20,000 \mathrm{~m}^{-1}$. These features clearly have 3-fold symmetry that is distinct from the crushed glass; visualization of the symmetry is enhanced by the shrinkage cracks. The phases are also much smaller than the crushed glass. Their composition is consistent with that of the zeolites identified to be present after longer test durations. Although alteration phases may form after a short time period, when they affect the glass dissolution rate will be determined by the relative surface areas 
of the alteration phases and the glass, as well as the precipitation rate of the alteration phases.

Table 6 presents the results of XRD analysis of a representative sample of a clay layer that formed on the corroded glass in all tests at both $S / N$ ratios. The d-spacings and intensities of nontronite, the iron-rich end-member smectite clay, match well with the XRD results. Intensities are not reported for the layer analysis because of the high background from the glass underlying the clay, although three strong peaks were observed that are consistent with the strongest peaks of nontronite. While the composition of the clay measured with SEM/EDS has less iron than the reference nontronite, compositions intermediate between nontronite and montmorillonite are common in nature [BRINDLY-1980]. The d-spacings and composition of montmorillonite are included for comparison.

An opaque white phase having a square bipyramid morphology formed in tests conducted at $2000 \mathrm{~m}^{-1}$ after about 1 year. This phase is referred to as phase 4. An SEM photomicrograph of this phase is displayed in Figure 7, and its composition as measured with SEM/EDS and d-spacings measured with XRD is included in Table 8. The composition and d-spacings are consistent with those of a sodium aluminum silicate hydrate phase that is different from the sodium aluminum silicate hydrate phase formed in tests conducted at $20,000 \mathrm{~m}^{-1}$. Analcime formed in tests conducted at $2000 \mathrm{~m}^{-1}$ for 313 days and longer, but gmelinite was not detected in any test at $2000 \mathrm{~m}^{-1}$.

Examination of the alteration layers formed in tests at both S/V ratios with AEM revealed the presence of small crystallites of calcium-bearing phases within the layer. These phases were not observed during examination of the reacted solids with optical microscopy and were not isolated for SEM/EDS or XRD analysis. The d-spacings of two phases as measured with AEM/SAED are summarized in Table 9. The compositions of the alteration phases were not quantified, but are consistent with those of boggsite $\left[\mathrm{Na}_{3.7} \mathrm{Ca}_{7.4} \mathrm{Al}_{18.5} \mathrm{Si}_{77.5} \mathrm{O}_{192} \cdot 74 \mathrm{H}_{2} \mathrm{O}\right]$ and tobermorite $\left[\mathrm{Ca}_{5}(\mathrm{OH})_{2} \mathrm{Si}_{6} \mathrm{O}_{16} \cdot 4 \mathrm{H}_{2} \mathrm{O}\right]$. The phases were too small to be detected during examination with SEM. 


\section{DISCUSSION}

In this section we consider how the results of the dissolution tests and solids analysis provide insight into the long-term corrosion behavior of the EA glass. The aspects of the test results are evaluated to determine whether the general corrosion behavior indicate that the EA glass corrodes by the same mechanism as other DWPF glasses and how the dissolution rates of the EA glass compare with the dissolution rates of other glasses measured with the same test methods. We consider first the results of the 7-day tests that were conducted following the PCT-A method. The difference in the mean concentrations from the two sets of triplicate tests conducted as a part of this Task are statistically significant. While the difference may be due, in part, to the fact that the first set of tests was conducted with about $1 \mathrm{~g}$ glass and $10 \mathrm{~g}$ demineralized water and the second set was conducted with about $1.5 \mathrm{~g}$ glass and $15 \mathrm{~g}$ demineralized water, this is not considered to be the primary cause of the difference, since both sets had the same $\mathrm{S} / \mathrm{V}$ ratio. More likely, the differences simply reflect the combined testing and analytical uncertainties. In Table 10, the results of three PCT-A conducted as part of another Task at ANL and the mean results of replicate tests conducted at Pacific Northwest National Laboratory (PNNL) and at SRTC are presented for comparison with the results of this Task. The overall average of the three sets of triplicate tests conducted at ANL are in good agreement with the results obtained at PNNL and SRTC, although the standard deviations of the ANL tests are higher. The agreement in the results for different laboratories varies with each element, although the concentrations measured in tests at SRTC are higher for each element. The normalized concentrations are presented for the mean values for each element. These are calculated by dividing the measured concentration of an element by the mass fraction of that element in the glass (those values are given in Table 1) then converting to units of $g / \mathrm{L}$. The normalized concentrations of different elements can be compared directly to determine if the glass dissolves stoichiometrically. The results show that the proportions of these elements in solution is different than the proportion in the glass. The order of preferential release is $\mathrm{B}>\mathrm{Na}>\mathrm{Li}>\mathrm{Si}$. The alkali metals are leached from the glass by hydration followed by ion exchange. Boron is released from the dealkalized layer. The release of boron from the dealkalized layer is more complete than the release of $\mathrm{Li}$ and $\mathrm{Na}$.

The amount of glass that has dissolved in the PCT-A can be compared with the amount that dissolved in 7 days in tests in the EJ-13 water to gauge the effect of dissolved silica on the dissolution rate. The average concentrations of $\mathrm{B}, \mathrm{Li}, \mathrm{Na}$, and $\mathrm{Na}$ in replicate tests are summarized in Table 11. The concentrations in the EJ-13 water are also included. Higher final concentrations of $\mathrm{B}, \mathrm{Li}, \mathrm{Na}$, and $\mathrm{Si}$ are attained in tests in demineralized water than in tests in EJ-13 water, which indicates that the glass dissolves faster in demineralized water than in EJ-13 water. However, the aluminum concentration is lower in tests in demineralized water. The aluminum concentrations are considered in this comparison because aluminum is an important component of the alteration phases detected to have formed in other tests, including clay. The ratios of the amounts of each element released to solution in tests in demineralized water and in EJ-13 water (after background subtraction) were calculated from the measured concentrations. The ratio of the concentrations indicates that the amount of glass that dissolved in tests in demineralized water was about 1.5 times the amount that dissolved in tests in EJ-13 water, and that $\mathrm{B}, \mathrm{Li}, \mathrm{Na}$, and $\mathrm{Si}$ were released to solution in the same proportions in both leachants. The average dissolution rates over the 7-day test period were 1.0 and 0.61 $\mathrm{g} /\left(\mathrm{m}^{2} \bullet \mathrm{d}\right)$ for tests in demineralized water and EJ-13 water, respectively. The observation that the glass reacted faster in tests in demineralized water than in tests in EJ-13 water and that higher concentrations of dissolved silica were attained in tests in demineralized 
water indicates that the concentration of dissolved silica (or the activity of orthosilicic acid) does not control the dissolution rate.

We next evaluate the results of tests in EJ-13 water to determine if the SRL EA glass corrodes by the same mechanism as other DWPF reference glasses and can be explained with the same phenomenological model that has been developed for waste glasses [EBERT-1996B]. The corrosion of DWPF glasses is characterized by the preferential release of alkali metals at short reaction times, the development of a smectite clay layer, and the slowing of dissolution as the solution approaches apparent saturation conditions. The formation of alteration phases in concentrated solutions has been observed to result in an increase in the dissolution rates of several waste glasses [EBERT1990; FENG-1993].

A rate expression has been developed to calculate the dissolution rates of silicate waste glasses by adaptation of a kinetic expression developed to describe the dissolution of silicate minerals [AAGAARD-1982]. In the dissolution model, the hydrolysis of Si-O$\mathrm{Si}$ bonds at the surface of the glass are assumed to be the rate-controlling reaction for dissolution of minerals and waste glasses. This is reasonable since they are the most abundant bonds and the primary structural unit. Four Si-O bonds must be broken before material can dissolve, and the rate-limiting step for dissolution is hydrolysis of the fourth bond to release orthosilicic acid into solution. (Fewer bonds must be broken to release silicon at a surface.) The rate of this reaction depends on the temperature and $\mathrm{pH}$. Because dissolved orthosilicic acid can react at the glass surface to reform Si-O-Si bonds, the net dissolution rate slows as silica builds up in solution and the back reaction becomes more important. In applying the model for silicate minerals to glass dissolution, a pseudo-equilibrium is assumed to exist between the forward rate of glass dissolution and the reverse reaction to form the Si-O-Si network. Since glass cannot be formed in the back reaction, a pure silica surrogate phase is assumed to be formed instead. Therefore, the solubility of the surrogate phase is used to approximate the apparent solubility limit for dissolved silica established by a glass [STRACHAN-1994]. Because the solubility product of chalcedony matches experimental data for many glasses, chalcedony is often used as the surrogate phase for glass in model calculations. As that solubility limit is approached, the dissolution rate of the glass will decrease to near zero, although the dissolution rate can never become zero. This is an artifact of applying a thermodynamic model to a thermodynamically unstable material, and the fact that the apparent approach to equilibrium observed during dissolution tests is actually due to continuously decreasing dissolution rate.

The rate expression currently used to model glass dissolution behavior can be written as [McGRAIL-1997]

$$
\text { rate }=k_{o} 10^{\eta \cdot p H} e^{-E_{a} / R T}\left[1-\left(\frac{Q}{K}\right)^{\sigma}\right]
$$

where $\mathrm{k}_{0}$ is an intrinsic dissolution rate that depends only on the glass composition, $\eta$ is the coefficient of the $\mathrm{pH}$-dependence, $\mathrm{E}_{\mathrm{a}}$ is the activation energy, $\mathrm{Q}$ is the ion activity product of the solution, $\mathrm{K}$ is the equilibrium constant for the hydrolysis reaction, for which the equilibrium constant of chalcedony is used, and $\sigma$ is the reaction order. The values of $\eta, E_{a}$, and $K$ have been measured to be about $0.4,80 \mathrm{~kJ} / \mathrm{mol}$, and $10^{-3.1}$, respectively, for DWPF glasses [BOURCIER-1994, KNAUSS-1990]. The value of the 
reaction order is usually assumed to be one. In the case that the hydrolysis of an $\mathrm{Si}-\mathrm{OSi}(\mathrm{OH})_{3}$ bond at the glass surface to release orthosilicic acid into solution is the ratedetermining step, $\mathrm{Q}$ and $\mathrm{K}$ will depend only on the activity of orthosilicic acid. The value of the term in brackets, which is referred to as the affinity term, can vary between 1 when the activity of orthosilicic acid is near zero and nearly 0 when the activity of orthosilicic acid is similar to the value of $\mathrm{K}$. Application of the rate expression to experimental data is straightforward. The glass dissolution rate is expressed in units of mass dissolved glass per unit surface area and time. It is usually measured experimentally based on the accumulation of B or another highly soluble glass component in the leachate solution, and can be expressed in terms of the normalized mass loss as rate $=N L(B) / t$. The value of $\mathrm{Q}$ (the activity of orthosilicic acid) can be calculated from the measured total concentration of silicon and $\mathrm{pH}$ using known dissociation constants. This expression has been found to adequately describe the corrosion behavior of many nuclear waste glasses prior to the formation of alteration phases. However, recent tests have indicated that the activity of dissolved aluminum (perhaps $\mathrm{Al}(\mathrm{OH})_{4}{ }^{-}$) affects the dissolution rate when the solution is nearly saturated with silica [GIN-1996]. In addition, it has not yet been demonstrated conclusively that the rate expression in Eq. 2 also describes the corrosion behavior after phases form that increase the dissolution rate, or if additional terms are required.

Some of the material freed as the glass dissolves becomes incorporated into stable alteration phases at the glass surface, which may include metal hydroxides and clays, while other material enters solution. The formation of some phases may affect the relative stability of the glass in the system and the dissolution rate [VAN ISEGHEM1988]. If those phases consume silicon, their formation provides a competing reaction pathway that decreases the formation of chalcedony on the glass surface. Depending on the relative amounts of glass and alteration phases and the precipitation rates of the alteration phases, their formation may result in a significant increase in the net glass dissolution rate.

Corrosion can be described in terms of three stages to facilitate relating test results to the rate expression for glass dissolution. Stage I occurs when the glass dissolution is not affected by dissolved glass components. This corresponds to the limit where $\mathrm{Q}=0$ in Eq. 2. Dissolved components do affect dissolution in Stage $I$, and a very low dissolution rate is attained as the solution concentration of silica approaches the saturation limit for amorphous silica. This corresponds to the limit where Q approaches $\mathrm{K}$ in Eq. 2. As the solution concentrations of dissolved glass components increase, the solution may become saturated with respect to other phases. Precipitation of some phases can affect the glass dissolution rate by establishing a solubility limit for dissolved silica that is less than the solubility limit for amorphous silica. Glass dissolution behavior that is affected by the precipitation of alteration phases is referred to as Stage III. Stage III corresponds to the case where alteration phases establish a solubility limit for dissolved silica and fixes the value of $Q$ such that $0<Q<K$. Test conditions under which the corrosion behavior of a glass is described by Stages I, II, or III will depend on the composition of the glass and the leachant composition.

A schematic representation of the three stages is shown in Figure 8. In this plot, the $\mathrm{x}$-axis represents the transformation of the system from glass and water on the far left to thermodynamically stable alteration phases and saturated solution on the far right. This is referred to as the reaction progress. The $y$-axis indicates the amount of glass reacted. In laboratory tests, the amount of glass is usually monitored with the solution concentration of highly soluble glass components, such as boron. Two limiting rates are shown for Stage III. The highest possible Stage III rate is the same as the rate in Stage I, while the lowest possible rate is when $\mathrm{Q}$ remains very near $\mathrm{K}$. The actual Stage III rate 
will depend on the assemblage of alteration phases that forms. The rates in all stages will change as the $\mathrm{pH}$ and temperature change.

Stage I behavior is not observed in these tests with EA glass because the solution concentrations of dissolved glass components affect the dissolution rate even in the shortest durations, namely, the 7-day tests. Stage II behavior is seen in tests conducted at $2000 \mathrm{~m}^{-1}$ for less than about a year. Although the corrosion behavior in tests at $2000 \mathrm{~m}^{-1}$ is clearly in Stage II through 98 days and in Stage III after about 470 days, when the transition between Stage $\Pi$ and Stage III occurs is difficult to discern. The increases in the solution concentrations of $\mathrm{Li}, \mathrm{Na}$, and $\mathrm{Si}$ suggest the transition occurs sometime between 70 and 313 days, whereas the increase in the boron concentration occurs between 313 and 470 days. The increase in the boron concentration has provided the best indication of Stage III in tests with other glasses, since alkali metals are incorporated into most alteration phases. However, the normalized boron mass loss in the 313-day test is significantly lower than the normalized mass loss of sodium. The measured boron concentration is probably in error, and we presume the increase in the dissolution rate occurs sometime between 70 and 313 days in tests at $2000 \mathrm{~m}^{-1}$ based on the increase in NL(Na).

The reaction time at which the transition to Stage III occurs in tests conducted at $20,000 \mathrm{~m}^{-1}$ is also difficult to identify because the transition occurs so quickly. As can be seen in Table 4, the concentrations of boron and alkali metals are very high even after 7 days and increase with test duration. Alteration phases are detected to form in tests within 20 days, but when precipitation begins to affect the dissolution rate is not obvious between any test durations. This may be because the solution does not approach saturation with respect to amorphous silica before the alteration phases form to drive corrosion into Stage III. Based on the extremely high silica concentrations measured in tests conducted for 7 and 14 days (and also after 35 days), it may be the case that the glass is dissolving faster than the alteration phases can form. The formation of the zeolite alteration phases may be limited by the aluminum concentration, which, based on the PCT-A results, is very low at early reaction times. The boron concentrations indicate that about $10 \%$ of the glass dissolves with the first 7 days but that the dissolution slows at longer times.

Alteration phase formation can affect both the $\mathrm{pH}$ and the reaction affinity (i.e., the value of $Q$ in Eq. 2). The other parameters depend only on the glass composition. In the limit that the solution chemistry becomes fixed by an equilibrium between the solution and the assemblage of alteration phases that has formed, the value of the affinity term will become constant. If the $\mathrm{pH}$ and temperature remain constant, then the glass dissolution rate will also be constant as long as the same suite of alteration phases controls the corrosion behavior. If the formation of alteration phases only affects the value of $\mathrm{Q}$, then Eq. 2 predicts that the long-term dissolution rate will vary with the precipitation rate of the alteration phases. If the alteration phases that affect the value of $\mathrm{Q}$ precipitate much faster than the glass can dissolve, then glass dissolution is predicted to proceed at a constant rate. If the precipitation rates of those alteration phases decrease, then $\mathrm{Q}$ can once again increase up to the value of $\mathrm{K}$ and the glass dissolution rate will decrease. It is important to remember that Eq. 2 describes glass dissolution, not the precipitation of alteration phases.

The results of the present tests with EA glass are consistent with this qualitative description of the corrosion mechanism. Tests at $2000 \mathrm{~m}^{-1}$ indicate that the dissolution rate is high initially but decreases as Si accumulates in the leachate solution: the average dissolution rate over the first 7 days is about $0.6 \mathrm{~g} /\left(\mathrm{m}^{2} \bullet \mathrm{d}\right)$, based on $\mathrm{NL}(\mathrm{B})$, while the average rate between 7 and 70 days is $0.01 \mathrm{~g} /\left(\mathrm{m}^{2} \cdot \mathrm{d}\right)$. The effect of the buildup of 
dissolved silica on the dissolution rate can also be seen by comparing tests conducted under the same conditions with demineralized water or with EJ-13 water: about one and a half times as much glass dissolves in tests conducted in demineralized water than in tests with EJ-13 water. The difference can be attributed to the presence of about $45 \mathrm{mg} / \mathrm{L}$ dissolved silica in the EJ-13 water. It is interesting to note that the amounts of silicon in the tests conducted in demineralized water are all higher than the amounts in the tests conducted in EJ-13 water. This may be due to the higher $\mathrm{pH}$ values attained in tests with demineralized water. The bicarbonate ion present in the EJ-13 water buffers against the $\mathrm{pH}$ rise as the glass reacts. Dissolution of silicate glasses is known to increase with the $\mathrm{pH}$.

The formation of clay layers at the glass surface does not significantly affect the dissolution rate either due to the effects of clay precipitation on the solution chemistry or mass transfer. The absence of a measurable effect of clay precipitation is probably due to the solubility limit for silica being similar when clay and amorphous silica are the controlling phases. That the clay does not act as a diffusion barrier is due to its fine-grain nature and the high degree of porosity of the layers that form. However, the glass dissolution rate does increase significantly after zeolite phases form. The same behavior has been observed in tests with other high-level waste glasses. The mechanism by which particular alteration phases affect the glass dissolution rate is not yet fully understood, but is likely due to the decrease in the solubility limit of orthosilicic acid as the controlling phase changes from amorphous silica to a zeolite. The reason why the initial formation of small particles of zeolites does not have a measurable effect on the dissolution rate may be that the surface area of the zeolites is not yet large enough to control the solution chemistry.

\section{A. Measured Dissolution Rates}

The measured solution $\mathrm{pH}$ was affected by the high concentrations of sodium generated in some tests due to the "sodium effect" on the electrode. To gauge the significance of the effect, a series of solutions was made by adding $\mathrm{NaCl}$ to $\mathrm{pH} 10$ and $\mathrm{pH} 12.45$ buffer solutions and the $\mathrm{pH}$ values were measured (at room temperature). The results are plotted in Figure 9. In both buffer solutions, sodium concentrations greater than $1000 \mathrm{mg} / \mathrm{L}$ have a significant effect on the $\mathrm{pH}$ measurement. Concentrations near $50,000 \mathrm{mg} / \mathrm{L}$ result in a decrease of about $1 \mathrm{pH}$ unit. While these results cannot be applied directly to the results of tests with EA glass because the solution chemistries of the buffer solutions and test leachate solutions are different, the results provide a qualitative indication that the sodium concentrations generated in the present tests probably do significantly affect the measured $\mathrm{pH}$. This probably explains the observed constancy of or decrease in the measured $\mathrm{pH}$ in long-term tests at $20,000 \mathrm{~m}^{-1}$. However, no attempt was made to adjust the measured $\mathrm{pH}$ values for the sodium effect. The error in the $\mathrm{pH}$ due to the sodium effect does not affect the measured dissolution rates. However, extraction of values for the parameters in the rate expression in Eq. 2 will be affected, including $k_{0},{ }_{\eta} E_{a}$, and the affinity term.

Two different dissolution rates can be calculated from the test results: the integrated rate based on the accumulated amount of glass dissolved over the entire test duration and the differential rate based on the change in the amount dissolved between consecutive tests. The integrated rate is calculated by simply dividing the value of NL(i) for a test by the test duration. The differential dissolution rate can be calculated by dividing the difference in NL(i) values for consecutive tests by the difference in reaction times. Graphically, the differential dissolution rate during a particular reaction stage can be estimated from a line fitted to data from tests at several durations. 


\section{B. Tests at $2000 \mathrm{~m}^{-1}$}

The dissolution rates over two reaction stages can be extracted from the results of tests at $2000 \mathrm{~m}^{-1}$, namely Stage II and Stage III. The Stage II rate is calculated with the $\mathrm{NL}(\mathrm{B})$ values for tests through 70 days. That rate is about $0.009 \mathrm{~g} /\left(\mathrm{m}^{2} \bullet \mathrm{d}\right)$. The rate for Stage III extracted from the test results in Figure 2 is uncertain because of the absence of test data for durations between 70 and 313 days. Also, as mentioned earlier, the measured boron concentration in the 313-day test is suspect. Two bounding rates can be calculated from the test results for $\mathrm{NL}(\mathrm{B})$ : an upper bound of $0.18 \mathrm{~g} /\left(\mathrm{m}^{2} \cdot \mathrm{d}\right)$ from the results at 313 and 470 days, and a lower bound of $0.073 \mathrm{~g} /\left(\mathrm{m}^{2} \bullet \mathrm{d}\right)$ from the results at 70 and 470 days. Lines are drawn through the $2000 \mathrm{~m}^{-1}$ test results in Figure 10 to show these bounding rates. The average of these bounds is $0.13 \mathrm{~g} /\left(\mathrm{m}^{2} \cdot \mathrm{d}\right)$. A rate of is 0.047 $\mathrm{g} /\left(\mathrm{m}^{2} \bullet \mathrm{d}\right)$ is calculated between 70 and 313 days based on the change in NL(Na). This rate is lower than the bounding rates calculated based on NL(B) because a significant fraction of the sodium released from the glass is incorporated into alteration phases. These rates were calculated assuming the surface area remains constant. Adjustment to take into account the decrease in surface area as the glass dissolves will result in higher calculated rates.

The highest NL(i) achieved in tests at $2000 \mathrm{~m}^{-1}$ was $\mathrm{NL}(\mathrm{B})=36 \mathrm{~g} / \mathrm{m}^{2}$ after 527 days. The value of $\mathrm{NL}(\mathrm{B})$ was slightly lower in the 600-day test. The maximum possible value of NL(i) can be calculated by assuming all of component $i$ that was initially in the glass entered the solution as the glass dissolved. The maximum value is equivalent to the inverse of the specific surface area of the crushed glass. For $-100+200$ mesh glass, the maximum value of NL(i) is about $50 \mathrm{~g} / \mathrm{m}^{2}$, based on a specific surface area of $0.02 \mathrm{~m} / \mathrm{g}$. Hence, about $72 \%$ of the glass (by mass) has reacted within 527 days. Most of the reaction has occurred between about 70 and 470 days.

\section{Tests at $20,000 \mathrm{~m}^{-1}$}

As discussed earlier, Stage II behavior cannot be discerned from the available test results. This is because the corrosion proceeds almost directly from Stage I to Stage III. Two lines are drawn through the measured values of NL(B) in Figure 10b. One line is drawn to fit the results of tests conducted for 20 days or less and represents the rate prior to phase formation, which is $0.50 \mathrm{~g} /\left(\mathrm{m}^{2} \bullet \mathrm{d}\right)$. This is interpreted to be a lower bound to the Stage I rate. The other line is drawn through the results at 56 and 98 days. This gives the Stage III rate after alteration phases have formed. That rate is $0.20 \mathrm{~g} /\left(\mathrm{m}^{2} \bullet \mathrm{d}\right)$. Note that the values of $N L(B), N L(N a)$ and $N L(S i)$ for the 56-day test are less than the trends shown in tests at other durations. The difference may be due to the fact that the shortterm tests (less than 42 days) were conducted about two years after the long-term tests (tests of 56 days and longer). It has been suggested that oxidation of the EA glass in air can affect its reactivity [JANTZEN-1993]. The maximum possible value of NL(i) for tests conducted at $20,000 \mathrm{~m}^{-1}$ with the $-100+200$ mesh glass is $50 \mathrm{~g} / \mathrm{m}^{2}$. The highest value attained was $\mathrm{NL}(\mathrm{B})=45 \mathrm{~g} / \mathrm{m}^{2}$ in the 527 -day test. About $90 \%$ of the glass had reacted in that test.

The diagonal line drawn in Figure 10c shows the dissolution rate for tests conducted at $20,000 \mathrm{~m}^{-1}$ with the $-200+325$ mesh glass based on the value of NL(B) measured at 56 days, which was the shortest test duration under these conditions. That rate is $0.16 \mathrm{~g} /\left(\mathrm{m}^{2} \cdot \mathrm{d}\right)$. This is interpreted to be a lower bound for the Stage III rate. The maximum possible values of NL(i) for tests with the $-200+325$ mesh glass is $25 \mathrm{~g} / \mathrm{m}^{2}$, based on a specific surface area of $0.04 \mathrm{~m}^{2} / \mathrm{g}$. The values of $\mathrm{NL}(\mathrm{B})$ from long-term tests are very near the maximum value for tests at $20,000 \mathrm{~m}^{-1}$ conducted with both size fractions. This indicates that the glass becomes almost completely reacted in these tests. 
Calculation of the dissolution rate based on measured solution concentrations is complicated by the decrease in the surface area of the glass particles as they dissolve [EBERT-1997]. The values of NL(B) used to estimate the Stage III rates for tests at $20,000 \mathrm{~m}^{-1}$ are low enough that the effect of the loss of surface area on the rate will be insignificant. In general, the decrease in surface are is not expected to be significant until about $25 \%$ of the glass has reacted. The effect must be taken into account to evaluate long-term test results.

An expression for the surface area that remains after an amount of glass has dissolved can be readily derived by modeling the crushed glass as spherical particles, using the mass of boron in solution to calculate the volume of glass that has dissolved, and then calculating the surface area of the remaining glass [McGRAIL-1997]. The surface area that remains as the glass dissolves (i.e., as the radius of the spheres decreases) can be expressed in terms of the initial mass of glass and the measured mass of boron in solution as:

$$
S_{t}=\left(\frac{3 m_{o}^{1 / 3}\left(m_{o}-\frac{m_{B}}{f_{B}}\right)^{2 / 3}}{\left(\rho r_{0}\right)}\right)
$$

where $S_{t}$ is the surface area remaining at time $t, m_{0}$ is the initial mass of glass, $m_{B}$ is the mass of boron in solution at time $t, f_{B}$ is the mass fraction of boron in the glass, $\rho$ is the density of the glass, and $d_{i}$ is the initial diameter of the glass spheres. In Figure 11, the surface area that remains as $5 \mathrm{~g}$ of glass dissolves into $5 \mathrm{~mL}$ of solution calculated using Eq. 3 is plotted vs. the mass of boron in solution $\left(m_{0}=5 \mathrm{~g}, \mathrm{f}_{\mathrm{B}}=0.03, \rho=2.7 \mathrm{~g} / \mathrm{cm}^{3}\right.$, and $\left.\mathrm{d}_{\mathrm{i}}=112 \mu \mathrm{m}\right)$. The initial total surface area of all particles in this example is $0.10 \mathrm{~m}^{2}$. The surface area decreases nearly linearly until about $75 \%$ of the glass has dissolved, so that the average amount of surface area that is available for reaction over the reaction time can be calculated from the arithmetic average of the initial surface area and the surface area that remains at time $t$. The average value of the surface area between two test durations can be used along with the difference in the accumulated amount of boron (or other glass component) to calculate the dissolution rate over that time period.

Using Eq. 3, the surface area remaining in the 470 -day test at $2000 \mathrm{~m}^{-1}$ is about $0.007 \mathrm{~m}^{2}$. The initial surface area was about $0.02 \mathrm{~m}^{2}$. The average surface area between test durations of 70 and 470 days (and also between 313 and 470 days) was about 0.014 $\mathrm{m}^{2}$. Adjusting the average of the bounding rates to take the loss of surface area into account gives an average rate of $0.18 \mathrm{~g} /\left(\mathrm{m}^{2} \bullet \mathrm{d}\right)$ for the Stage III rate. This is in excellent agreement with the results of tests at $20,000 \mathrm{~m}^{-1}$ in which the effect of the loss of surface area was negligible.

\section{Comparison of Stage III Behavior of EA and Other DWPF Glasses}

The results of long-term tests can be utilized to address the use of Eq. 2 for describing glass corrosion behavior after rate-controlling alteration phases have formed and to determine if the glass dissolution rate becomes constant at advanced stages of 
corrosion (i.e., in Stage III). An important complication of extracting dissolution rates from the results of tests with crushed glass is that the available surface area decreases appreciably as the glass dissolves. In the following, we approximate the impact of the loss of surface area as the glass dissolves on the test results by modeling the dissolving glass particles to be spheres, then extracting the value of a dissolution rate corresponding to a linear decrease in the radius with time. The change in the amount of dissolved glass that corresponds to this constant shrinkage rate over time can be compared with test results that were adjusted to take into account the decrease in the surface area with the same geometric model.

The data base with which the long-term results of tests with EA glass can be compared is small. Although Stage III behavior has been observed in tests with many glasses, enough data are available to characterize the dissolution rates of only a few glasses. For some glasses, rate-affecting alteration phases have only been observed in the test with the longest duration. Other glasses had completely altered within the test interval in which the rate-affecting phases had formed, so no rate could be extracted. While the qualitative behavior observed in those tests is consistent with the effects of alteration phase formation seen in other tests, only lower bounces to the Stage III dissolution rate can be compared.

We, therefore, limit our comparison to the results of static dissolution tests conducted with the EA glass and two other DWPF reference glasses tested previously at ANL, namely, SRL 131A and SRL 202A. These are glasses made with SRL 131 and SRL 202 frits and doped with technetium and actinide elements. All results discussed here are from tests conducted with the $-100+200$ mesh fraction in EJ-13 water at S/V ratios of $20,000 \mathrm{~m}^{-1}$. The pertinent test results are summarized in Table 12 . The test durations before and after rate-affecting alteration phases formed are listed in Table 12. For example, rate-affecting alteration phases were detected in the 364-day test with SRL $202 \mathrm{~A}$ at $20,000 \mathrm{~m}^{-1}$, but not in the 182 -day test. The alteration phases that formed coincident with the increase in the dissolution rate are also listed in Table 12.

To simplify the calculations, we have calculated $S_{t}$ with the final surface area instead of the average surface area of the interval. The calculations will yield an upper limit for the dissolution rate. The lower limit of the dissolution rate is calculated with the initial surface area. The values of NL(B) for tests with SRL EA, SRL 131A, and SRL $202 \mathrm{~A}$ glasses conducted with $-100+200$ mesh glass at $20,000 \mathrm{~m}^{-1}$ and at $90^{\circ} \mathrm{C}$ that were calculated with the initial surface area and the final surface area are plotted in Figure 12. For each test, the values of NL(B) calculated with the final surface area, referred to as $N L(B)_{\text {final }}$ are greater than those calculated with the initial surface area, referred to as $\mathrm{NL}(B)_{\text {initial }}$, because the final surface area is less than the initial surface area. The upward curvature of the data is primarily due to the decreasing value of the surface area used to calculate NL(B). Work described below was done to deconvolute this effect from the tests results.

Analcime and other mineral alteration phases had formed within 22 days in tests conducted with SRL EA glass, within 182 days in tests with SRL 131A glass, and within 364 days in tests with SRL 202A glass. Lines in Figure 12 show the dissolution rates for the three glasses immediately after these phases formed. These lines were drawn through the average of $N L(B)_{\text {initial }}$ and $N L(B)_{\text {final }}$ in the two tests sampled after the phases had formed for SRL 131A and SRL 202A glasses. The line for tests with the SRL EA glass was drawn through the origin and the average value of NL(B) from the 56-day test because of uncertainty in when phase formation affected the rate. The average of $\mathrm{NL}(\mathrm{B})_{\text {initial }}$ and $\mathrm{NL}(\mathrm{B})_{\text {rinal }}$ was used because that value better represents the surface area of 
the glass during the test than either the initial or final surface area. (This is equivalent to using the average surface area to calculate NL(B).) The slope of the line for each glass gives what is referred to as the limiting rate. This rate is assumed to be the least affected by phenomena that may affect the rate at longer times, such as the buildup of a diffusion barrier, kinetic limitation of processes other than glass dissolution, etc. The limiting rates are about $0.22,0.068$, and $0.035 \mathrm{~g} /\left(\mathrm{m}^{2} \bullet \mathrm{d}\right)$ for the SRL EA, SRL 131A, and SRL 202A glasses, respectively. The limiting rates were used to calculate the rate at which the radius of the spherical particles decreases, which is defined as $\mathrm{k}=\mathrm{dr} / \mathrm{dt}$. That value was calculated for each glass by dividing the limiting rate by the density of the glass, which is near $2.7 \mathrm{~g} / \mathrm{cm}^{3}$ for the three glasses evaluated here. The rates extracted from the test results are summarized in Table 13. We emphasize that the glass dissolves at this rate only after rate-affecting alteration phases have formed.

An analytical expression relating the mass of glass that has dissolved with the remaining surface area can be written based on the geometry of shrinking spherical particles. In this approximation, the mass of glass that dissolves is simply the density of the glass times the loss of volume of the sphere as the radius decreases over time. The decrease in the volume can then be related to the decrease in surface area through the radius of the sphere. The geometric relationship between the mass of glass dissolved, the remaining surface area, and the dissolution rate can be written as

$$
\mathrm{NL}(\mathrm{B})(\mathrm{t})=\frac{\mathrm{M}(\mathrm{t})}{\mathrm{S}(\mathrm{t})}=\left(\frac{\rho \mathrm{kt} \mathrm{t}^{\prime}}{3}\right)\left\{1+\frac{2-\left(\frac{\mathrm{kt^{ \prime }}}{\mathrm{R}_{\mathrm{p}}}\right)}{\left(1-\frac{\mathrm{kt^{ \prime }}}{\mathrm{R}_{\mathrm{p}}}\right)^{2}}\right\}+X
$$

where $M(t)$ is the total mass of glass dissolved through the entire test duration of time $t$, $\mathrm{S}(\mathrm{t})$ is the surface area that remains at time $t, \rho$ is the glass density, $\mathrm{k}$ is the rate at which the radius of the sphere decreases, and $R_{p}$ is the radius of the sphere when rate-affecting alteration phases first form. The term $X$ represents the value of NL(B) immediately before rate-affecting alteration phases formed. The form of the $\mathrm{X}$ term is identical to that of the first term, except the dissolution constant has a different (smaller) value. The contribution of the $X$ term to long-term dissolution is negligible after rate-affecting alteration phases form, and is not further considered here. We emphasize that the first term on the right hand side of Eq. 4 applies to corrosion after rate-affecting alteration phases have formed by using $t^{\prime}$ as the time variable; $t$ ' is the time after rate-affecting phases have formed. Since $M(t)$ increases as $S(t)$ decreases, the curve described by Eq. 4 will curve upward as time increases. This does not necessarily mean the dissolution rate increases with time. It is simply a mathematical result of the form of the expression with $\mathrm{S}(\mathrm{t})$ in the denominator.

To better show the common corrosion behavior of these glasses, the data were normalized so they could be presented on a single plot. The time $\tau$ that is required for the glass to completely dissolve after alteration phases form can be defined as $\tau=R_{p} / k$. The test durations were then scaled by $\tau$ to generate a dimensionless time variable, $t_{R}$, as $t_{R}=$ $t^{\prime} / \tau$. The value of $t_{R}$ is 1 when the glass is completely dissolved. Similarly, the amount of glass dissolved per unit area is normalized to a dimensionless quantity $M_{R}$, as 


$$
M_{R}=\left(\frac{M(t)}{S(t)}\right)\left(\rho \bullet R_{P}\right)
$$

The values of $k, t_{p}$ and $R_{p}$ are included in Table 12 for the three glasses. By substituting these dimensionless quantities, Eq. 4 is transformed to

$$
M_{R}=\left(\frac{t_{R}}{3}\right)\left(1+\frac{\left(2-t_{R}\right)}{\left(1-t_{R}\right)^{2}}\right)
$$

This expression gives a universal relationship between the mass measured in solution and the extent to which a glass has dissolved if the radius of each glass particle decreases at a constant rate. The plot of $M_{R}$ vs. $t_{R}$ is shown as the curve in Figure 13. Test results have been transformed into the same reduced coordinates as in Eq. 6 by dividing NL(B) $)_{\text {rinal }}$ by the quantity $\rho \cdot R_{p}$ and scaling the test time as $t_{R}=\left(t-t_{p}\right) \cdot k / R_{p}$. Average values of duplicate tests are plotted in Figure 13 for clarity. After the differences in the values of $k$ and $t_{p}$ for the different glasses are taken into account, all three glasses show essentially the same behavior. The experimental values for all glasses are well described by the theoretical curve for reduced times less than about 0.3 , but test data clearly fall below the curve for values of $t_{R}>0.3$. Tests with SRL EA glass have the progressed the furthest and show the deviation most clearly, while tests with SRL 202 show only a small deviation at the longest reaction time. Note that the deviation from the curve does not correspond with the formation of the alteration phases. The data have been normalized so that the effect of phase formation occurs at $t_{R}=0$ for all glasses. Neither is the deviation a result of using the final surface area of the glass in the calculations, since both $M_{R}$ and the experimental rate are calculated with the final surface area.

The observation that the data follow the curve soon after rate-affecting phases form, while data from more advanced tests do not, indicates that the glass dissolution rate becomes moderated by another process after extended time periods (i.e., for $t_{R}>0.3$ ) that is not taken into account in Eq. 6 . This other process may be associated with the glass, the solution, or the alteration phases. Alteration layers are known to form on the surface of the glass particles as the glass corrodes, and the thickness of the layer increases with the extent of corrosion. However, these layers are very porous and probably ineffective diffusion barriers [FENG-1993; EBERT-1993A].

In these PCTs, the crushed glass settles at the bottom of the vessel and is covered by a $2-3 \mathrm{~cm}$ layer of water in tests at $20,000 \mathrm{~m}^{-1}$. Precipitated phases are generally observed to form as a layer of sediment on top of the glass, which suggests that most precipitates form in the bulk solution and not within the solution between the glass grains. Diffusion of material from the glass to the bulk solution may affect the rate at long times. Because of differences in the compositions of the glass and of the suite of alteration phases, the solution will become depleted of some components needed to form alteration phases over time. This may slow the formation of some phases and limit their abundance, and may result in a slowing of glass dissolution. For example, based on the $\mathrm{Na}$ :Al:Si ratios of these glasses, the formation of zeolite alteration phases will be limited by the amount of aluminum that is available. Hence, the solution concentration of aluminum may eventually become low enough to limit the formation of these phases.

The impact of other assumptions made in the present analysis on these results must be further evaluated, such as assumption of spherical particles and the assumption 
that $B$ released from the glass is completely dissolved. Incorporation of small amounts of $B$ into alteration phases would result in an apparent decrease in the dissolution rate. The significant change in the relative amounts of glass and alteration phases that occurs as the test proceeds may also affect the dissolution rate of the glass. Clearly, more work is needed to elucidate phenomena that affect the long-term corrosion behavior of waste glasses.

Regardless of the cause for the difference between the measured and predicted extents of dissolution that are plotted in Figure 13, the linear dissolution rate (the solid curve) provides an upper limit for the measured extents of dissolution over long test durations for the three glasses that were evaluated. The long-term dissolution rates of these glasses at $90^{\circ} \mathrm{C}$ in solutions with $\mathrm{pH}$ values near 12 are: $0.05 \mathrm{~g} /\left(\mathrm{m}^{2} \bullet \mathrm{d}\right)$ for SRL 131 frit-based glasses, $0.04 \mathrm{~g} /\left(\mathrm{m}^{2} \bullet \mathrm{d}\right)$ for SRL 202 frit-based glasses, and $0.2 \mathrm{~g} /\left(\mathrm{m}^{2} \bullet \mathrm{d}\right)$ for the EA glass. Finally, based on Eq. 2, the glass dissolution rates will depend on the pH. The rates that were extracted in this paper are only relevant at $\mathrm{pH}$ values near 12 . Tests conducted at lower S/V usually result in leachate solutions with lower $\mathrm{pH}$ values than tests at $20,000 \mathrm{~m}^{-1}$. A few very long term tests are in progress at $2000 \mathrm{~m}^{-1}$ that may provide dissolution rates at lower $\mathrm{pH}$ values that can be compared to those discussed in this paper. 


\section{CONCLUSIONS}

We have conducted static dissolution tests at $\mathrm{S} / \mathrm{V}$ ratios of 2000 and $20,000 \mathrm{~m}^{-1}$ at $90^{\circ} \mathrm{C}$ for as long as 600 days to characterize the long-term corrosion behavior of the Environmental Assessment glass. Dissolution of the glass led to the formation of smectite clay within the shortest times tested (7 days). Several zeolite phases, including analcime, gmelinite, and sodium aluminum silicate hydrates, formed within 1 year in tests at $2000 \mathrm{~m}^{-1}$ and within 22 days in tests at $20,000 \mathrm{~m}^{-1}$. The same corrosion behavior was observed in tests conducted with the $-100+200$ and $-200+325$ mesh size fractions. The initial dissolution rate in tests at $2000 \mathrm{~m}^{-1}$ was about $0.6 \mathrm{~g} /\left(\mathrm{m}^{2} \cdot \mathrm{d}\right)$ in 7-day tests in tuff groundwater EJ-13 and about $1 \mathrm{~g} /\left(\mathrm{m}^{2} \cdot \mathrm{d}\right)$ in 7 -day tests in demineralized water. The dissolution rate decreased by a factor of about 100 as the solution became saturated with dissolved silica. However, the dissolution rate increased to near the initial rate after zeolite phases formed. The dissolution rate of the EA glass was measured to be about $0.009 \mathrm{~g} /\left(\mathrm{m}^{2} \cdot \mathrm{d}\right)$ before zeolites formed, and about $0.2 \mathrm{~g} /\left(\mathrm{m}^{2} \bullet \mathrm{d}\right)$ after they formed. The dissolution rate during the first twenty days in tests at $20,000 \mathrm{~m}^{-1}$ was about $0.5 \mathrm{~g} /\left(\mathrm{m}^{2} \bullet \mathrm{d}\right)$. Alteration phases formed within a few weeks in tests at $20,000 \mathrm{~m}^{-1}$, so the solutions did not become saturated with respect to the glass and the rate did not become as low as it did in the $2000 \mathrm{~m}^{-1}$ tests.

The rate after alteration phases formed was shown not to be an effect of the size of the crushed glass used in the test: the same phases formed in tests with $-100+200$ mesh glass as in tests with $-200+325$ mesh glass, and the glass dissolution rates were about the same for both size fractions after the phases formed. The fact that similar dissolution rates were measured for tests at different $\mathrm{S} / \mathrm{V}$ ratios and with different size fractions of glass indicates that the effect of phase formation on the solution chemistry is the predominant effect. The dissolution rate in the presence of these alteration phases is about five times less than the average dissolution rate measured in 7-day PCTs in demineralized water and about half the rate measured in a 7-day PCT in EJ-13 water. The long-term dissolution rate of the EA glass is bounded by the rate measured in a 7-day PCT in demineralized water.

The long-term behavior of the EA glass after the formation of rate-affecting phases was the same as has been observed previously in similar tests with glasses made with SRL 131 and SRL 202 frits. Differences between the corrosion rates of these glasses were when the rate-affecting phases formed and the dissolution rate of the glass after those phases formed. By deconvoluting the effects of the decrease in surface area as the glasses dissolve, the long-term corrosion rate was shown not to remain constant. Rather, the long-term rate decreases. While additional work is needed to determine the mechanistic description of the long-term behavior, a possible mechanistic explanation for the decrease is a decrease in the precipitation rate of the alteration phases due to depletion of components, such as aluminum. 


\section{ACKNOWLEDGMENTS}

Solution analyses were performed by Dr. S. F. Wolf (ICP-MS), Mr. E. A. Huff (ICPAES), and Ms. F. Smith (IC). Technical assistance was provided by J. C. Hoh and J. W. Emery. Samples were prepared for AEM/SAED analyses by Ms. N. L. Dietz. This work was supported by the U.S. Department of Energy, Office of Environmental Restoration and Waste Management, under contract W-31-109-ENG-38. 


\section{REFERENCES}

AAGAARD-1982

P. Aagaard and H. C. Helgeson, "Thermodynamics and Kinetic Constraints on Reaction Rates Among Minerals and Aqueous Solutions. I. Theoretical Considerations," Am. J. Sci. 282, 237-285 (1982).

ASTM-1994

American Society for Testing and Materials, Standard Test Methods for Determining Chemical Durability of Nuclear Waste Glasses: The Product Consistency Test (PCT), Standard C1285-94, ASTM, Philadelphia PA (1994).

BATES-1992

J. K. Bates, W. L. Ebert, X. Feng, and W. L. Bourcier, "Issues Affecting the Prediction of Glass Reactivity in an Unsaturated Environment," J. Nucl. Mater. 190, 198-227 (1992).

BOURCIER-1994

W. L. Bourcier, S. A. Carroll, and B. L. Phillips, "Constraints on the Affinity Term for Modeling Long-Term Glass Dissolution Rates," Mater. Res. Soc. Symp. Proc. 333, 507512 (1994).

\section{BRINDLY-1980}

G. W. Brindley, "Order-Disorder in Clay Mineral Structures," in The X-ray Identification and Crystal Structures of Clay Minerals, G. W. Brindley and G. Brown, Eds., Monograph No. 5, Mineralogical Society, London, pp. 125-195 (1980).

DOE-1993

U.S. Department of Energy, Office of Environmental Restoration and Waste Management, Waste Acceptance Product Specifications for Vitrified High-Level Waste Forms. Rev. 0, U.S. DOE Document EM-WAPS, U.S. Department of Energy, Germantown, MD (1993).

EBERT-1997

W. L. Ebert and S. -W. Tam, "Dissolution Rates of DWPF Glass from Long-Term PCT," Mater. Res. Soc. Symp. Proc. 465, 149-156 (1997).

EBERT-1996B

W. L. Ebert and J. K. Bates, "The Corrosion Behavior of DWPF Glasses," Ceram. Trans. Environmental and Waste Management Issues in the Ceramics Industry 61, 479-488 (1995).

EBERT-1996A

W. L. Ebert, "Laboratory Testing of West Valley Reference 6 Glass," Ceram. Trans. Environmental and Waste Management Issues in the Ceramics Industry 61, 471-478 (1995).

EBERT-1993B

W. L. Ebert and J. K. Bates, "A Comparison of Glass Reaction at High and Low Surface Area to Volume," Nucl. Technol. 104(3), 372-384 (1993).

EBERT-1993A

W. L Ebert, J. K. Bates, E. C. Buck, and C. R. Bradley, "Accelerated Glass Reaction Under PCT Conditions," Mater. Res. Soc. Symp. Proc. 294, 569-576(1993). 
EBERT-1990

W. L. Ebert and J. K. Bates, "The Reaction of Synthetic Nuclear Waste Glass in Steam and Hydrothermal Solution," Mater. Res. Soc. Symp. Proc. 176, 339-346 (1990).

FENG-1993

X. Feng, J. K. Bates, C. R. Bradley, and E. C. Buck, "Does Fully Radioactive Glass Behave Differently Than Simulated Waste Glass?” Mater. Res. Soc. Symp. Proc. 294, 207-214 (1993).

GIN-1996

S. Gin, "Control of R7T7 Nuclear Glass Alteration Kinetics under Saturation Conditions," Mater. Res. Soc. Symp. Proc. 412 , 189-196 (1996).

JANTZEN-1993

C. M. Jantzen, Westinghouse Savannah River Site, private communication (1993).

KNAUSS-1990

K. G. Knauss, W. L. Bourcier, K. D. McKeegan, C. I. Merzbacher, S. N. Nguyen, F. J. Ryerson, D. K. Smith, and H. C. Weed, "Dissolution Kinetics of a Simple Analogue Nuclear Waste Glass as a Function of $\mathrm{pH}$, Time, and Temperature," Mater. Res. Soc. Symp. Proc. 176, 371-381 (1990).

McGRAIL-1997

B. P. McGrail, W. L. Ebert, A. J. Bakel, and D. K. Peeler, "Measurement of Kinetic Rate Law Parameters on a Na-Ca-Al Borosilicate Glass for Low-Activity Waste," J. Nucl. Mater. 249, 175-189 (1997).

OLSON-1995

K. M. Olson, G. L. Smith, and S. C. Marschman, Product Consistency Testing of Three Reference Glasses in Stainless Steel and Perfluoroalkoxy Resin Vessels, Pacific Northwest Laboratory Report PNL-10497 (1995).

PLODINEC-1991

M. J. Plodinec, "The DWPF Product, and its Qualification Program," Proc. of the Second Annual Int. High-Level Radioactive Waste Management Topical Meeting, Am. Nucl. Soc., Las Vegas, NV 1, 1124-1131 (1991).

STRACHAN-1994

D. M. Strachan, W. L. Bourcier, and B. P. McGrail, "Towards a Consistent Model for Glass Dissolution," Radioactive Waste Management and Environmental Restoration 19, 129-145 (1994).

VAN ISEGHEM-1988

P. Van Iseghem and B. Grambow, "The Long-Term Corrosion and Modeling of Two Simulated Belgian Reference High-Level Waste Glasses," Mater. Res. Soc. Symp. Proc. 112, 631-639 (1988). 


\section{LIST OF TABLES}

Page

Table 1. Composition of SRL EA Glass as Analyzed at ANL, SRTC, and CELS, and Mass Fraction used to Normalize Solution Results ......... 28

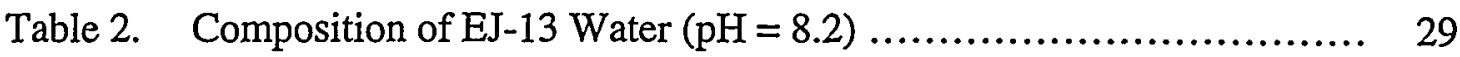

Table 3. Measured $\mathrm{pH}$ and Solution Concentrations for PCT-A with EA Glass ......................................................... 30

Table 4. Measured $\mathrm{pH}$ and Solution Concentrations for PCT-B with EA Glass

Table 5. Glass, Layer, and Alteration Phase Compositions as Measured with EDS, in elemental mass \%

Table 6. Analyses of Isolated Alteration Phases with XRD and SAED

Table 7. Analyses of Clay from Tests at 2000 and $20,000 \mathrm{~m}^{-1}$ with XRD and SAED

Table 8. Analyses of Alteration Phase from Test at $2000 \mathrm{~m}^{-1}$ with XRD 36

Table 9. Analysis of Alteration Phases from Tests Conducted at 2000 and $20,000 \mathrm{~m}^{-1}$ with SAED

Table 10. Measured $\mathrm{pH}$ and Solution Concentrations for PCT-A with EA Glass

Table 11. Comparison of Average 7-day Test Results with EA Glass and SRL 202 Glass in Demineralized Water and EJ-13 Water.

Table 12. Summary of Test Results with DWPF Reference Glasses ............. 40

Table 13. Dissolution Rates and $\mathrm{pH}$ Values Attained After Alteration Phases Form in Tests with Various DWPF Glasses ............................ 41

Appendix I. Test Matrix and Test Data .................................. 56

Appendix II. Solution Analytical Results for Cations in PCT-A Tests.......... 59

Appendix III. Solution Analytical Results for Cations in PCT-B Tests.......... 61

Appendix IV. Solution Analytical Results for Carbon and Anions ............. 66 
Table 1. Composition of SRL EA Glass as Analyzed at ANL, SRTC, and CELS, and Mass Fraction used to Normalize Solution Results

\begin{tabular}{|c|c|c|c|c|}
\hline & ANL & SRTC & CELS & $\mathrm{f}(\mathrm{i})$ \\
\hline $\mathrm{Al}_{2} \mathrm{O}_{3}$ & 3.73 & 3.60 & 3.70 & 0.019 \\
\hline $\mathrm{B}_{2} \mathrm{O}_{3}$ & 11.7 & 11.2 & 11.3 & 0.0347 \\
\hline $\mathrm{CaO}$ & 1.05 & 1.23 & 1.12 & 0.0088 \\
\hline $\mathrm{Fe}_{2} \mathrm{O}_{3}$ & $8.36^{\mathrm{a}}$ & 7.58 & 7.38 & $-^{b}$ \\
\hline $\mathrm{FeO}$ & $-^{\mathrm{a}}$ & 1.59 & 1.45 & $-{ }^{b}$ \\
\hline $\mathrm{K}_{2} \mathrm{O}$ & $<0.1$ & 0.04 & 0.04 & $-{ }^{b}$ \\
\hline $\mathrm{La}_{2} \mathrm{O}_{3}$ & 0.54 & 0.28 & 0.42 & $-^{b}$ \\
\hline $\mathrm{Li}_{2} \mathrm{O}$ & 4.39 & 4.21 & 4.26 & 0.0196 \\
\hline $\mathrm{MgO}$ & 1.56 & 1.79 & 1.72 & $\mathrm{-}^{\mathrm{b}}$ \\
\hline $\mathrm{MnO}_{2}$ & 1.52 & 1.36 & 1.34 & $-\mathrm{b}$ \\
\hline $\mathrm{Na}_{2} \mathrm{O}$ & 16.7 & 16.9 & 16.8 & 0.125 \\
\hline $\mathrm{NiO}$ & 0.50 & 0.53 & 0.57 & $-^{b}$ \\
\hline $\mathrm{SiO}_{2}$ & 48.9 & 48.8 & 48.7 & 0.228 \\
\hline $\mathrm{TiO}_{2}$ & 0.66 & 0.65 & 0.70 & $-^{b}$ \\
\hline $\mathrm{ZnO}$ & 0.02 & 0.26 & & $-b$ \\
\hline $\mathrm{ZrO}_{2}$ & 0.42 & 0.48 & 0.46 & $-{ }^{b}$ \\
\hline Total & 100.05 & 100.50 & 99.96 & \\
\hline
\end{tabular}

${ }^{a}$ All Fe represented as $\mathrm{Fe}(\mathrm{III})$.

${ }^{\mathrm{b}}$ Component was not used to calculate NL(i). 
Table 2. Composition of EJ-13 Water $(\mathrm{pH}=8.2)$

\begin{tabular}{llllll}
\hline Species & Conc., $\mathrm{mg} / \mathrm{L}$ & Species & Conc., $\mathrm{mg} / \mathrm{L}$ & Species & Conc., $\mathrm{mg} / \mathrm{L}$ \\
\hline $\mathrm{Al}$ & 1.3 & $\mathrm{Mg}$ & 0.04 & $\mathrm{~F}^{-}$ & 3.8 \\
$\mathrm{~B}$ & 0.2 & $\mathrm{Na}$ & 55 & $\mathrm{Cl}^{-}$ & 11 \\
$\mathrm{Ca}$ & 4.2 & $\mathrm{Si}$ & 46 & $\mathrm{NO}_{3}^{-}$ & 16 \\
$\mathrm{Fe}$ & 0.04 & total C & 12 & $\mathrm{SO}_{4}{ }^{2-}$ & 30 \\
$\mathrm{~K}$ & 6.8 & organic C & 2 & $\mathrm{HPO}_{4}{ }^{2-}$ & $<0.5$ \\
$\mathrm{Li}$ & 0.03 & & & & \\
\hline
\end{tabular}


Table 3. Measured pH and Solution Concentrations for PCT-A with EA Glass

\begin{tabular}{lccccccccc}
\hline Test No. & $\mathrm{pH}$ & $\begin{array}{c}\mathrm{Li}, \\
\mathrm{mg} / \mathrm{L}\end{array}$ & $\begin{array}{c}\mathrm{NC}(\mathrm{Li}), \\
\mathrm{g} / \mathrm{L}\end{array}$ & $\begin{array}{c}\mathrm{B}, \\
\mathrm{mg} / \mathrm{L}\end{array}$ & $\begin{array}{c}\mathrm{NC}(\mathrm{B}), \\
\mathrm{g} / \mathrm{L}\end{array}$ & $\begin{array}{c}\mathrm{Na}, \\
\mathrm{mg} / \mathrm{L}\end{array}$ & $\begin{array}{c}\mathrm{NC}(\mathrm{Na}), \\
\mathrm{g} / \mathrm{L}\end{array}$ & $\begin{array}{c}\mathrm{Si}, \\
\mathrm{mg} / \mathrm{L}\end{array}$ & $\begin{array}{c}\mathrm{NC}(\mathrm{Si}), \\
\mathrm{g} / \mathrm{L}\end{array}$ \\
\hline EA-21 & 11.81 & 156 & 6.52 & 456 & 13.1 & 1360 & 10.9 & 807 & 3.54 \\
EA-22 & 11.72 & 126 & 5.27 & 354 & 10.2 & 1060 & 8.48 & 670 & 2.94 \\
EA-23 & 11.73 & 134 & 5.61 & 379 & 10.9 & 1140 & 9.12 & 721 & 3.16 \\
mean & & $139 \pm 16$ & & $396 \pm 53$ & & $1190 \pm 155$ & & $733 \pm 69$ & \\
EA-21X & 11.91 & 207 & 8.66 & 565 & 16.3 & 1690 & 13.5 & 954 & 4.18 \\
EA-22X & 11.91 & 232 & 9.71 & 660 & 19.0 & 1920 & 15.4 & 1060 & 4.65 \\
EA-23X & 11.91 & 265 & 11.1 & 669 & 19.3 & 1870 & 15.0 & 1090 & 4.78 \\
mean & & $235 \pm 29$ & & $631 \pm 58$ & & $1830 \pm 121$ & & $1030 \pm 71$ & \\
\hline
\end{tabular}


Table 4. Measured $\mathrm{pH}$ and Solution Concentrations for PCT-B with EA Glass

\begin{tabular}{|c|c|c|c|c|c|c|c|}
\hline \multirow{2}{*}{$\begin{array}{l}\text { Time, } \\
\text { days }\end{array}$} & \multirow[b]{2}{*}{$\mathrm{pH}$} & \multicolumn{5}{|c|}{ Solution Concentration, $\mathrm{mg} / \mathrm{L}$} & \multirow[b]{2}{*}{$\begin{array}{l}\text { Zeolites } \\
\text { Formed? }\end{array}$} \\
\hline & & $\mathrm{Li}$ & B & $\mathrm{Na}$ & $\mathrm{Al}$ & $\mathrm{Si}$ & \\
\hline \multirow{3}{*}{$\begin{array}{l}7^{\mathrm{a}} \\
30^{\mathrm{a}} \\
70^{\mathrm{a}} \\
313 \\
470 \\
592 \\
600\end{array}$} & \multicolumn{6}{|c|}{$-100+200$ mesh glass; $2000 \mathrm{~m}^{-1} ; \mathrm{EJ}-13$} & \\
\hline & $\begin{array}{l}11.61 \\
11.94 \\
11.73 \\
12.07 \\
12.04 \\
11.97 \\
12.05\end{array}$ & $\begin{array}{l}110 \\
150 \\
120 \\
220 \\
350 \\
380 \\
360\end{array}$ & $\begin{array}{r}310 \\
310 \\
360 \\
400 \\
2400 \\
2500 \\
2400\end{array}$ & $\begin{array}{r}950 \\
1000 \\
1200 \\
4100 \\
6300 \\
6400 \\
5400\end{array}$ & $\begin{array}{l}1.5 \\
1.1 \\
2.8 \\
0.85 \\
0.89 \\
0.61 \\
1.1\end{array}$ & $\begin{array}{r}640 \\
680 \\
680 \\
1800 \\
1800 \\
2600 \\
2400\end{array}$ & $\begin{array}{l}\text { No } \\
\text { No } \\
\text { No } \\
\text { No } \\
\text { Yes } \\
\text { Yes } \\
\text { Yes }\end{array}$ \\
\hline & \multicolumn{6}{|c|}{$-100+200$ mesh glass; $20,000 \mathrm{~m}^{-1} ; \mathrm{EJ}-13$} & \\
\hline $\begin{array}{l}7 \\
14 \\
20 \\
22 \\
35 \\
42 \\
56^{\mathrm{a}} \\
98^{\mathrm{a}} \\
182^{\mathrm{a}} \\
367^{\mathrm{a}} \\
407 \\
470 \\
592\end{array}$ & $\begin{array}{l}11.86 \\
11.71 \\
11.87 \\
11.96 \\
11.91 \\
11.92 \\
12.26 \\
12.37 \\
12.22 \\
11.31 \\
11.58 \\
- \\
11.41\end{array}$ & $\begin{array}{r}1000 \\
1010 \\
1360 \\
1110 \\
1340 \\
1340 \\
950 \\
1200 \\
1900 \\
2030 \\
1890 \\
1730 \\
2260\end{array}$ & $\begin{array}{r}3550 \\
3870 \\
5670 \\
7550 \\
9910 \\
9920 \\
7600 \\
11000 \\
17000 \\
24000 \\
25000 \\
29000 \\
31000\end{array}$ & $\begin{array}{l}16000 \\
16600 \\
24600 \\
21000 \\
26000 \\
26400 \\
25000 \\
30000 \\
53000 \\
75000 \\
57000 \\
59000 \\
72000\end{array}$ & $\begin{array}{l}<20 \\
<20 \\
<20 \\
<20 \\
<20 \\
<20 \\
4.1 \\
<1 \\
12 \\
36 \\
7.9 \\
30 \\
20\end{array}$ & $\begin{array}{r}3470 \\
3610 \\
1190 \\
527 \\
3921 \\
973 \\
880 \\
1000 \\
3700 \\
3700 \\
3700 \\
3700 \\
12000\end{array}$ & $\begin{array}{l}\text { Probably } \\
\text { Probably } \\
\text { Yes } \\
\text { Yes } \\
\text { Yes } \\
\text { Yes } \\
\text { Yes } \\
\text { Yes } \\
\text { Yes } \\
\text { Yes } \\
\text { Yes } \\
\text { Yes } \\
\text { Yes }\end{array}$ \\
\hline 592 & \multicolumn{6}{|c|}{$-200+325$ mesh glass; $20,000 \mathrm{~m}^{-1} ; \mathrm{EJ}-13$} & \\
\hline $\begin{array}{l}56^{\mathrm{a}} \\
98^{\mathrm{a}} \\
182^{\mathrm{a}} \\
367^{\mathrm{a}} \\
592^{\mathrm{a}}\end{array}$ & $\begin{array}{l}12.24 \\
12.28 \\
12.23 \\
11.77 \\
11.60\end{array}$ & $\begin{array}{r}750 \\
1040 \\
1320 \\
1370 \\
1330\end{array}$ & $\begin{array}{r}6300 \\
9900 \\
11000 \\
17000 \\
17000\end{array}$ & $\begin{array}{l}20000 \\
26000 \\
43000 \\
43000 \\
41000\end{array}$ & $\begin{array}{c}1.9 \\
<0.5 \\
6.6 \\
17 \\
7.8\end{array}$ & $\begin{array}{l}1300 \\
2800 \\
7700 \\
7700 \\
5300\end{array}$ & $\begin{array}{l}\text { Yes } \\
\text { Yes } \\
\text { Yes } \\
\text { Yes } \\
\text { Yes }\end{array}$ \\
\hline
\end{tabular}

average of duplicate tests

b $\mathrm{No}=$ alteration phases (other than clay) not detected Yes = alteration phases (other than clay) detected Probably $=$ small features appear to be newly nucleated alteration phases 
Table 5. Glass, Layer, and Alteration Phase Compositions as Measured with EDS, in elemental mass \%

\begin{tabular}{|c|c|c|c|c|c|c|c|}
\hline \multirow[b]{2}{*}{ Element } & \multirow[b]{2}{*}{ Glass $^{\mathbf{a}}$} & \multicolumn{5}{|c|}{ EDS Results } & \multirow[b]{2}{*}{ Phase 4} \\
\hline & & Glass & Layer & Phase 1 & Phase 2 & Phase 3 & \\
\hline $\mathrm{Al}$ & 1.90 & $1.97 \pm 0.09$ & $0.98 \pm 0.32$ & $11.45 \pm 0.04$ & $11.40 \pm 0.29$ & $11.11 \pm 0.12$ & $10.34 \pm 0.13$ \\
\hline $\mathrm{B}$ & 3.42 & $3.42^{\mathrm{b}}$ & $3.42^{b}$ & & & & \\
\hline $\mathrm{Ca}$ & 0.86 & $0.84 \pm 0.10$ & $2.49 \pm 0.67$ & $0.11 \pm 0.05$ & $0.12 \pm 0.08$ & $0.32 \pm 0.16$ & $0.16 \pm 0.10$ \\
\hline $\mathrm{Fe}^{\mathrm{c}}$ & 5.31 & $5.48 \pm 0.32$ & $8.50 \pm 0.48$ & $0.08 \pm 0.01$ & $0.94 \pm 0.50$ & $0.69 \pm 0.53$ & $0.54 \pm 0.42$ \\
\hline$K$ & 0.03 & $0.03 \pm 0.05$ & $0.27 \pm 0.16$ & $0.22 \pm 0.13$ & $0.01 \pm 0.03$ & $2.48 \pm 0.68$ & $2.31 \pm 0.71$ \\
\hline $\mathrm{La}$ & 0.24 & $0.24^{\mathrm{b}}$ & $0.24^{\mathrm{b}}$ & & & & \\
\hline$\overline{\mathrm{Li}}$ & 1.95 & $1.95^{\mathrm{b}}$ & $1.95^{\mathrm{b}}$ & & & & \\
\hline $\mathrm{Mg}$ & 1.09 & $0.59 \pm 0.09$ & $1.75 \pm 0.14$ & 0 & 0 & 0 & 0 \\
\hline $\mathrm{Mn}$ & 0.89 & $0.91 \pm 0.12$ & $1.70 \pm 0.43$ & $0.05 \pm 0.01$ & 0 & $0.30 \pm 0.41$ & 0 \\
\hline $\mathrm{Na}$ & 12.6 & $13.59 \pm 0.52$ & $7.41 \pm 1.24$ & $12.42 \pm 0.27$ & $8.43 \pm 0.31$ & $7.46 \pm 0.33$ & $6.39 \pm 0.66$ \\
\hline $\mathrm{Ni}$ & 0.42 & $0.42^{b}$ & $0.42^{\mathrm{b}}$ & & & & \\
\hline $\mathrm{Si}$ & 22.9 & $22.94 \pm 0.43$ & $28.22 \pm 0.77$ & $28.44 \pm 0.12$ & $30.76 \pm 0.08$ & $29.92 \pm 0.29$ & $31.72 \pm 0.15$ \\
\hline $\mathrm{Ti}$ & 0.39 & $0.37 \pm 0.07$ & $0.81 \pm 0.17$ & $0.06 \pm 0.04$ & $0.08 \pm 0.08$ & $0.03 \pm 0.04$ & 0 \\
\hline $\mathrm{Zn}$ & 0.21 & $0.21^{\mathrm{b}}$ & $0.21^{\mathrm{b}}$ & & & & \\
\hline $\mathrm{Zr}$ & 0.36 & $0.36^{b}$ & $0.36^{b}$ & & & & \\
\hline $\mathrm{O}^{\mathrm{d}}$ & 47.43 & 46.68 & 41.27 & 47.17 & 48.26 & 47.69 & 48.54 \\
\hline Total & 100 & 100 & 100 & 100 & 100 & 100 & 100 \\
\hline
\end{tabular}

${ }^{a}$ Composition from Table 1.

${ }^{b}$ Not analyzed, concentration assumed from solution results.

${ }^{c}$ All iron expressed as $\mathrm{Fe}_{2} \mathrm{O}_{3}$.

${ }^{\mathrm{d}}$ Oxygen by stoichiometry. 
Table 6. Analyses of Isolated Alteration Phases with XRD and SAED

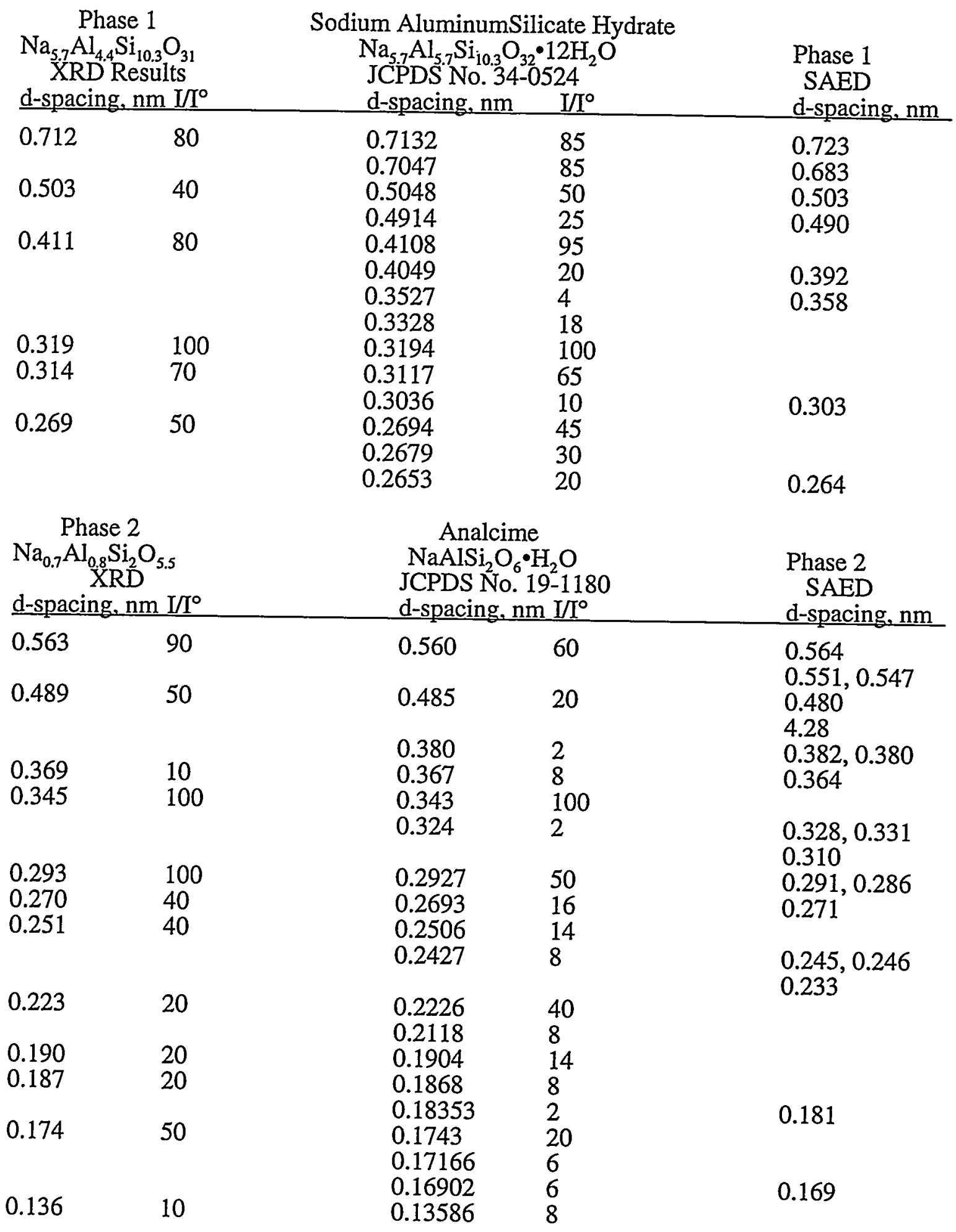


Phase 3

\begin{tabular}{|c|c|c|c|c|}
\hline \multicolumn{2}{|c|}{$\begin{array}{l}\mathrm{Na}_{1.2} \mathrm{Al}_{1.5} \mathrm{Si}_{4} \mathrm{O}_{11} \\
\text { XRD } \\
\text { d-spacing.nm I// } \\
\end{array}$} & \multicolumn{2}{|c|}{$\begin{array}{l}\mathrm{Na}_{2} \mathrm{Al}_{2} \mathrm{Si}_{4} \mathrm{O}_{12} \cdot \mathrm{H}_{2} \mathrm{O} \\
\mathrm{JCPDS} \mathrm{No} .38-0435 \\
\text { d-spacing, nm } \quad \text { // } \\
\end{array}$} & $\begin{array}{l}\text { Phase } 3 \\
\text { SAED } \\
\text { d-spacing, } \mathrm{nm}\end{array}$ \\
\hline 1.184 & 100 & 1.19 & 63 & \\
\hline 0.772 & 20 & 0.768 & 29 & \\
\hline 0.691 & 50 & 0.6875 & 10 & 0.689 \\
\hline 0.596 & 10 & $\begin{array}{l}0.595 \\
0.5121\end{array}$ & $\begin{array}{l}9 \\
23\end{array}$ & 0.595 \\
\hline 0.504 & 80 & 0.5026 & 28 & 0.503 \\
\hline 0.450 & 40 & 0.4498 & 25 & \\
\hline 0.414 & 90 & 0.4106 & 100 & 0.411 \\
\hline 0.345 & 40 & 0.344 & 21 & 0.346 \\
\hline 0.325 & 30 & 0.3227 & 41 & \\
\hline 0.298 & 80 & 0.2978 & 55 & \\
\hline 0.287 & 50 & 0.2922 & 18 & \\
\hline 0.270 & 20 & 0.2855 & 42 & 0.286 \\
\hline 0.261 & 20 & 0.269 & 44 & 0.262 \\
\hline & & 0.2597 & 14 & \\
\hline & & $\begin{array}{l}0.2400 \\
0.2355\end{array}$ & $\begin{array}{l}1 \\
1\end{array}$ & 0.234 \\
\hline 0.209 & 20 & 0.2086 & 12 & \\
\hline & & 0.19418 & 4 & \\
\hline & & 0.19212 & 2 & \\
\hline 0.181 & 20 & 0.1808 & 8 & \\
\hline 0.172 & 20 & 0.1719 & 9 & 0.172 \\
\hline & & 0.16903 & 2 & \\
\hline
\end{tabular}


Table 7. Analyses of Clay from Tests at 2000 and $20,000 \mathrm{~m}^{-1}$ with XRD and SAED

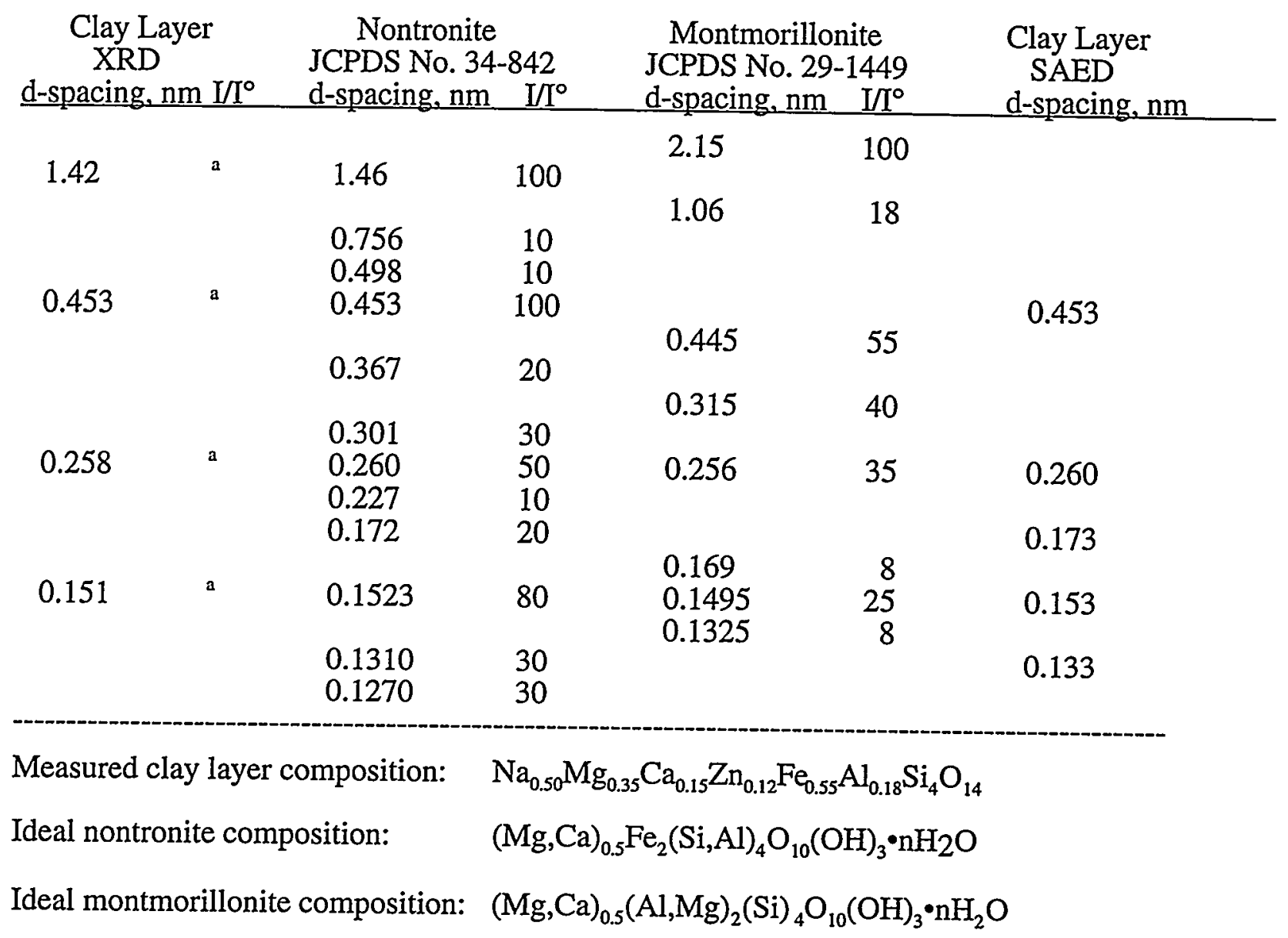

a Intensity not determined due to high background. 
Table 8. Analyses of Alteration Phase from Test at $2000 \mathrm{~m}^{-1}$ with XRD

\begin{tabular}{|c|c|c|c|}
\hline \multicolumn{2}{|c|}{$\begin{array}{l}\text { Phase } 4 \\
\mathrm{Na}_{3.0} \mathrm{~K}_{0.62} \mathrm{Al}_{4.1} \mathrm{Si}_{12.4} \mathrm{O}_{33} \\
\text { XRD Results }\end{array}$} & \multicolumn{2}{|c|}{$\begin{array}{c}\text { Sodium Aluminum Silicate Hydrate } \\
\mathrm{Na}_{3.6} \mathrm{Al}_{3.6} \mathrm{Si}_{12.4} \mathrm{O}_{32} \cdot 14 \mathrm{H}_{2} \mathrm{O} \\
\text { JCPDS No. } 40-1464\end{array}$} \\
\hline d-spacing, $\mathrm{nm}$ & $I / 1^{\circ}$ & d-spacing, $\mathrm{nm}$ & $\mathrm{I} / \mathrm{I}^{\circ}$ \\
\hline 0.714 & 96 & 0.70924 & 91 \\
\hline 0.504 & 26 & 0.49984 & 61 \\
\hline 0.411 & 84 & 0.41014 & 53 \\
\hline & & 0.40846 & 16 \\
\hline & & 0.31818 & 33 \\
\hline 0.318 & 100 & 0.31641 & 100 \\
\hline 0.269 & 54 & 0.26774 & 97 \\
\hline 0.252 & 1 & 0.25170 & 16 \\
\hline 0.224 & 1 & 0.22366 & 21 \\
\hline 0.197 & 3 & 0.19613 & 20 \\
\hline 0.177 & 3 & 0.17737 & 52 \\
\hline 0.172 & 4 & 0.17236 & 36 \\
\hline & & 0.17179 & 52 \\
\hline 0.167 & 1 & 0.16665 & 49 \\
\hline 0.148 & 1 & 0.14746 & 46 \\
\hline 0.137 & 2 & 0.13619 & 41 \\
\hline 0.127 & 2 & 0.12704 & 55 \\
\hline
\end{tabular}


Table 9. Analysis of Alteration Phases from Tests Conducted at 2000 and $20,000 \mathrm{~m}^{-1}$ with SAED

\begin{tabular}{lcc}
$\begin{array}{c}\text { Phase } 5 \\
\text { SAED }\end{array}$ & $\mathrm{Na}_{3.7} \mathrm{Ca}_{7.4} \mathrm{Al}_{18.5} \mathrm{Si}_{77.5} \mathrm{O}_{192} \cdot 74 \mathrm{H}_{2} \mathrm{O}$ \\
JCPDS No. $42-1379$ & $\mathrm{I} / \mathrm{I}^{\circ}$ \\
\hline d-spacing, nm & d-spacing,nm & 92 \\
& 1.128 & 18 \\
0.676 & 1.082 & 17 \\
0.572 & 1.012 & 14 \\
0.496 & 0.6743 & 6 \\
& 0.5637 & 8 \\
& 0.4923 & 33 \\
& 0.4462 & 31 \\
& 0.4356 & 100 \\
0.320 & 0.3858 & 38 \\
0.397 & 0.3606 & 54 \\
& 0.3386 & 70 \\
& 0.3371 & 6 \\
& 0.3199 & 14
\end{tabular}

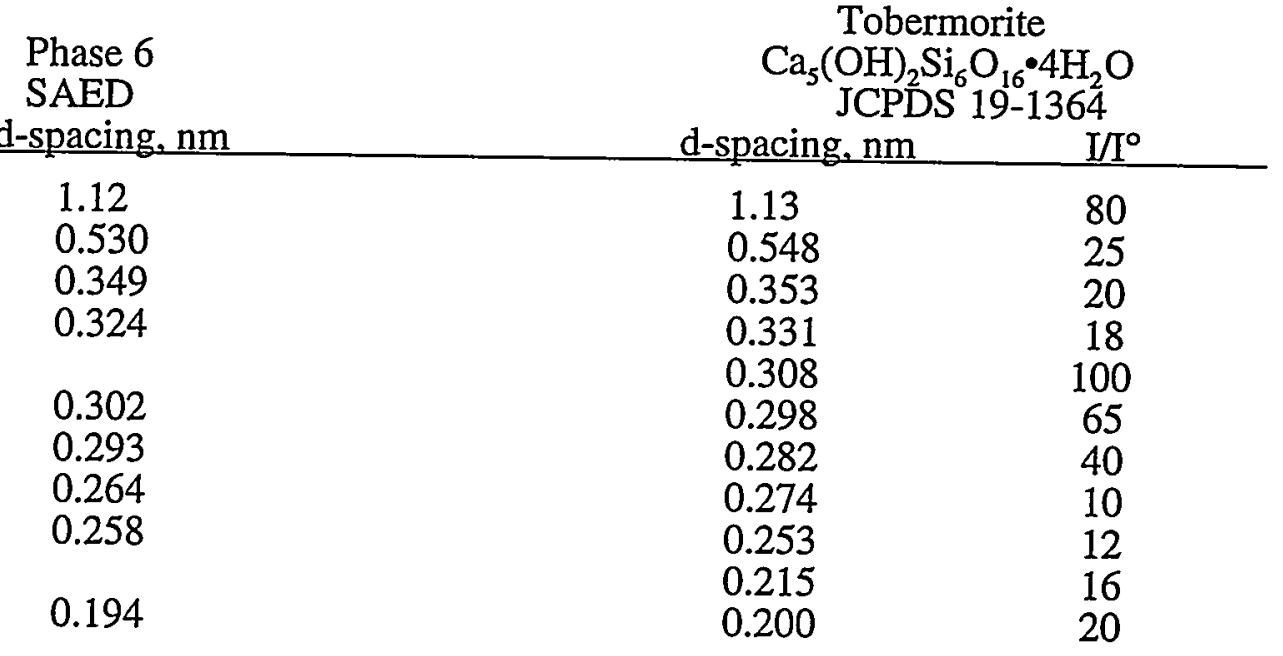


Table 10. Measured pH and Solution Concentrations for PCT-A with EA Glass

\begin{tabular}{lccccccccc}
\hline Test No. & pH & $\begin{array}{c}\mathrm{Li}, \\
\mathrm{mg} / \mathrm{L}\end{array}$ & $\begin{array}{c}\mathrm{NC}(\mathrm{Li}), \\
\mathrm{g} / \mathrm{L}\end{array}$ & $\begin{array}{c}\mathrm{B}, \\
\mathrm{mg} / \mathrm{L}\end{array}$ & $\begin{array}{c}\mathrm{NC}(\mathrm{B}), \\
\mathrm{g} / \mathrm{L}\end{array}$ & $\begin{array}{c}\mathrm{Na}, \\
\mathrm{mg} / \mathrm{L}\end{array}$ & $\begin{array}{c}\mathrm{NC}(\mathrm{Na}), \\
\mathrm{g} / \mathrm{L}\end{array}$ & $\begin{array}{c}\mathrm{Si}, \\
\mathrm{mg} / \mathrm{L}\end{array}$ & $\begin{array}{c}\mathrm{NC}(\mathrm{Si}), \\
\mathrm{g} / \mathrm{L}\end{array}$ \\
\hline $\mathrm{ANL}^{\mathrm{a}}$ & 11.83 & $187 \pm 49$ & 9.54 & $528 \pm 135$ & 15.2 & $1530 \pm 350$ & 12.2 & $886 \pm 160$ & 3.89 \\
$\mathrm{PNL}^{\mathrm{b}}$ & 11.92 & $145 \pm 12$ & 7.39 & $545 \pm 32$ & 15.7 & $1540 \pm 65$ & 12.3 & $634 \pm 58$ & 2.78 \\
$\mathrm{SRTC}^{\mathrm{c}}$ & 11.85 & $190 \pm 14$ & 9.69 & $587 \pm 43$ & 16.9 & $1660 \pm 112$ & 13.3 & $893 \pm 86$ & 3.92 \\
\hline
\end{tabular}

${ }^{\mathrm{a}}$ Mean and standard deviation for 9 tests.

${ }^{b}$ Mean and standard deviation for 14 tests [OLSON-1995].

${ }^{c}$ Mean and standard deviation for 42 tests [JANTZEN-1993]. 
Table 11. Comparison of Average 7-day Test Results with EA Glass and SRL 202 Glass in Demineralized Water and EJ-13 Water

\begin{tabular}{|c|c|c|c|c|c|}
\hline & $\mathrm{Al}$ & B & $\mathrm{Li}$ & $\mathrm{Na}$ & $\mathrm{Si}$ \\
\hline $\begin{array}{l}\text { Concentrations from Tests in } \\
\text { Demineralized Water, } \mathrm{mg} / \mathrm{L}\end{array}$ & 0.04 & 515 & 188 & 1510 & 883 \\
\hline $\begin{array}{l}\text { Concentrations from Tests in } \\
\text { EJ-13 Water, } \mathrm{mg} / \mathrm{L}\end{array}$ & 1.5 & 310 & 110 & 950 & 640 \\
\hline $\begin{array}{l}\text { Concentrations in } \mathrm{EJ}-13 \\
\text { Water, mg/L }\end{array}$ & 1.3 & 0.2 & 0.03 & 55 & 46 \\
\hline Ratio for Tests with EA Glass ${ }^{\mathrm{a}}$ & 0.2 & 1.66 & 1.71 & 1.59 & 1.49 \\
\hline
\end{tabular}

${ }^{2}$ Ratio of the concentration in tests in demineralized water divided by the concentration in tests in EJ-13 water minus the EJ-13 background concentration. 
Table 12. Summary of Test Results with DWPF Reference Glasses

\begin{tabular}{|c|c|c|c|c|c|}
\hline Glass & $\mathrm{S} / \mathrm{V}, \mathrm{m}^{-1}$ & Time, days & $\mathrm{pH}$ & Alteration Phases & Ref. \\
\hline SRL 131A & 2000 & $140-280$ & $10.7-11.5$ & $\begin{array}{l}\text { SMEC; ANAL; } \\
\text { GYR; WEEK }\end{array}$ & $\begin{array}{l}\text { [EBERT- } \\
\text { 1993] }\end{array}$ \\
\hline SRL 131A & 20,000 & $98-182$ & $12.1-12.4$ & $\begin{array}{l}\text { SMEC; ANAL; } \\
\text { GYR; WEEK }\end{array}$ & $\begin{array}{l}\text { [EBERT- } \\
\text { 1993] }\end{array}$ \\
\hline SRL $131 S^{c}$ & 2000 & $980-1800$ & $11.7-12.0$ & SMEC; ANAL & $\begin{array}{l}\text { [FENG- } \\
1993]\end{array}$ \\
\hline SRL $131 R^{b}$ & 2000 & $>1800^{\mathrm{b}}$ & 11.9 & SMEC & $\begin{array}{l}\text { [FENG- } \\
\text { 1993] }\end{array}$ \\
\hline SRL 200S & 20,000 & $182-330$ & $11.8-12.3$ & $\begin{array}{l}\text { SMEC; ANAL; } \\
\text { CLIN; GYR; WEEK }\end{array}$ & $\begin{array}{l}\text { [FENG- } \\
1993]\end{array}$ \\
\hline SRL 200R ${ }^{b}$ & 20,000 & $>1800^{\mathrm{b}}$ & 11.7 & SMEC & $\begin{array}{r}\text { [FENG- } \\
1993]\end{array}$ \\
\hline SRL 202U & 20,000 & $182-364$ & $11.5-11.7$ & $\begin{array}{l}\text { SMEC; ANAL; } \\
\text { GYR; WEEK }\end{array}$ & $\begin{array}{c}\text { [EBERT- } \\
\text { 1993] }\end{array}$ \\
\hline SRL 202A ${ }^{c}$ & 2000 & 1822 & 11.3 & $\begin{array}{l}\text { SMEC; ANAL; } \\
\text { GYR; WEEK }\end{array}$ & $\begin{array}{l}\text { [EBERT- } \\
\text { 1993] }\end{array}$ \\
\hline SRL 202A & 20,000 & $182-364$ & $11.3-11.9$ & $\begin{array}{l}\text { SMEC; ANAL; } \\
\text { GYR; WEEK }\end{array}$ & $\begin{array}{l}\text { [EBERT- } \\
\text { 1993] }\end{array}$ \\
\hline SRL EA ${ }^{\mathrm{d}}$ & 2000 & $313-369$ & $11.8-12.1$ & $\begin{array}{l}\text { SMEC; ANAL; } \\
\text { GMEL; GYR; ZEO }\end{array}$ & This work \\
\hline SRL EA & 20,000 & $<22^{\mathrm{e}}$ & $12.0-12.4$ & $\begin{array}{l}\text { SMEC; ANAL; } \\
\text { GMEL; ZEO }\end{array}$ & This work \\
\hline
\end{tabular}

a SMEC = smectite clay; ANAL = analcime; GYR = gyrolite or other Ca-silicate phase;

WEEK = weeksite; ZEO = Na-Al-silicate phase; GMEL = gmelinite;

CLIN = clinoptilolite .

${ }^{b}$ Rate-affecting alteration phases did not form within the longest time tested.

c Rate-affecting alteration phases only formed at the longest time tested.

d Too few data to extract rate.

e Rate-affecting phases formed within the shortest time tested. 
Table 13. Dissolution Rates and $\mathrm{pH}$ Values Attained After Alteration Phases Form in Tests with Various DWPF Glasses

\begin{tabular}{lrrcc}
\hline Glass & $\mathrm{S} / \mathrm{V}, \mathrm{m}^{-1}$ & $\mathrm{t}_{\mathrm{p}}, \mathrm{d}^{\mathrm{a}}$ & $\mathrm{R}_{\mathrm{p}}, \mu \mathrm{m}^{\mathrm{b}}$ & $\mathrm{k}, \mathrm{nm} / \mathrm{d}$ \\
\hline SRL 131A & 20,000 & 98 & 50 & 25 \\
SRL 202A & 20,000 & 182 & 56 & 13 \\
SRL EA & 20,000 & 0 & 56 & 82 \\
\hline
\end{tabular}

Test duration prior to formation of rate-affecting phases.

${ }^{b}$ Estimated grain size at $t_{\mathrm{p}}$. 


\section{LIST OF FIGURES}

Page

Figure 1. SEM Photomicrographs of Unreacted SRL EA Glass:

(a) $-100+200$ Mesh and (b) $-200+325$ Mesh

43

Figure 2. Normalized Mass Loss vs. Reaction Time for Tests at $2000 \mathrm{~m}^{-1}$ with $-100+200$ Mesh Glass

Figure 3. (a) Normalized Mass Loss vs. Reaction Time for Tests at $20,000 \mathrm{~m}^{-1}$ with $-100+200$ Mesh Glass. (b) Short-term

Tests on Expanded Scale

Figure 4. Normalized Mass Loss vs. Reaction Time for Tests at $20,000 \mathrm{~m}^{-1}$ with $-200+325$ Mesh Glass.

Figure 5. SEM Photomicrographs of SRL EAGlass Reacted at $20,000 \mathrm{~m}^{-1}$ for 98 days: (a) Reacted Rod, (b) High-Magnification Image of Outer Surface, and (c) Cross Sectioned Grains.

Figure 6. SEM Photomicrographs of Alteration Phases Formed in Tests at $20,000 \mathrm{~m}^{-1}$ : (a) Analcime, (b) Gmelinite, and (c) Sodium Aluminum Silicate Hydrate formed at Reaction Times of 56 days and Longer, and (d) Solid from 22-day Test.

Figure 7. SEM Photomicrograph of Sodium Aluminum Silicate Hydrate Phase Formed in Tests at $2000 \mathrm{~m}^{-1}$ Conducted 313 days and Longer

Figure 8. Reaction Progress Plot 50

Figure 9. Effect of $\mathrm{Na}$ Concentration on Measured $\mathrm{pH}$ of Two Buffer Solutions

Figure 10. Measured Rates for Tests at (a) $2000 \mathrm{~m}^{-1}$, (b) $20,000 \mathrm{~m}^{-1}$ with $-100+200$ mesh glass, and (c) $20,000 \mathrm{~m}^{-1}$ with $-200+325$ mesh glass

Figure 11. Calculated Surface Area, in $\mathrm{m}^{2}$, vs. Amount of Boron in Solution, in $\mathrm{g}$

Figure 12. NL(B) for Tests at $20,000 \mathrm{~m}^{-1}$ with SRL EA glass, SRL 131A glass, and SRL 202A

Figure 13. Theoretical Curve and Results of Tests at $20,000 \mathrm{~m}^{-1}$ with SRL glass, SRL 131A glass, and SRL 202A. 

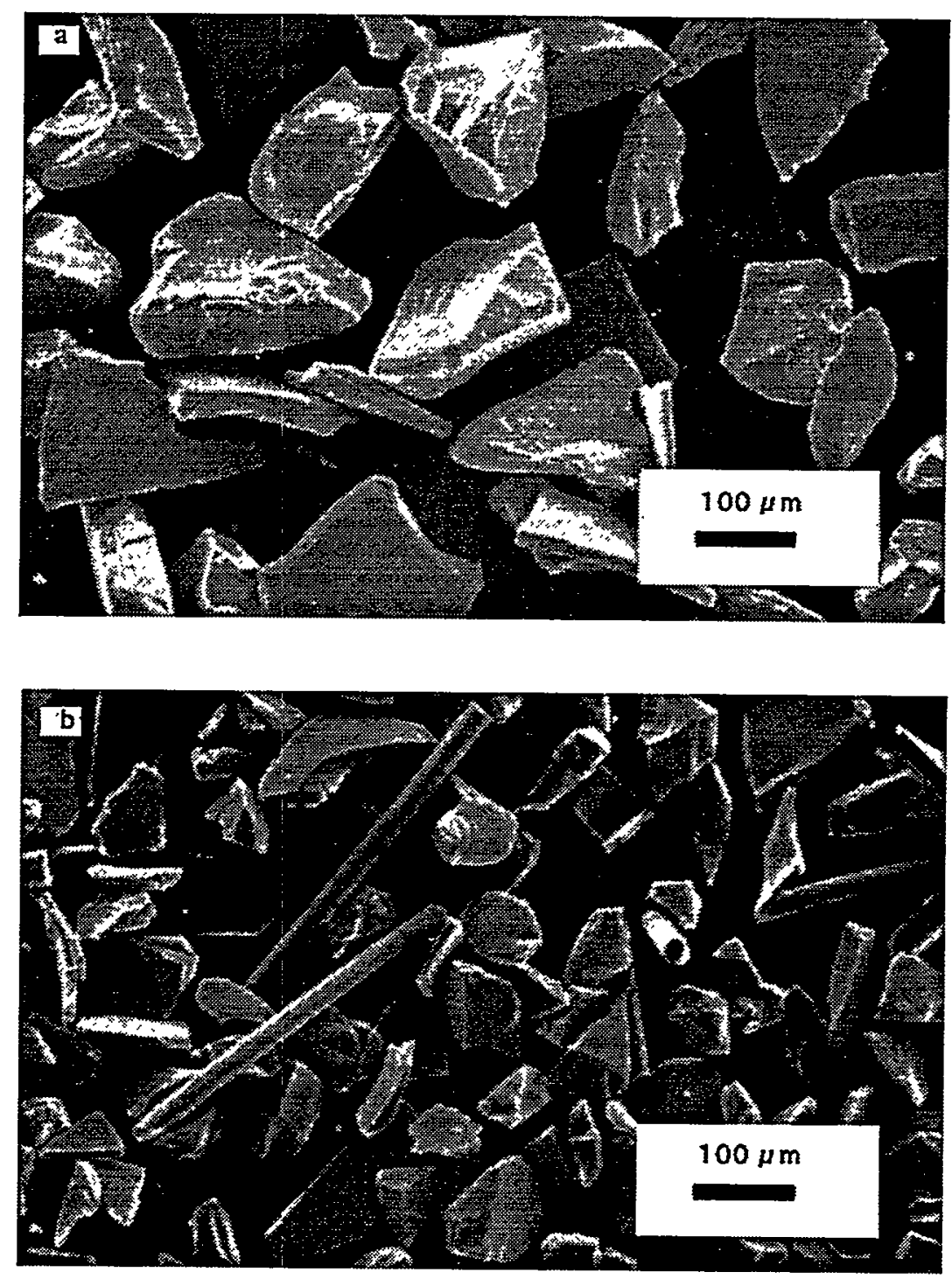

Figure 1. SEM Photomicrographs of Unreacted SRL EA Glass: (a) $-100+200$ Mesh and (b) $-200+325$ Mesh. 


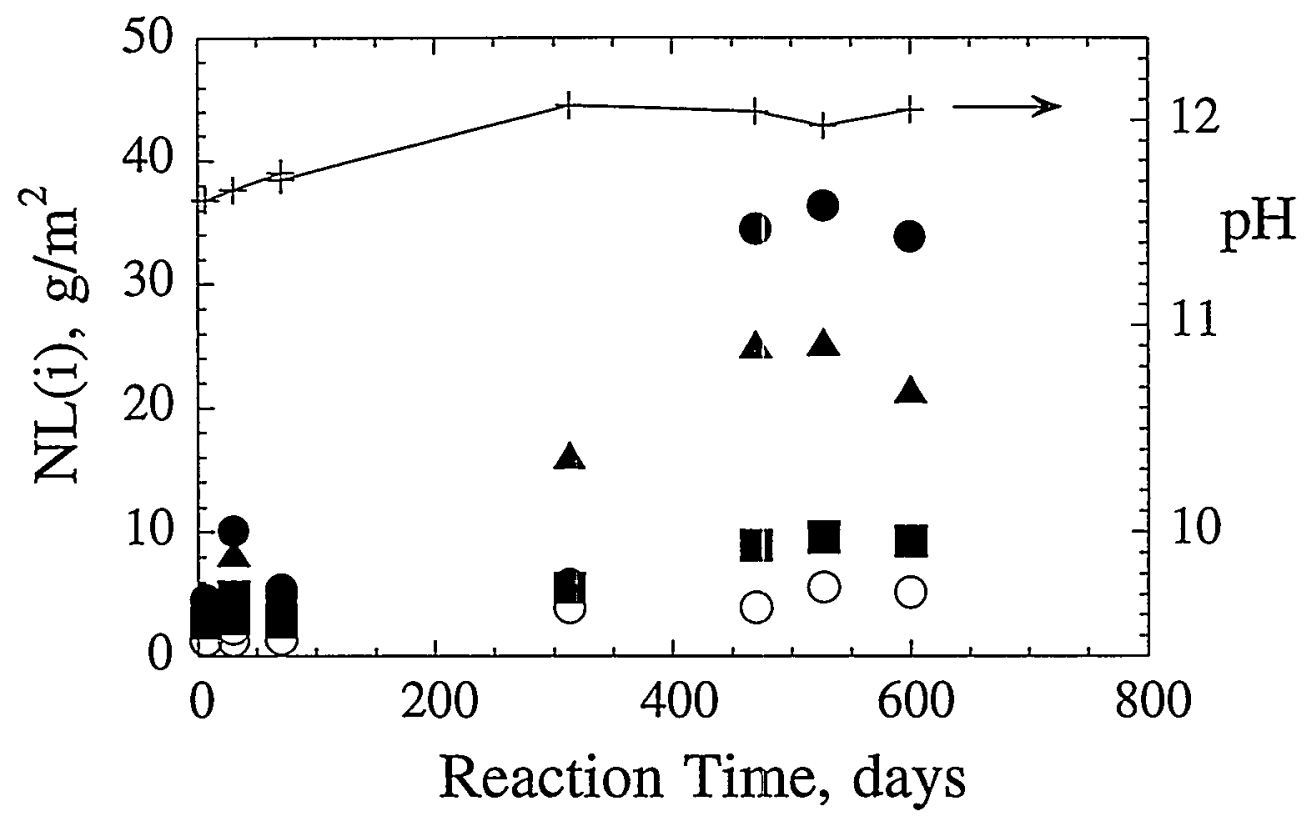

Figure 2. Normalized Mass Loss vs. Reaction Time for Tests at $2000 \mathrm{~m}^{-1}$ with $-100+200 \mathrm{Mesh}$ Glass: $\mathrm{NL}(\mathrm{B})-(\bullet), \mathrm{NL}(\mathrm{Li})-(\mathbf{E}), \mathrm{NL}(\mathrm{Na})-(\mathbf{A}), \mathrm{NL}(\mathrm{Si})-(\mathrm{O})$, and $\mathrm{pH}-(+)$. 

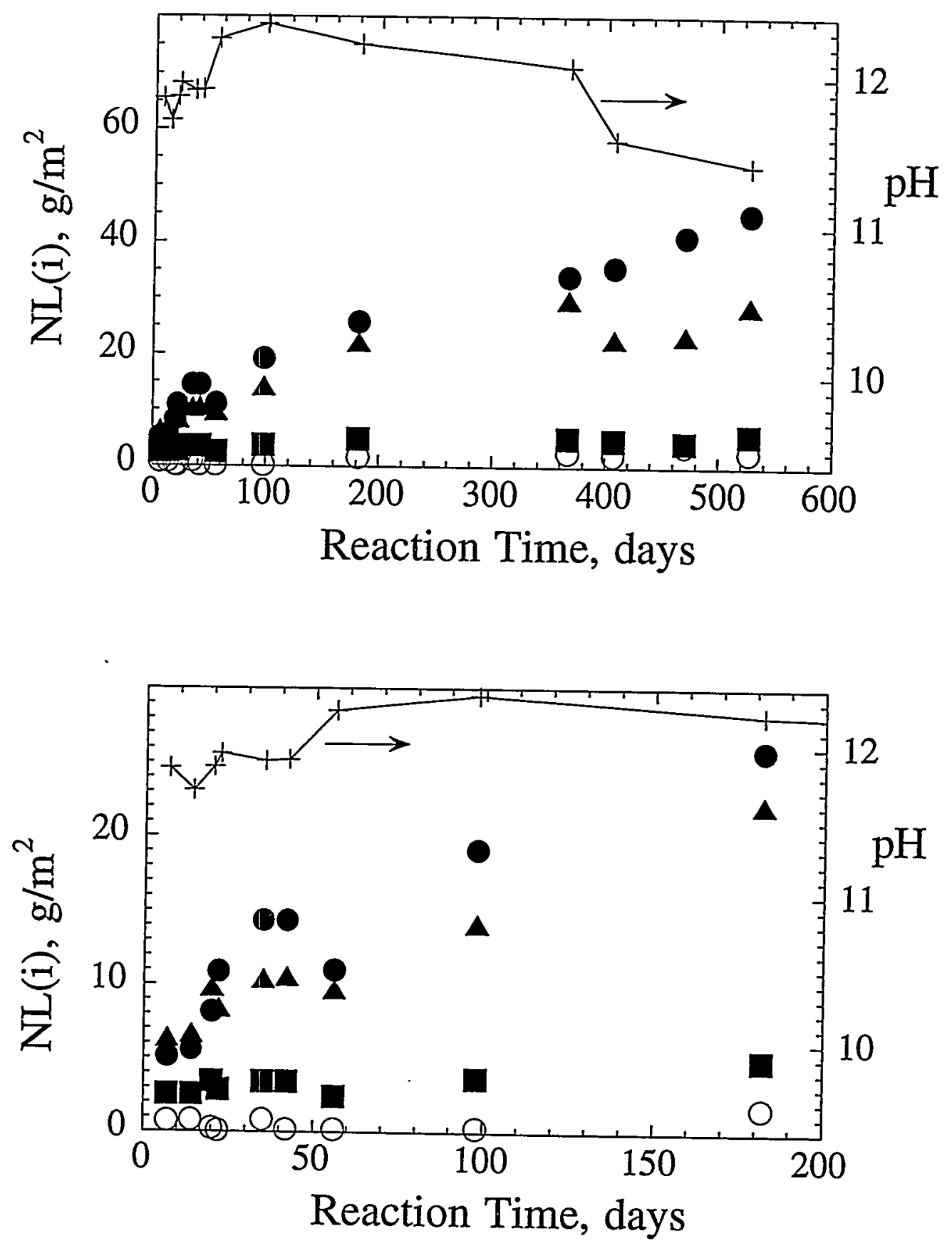

Figure 3. (a) Normalized Mass Loss vs. Reaction Time for Tests at $20,000 \mathrm{~m}^{-1}$ with $-100+200$ Mesh Glass (b) Short-term Tests on Expanded Scale : NL(B)-(•), NL(Li)-(ם), NL(Na)-(A), $\mathrm{NL}(\mathrm{Si})-(\mathrm{O})$, and $\mathrm{pH}-(+)$. 


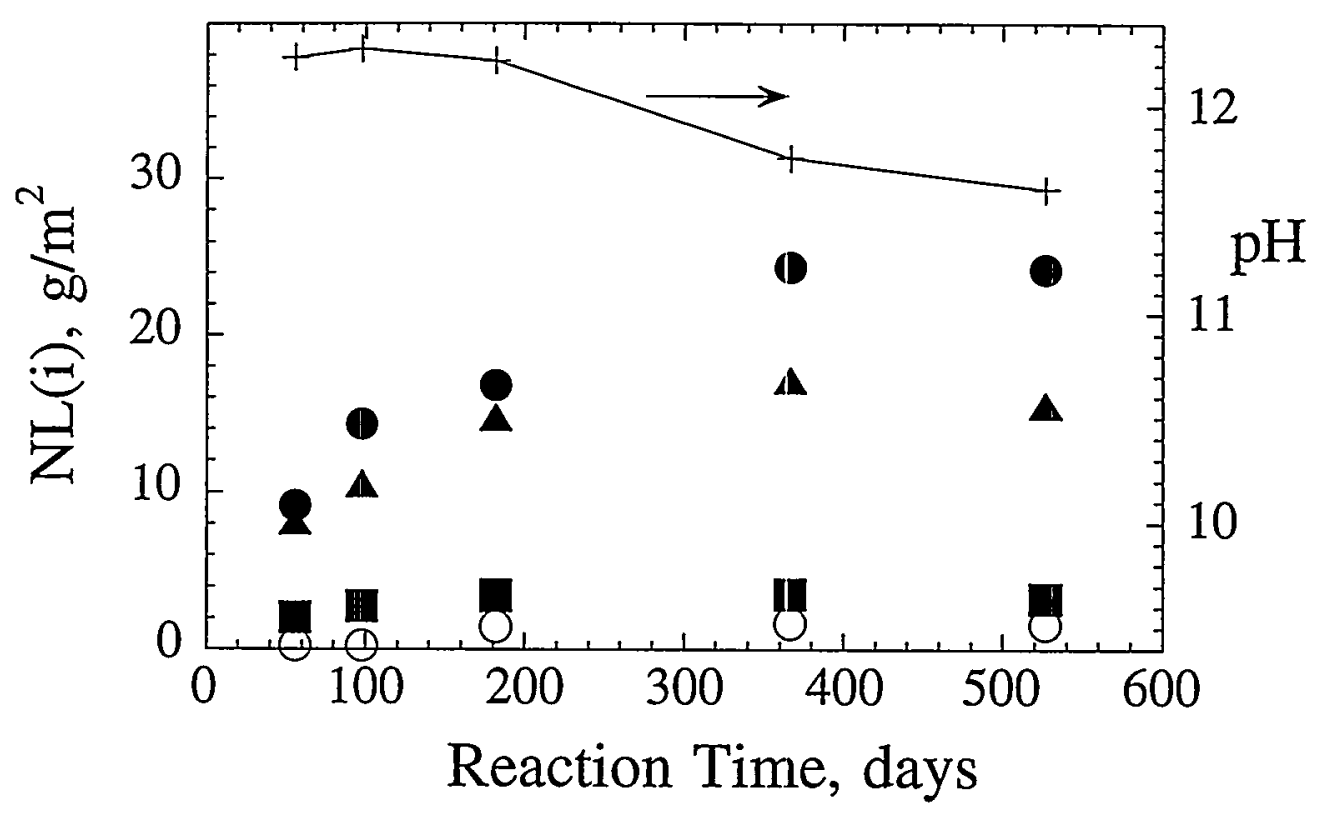

Figure 4. Normalized Mass Loss vs. Reaction Time for Tests at $20,000 \mathrm{~m}^{-1}$ with

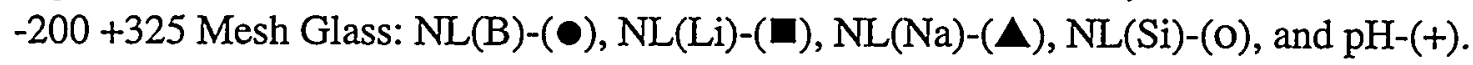



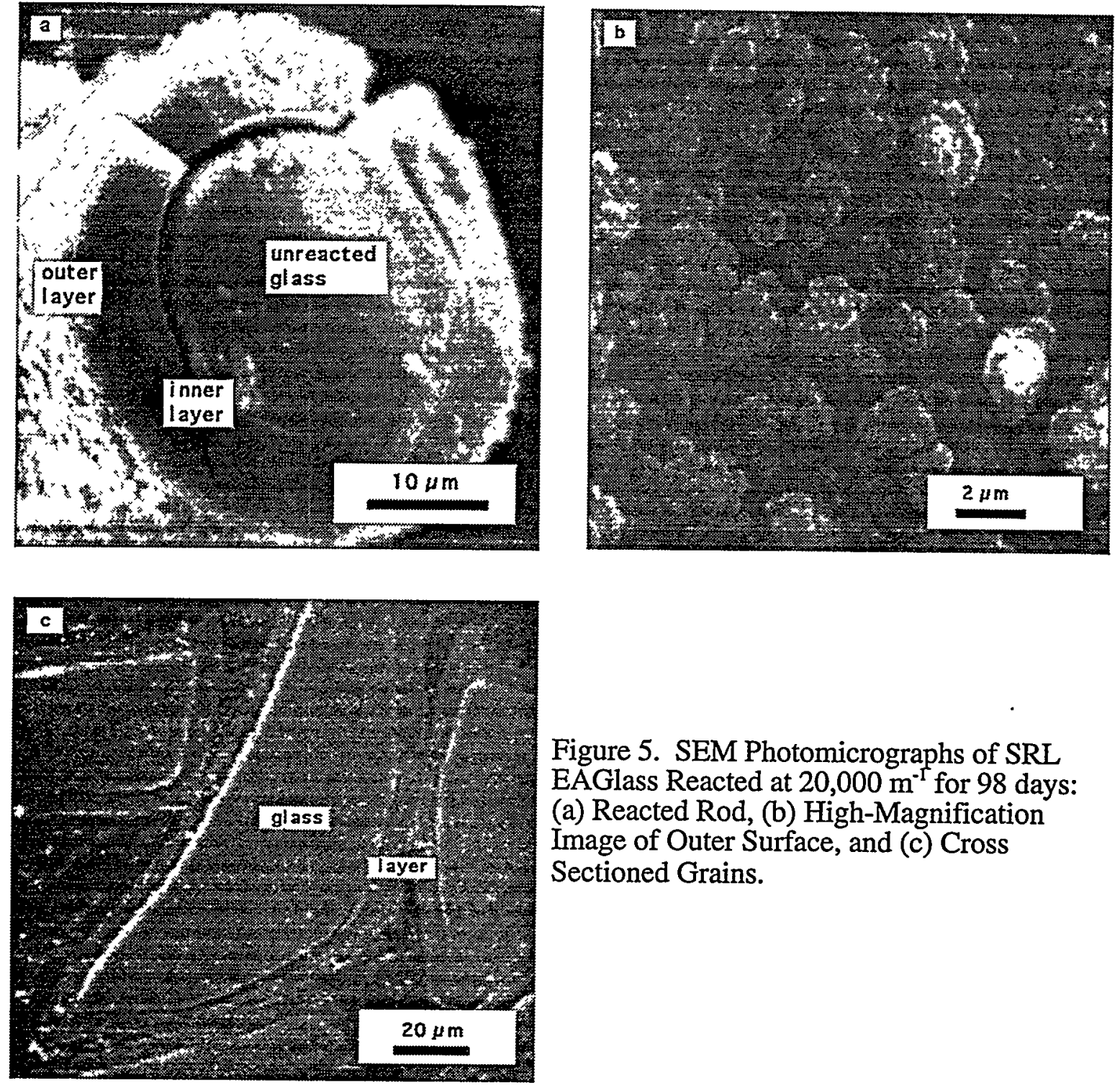

Figure 5. SEM Photomicrographs of SRL EAGlass Reacted at $20,000 \mathrm{~m}^{-1}$ for 98 days: (a) Reacted Rod, (b) High-Magnification Image of Outer Surface, and (c) Cross Sectioned Grains. 

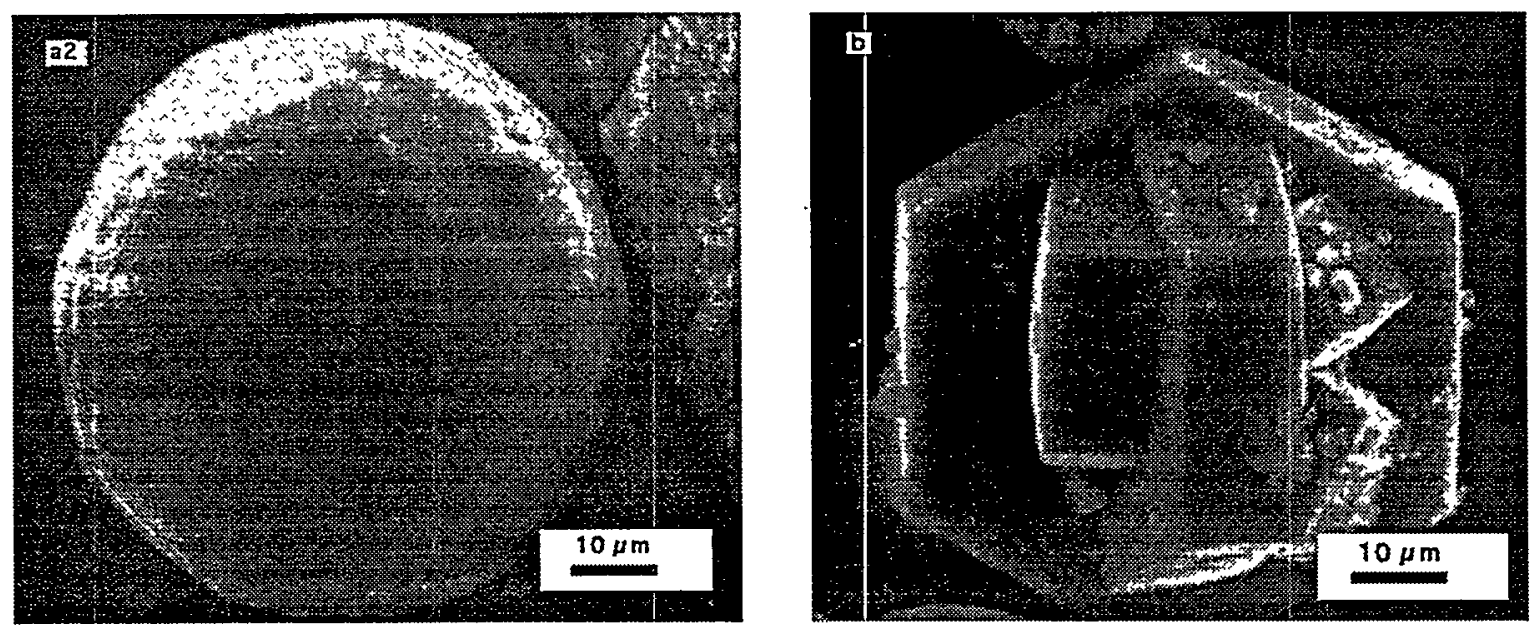

a.

b.
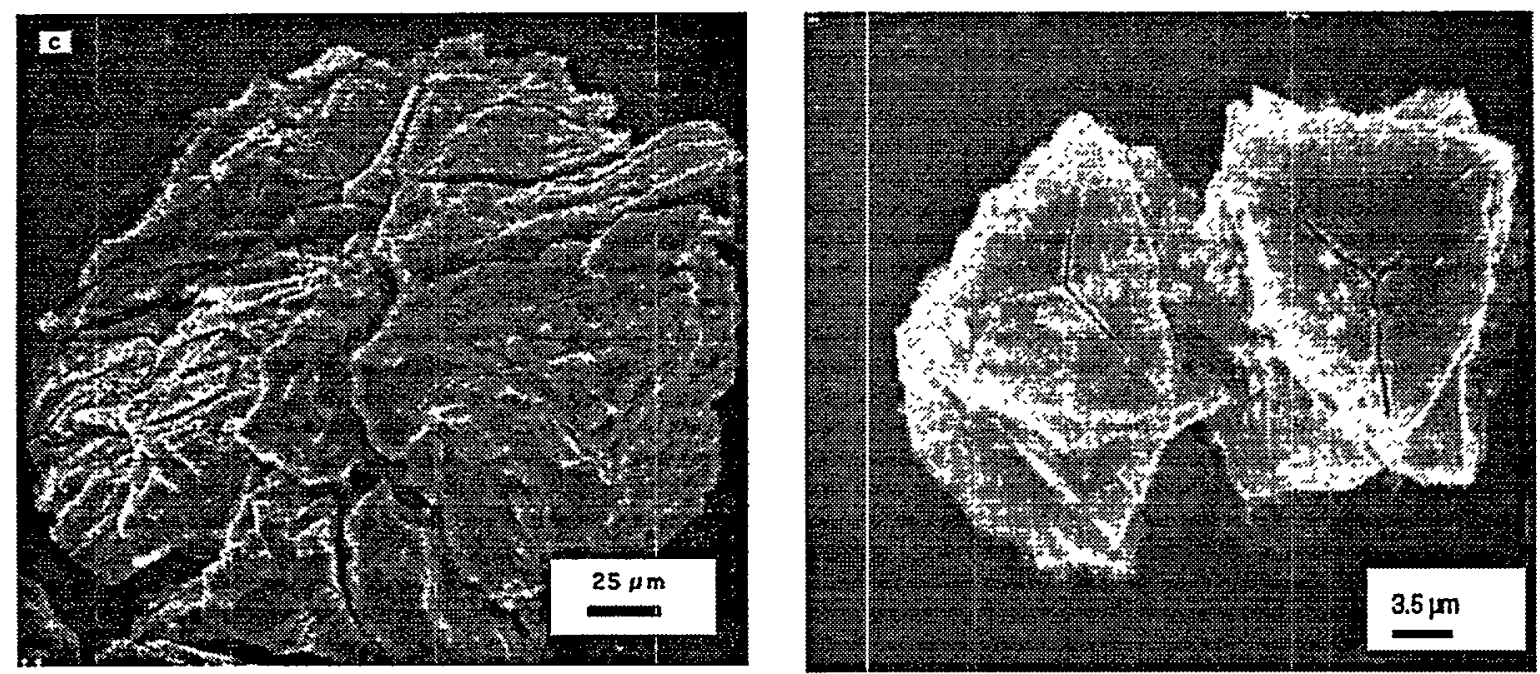

c.

d.

Figure 6. SEM Photomicrographs of Alteration Phases Formed in Tests at $20,000 \mathrm{~m}^{-1}$ : (a) Analcime, (b) Gmelinite, and (c) Sodium Aluminum Silicate Hydrate formed at Reaction Times of 56 days and Longer, and (d) Solid from 22-day Test. 


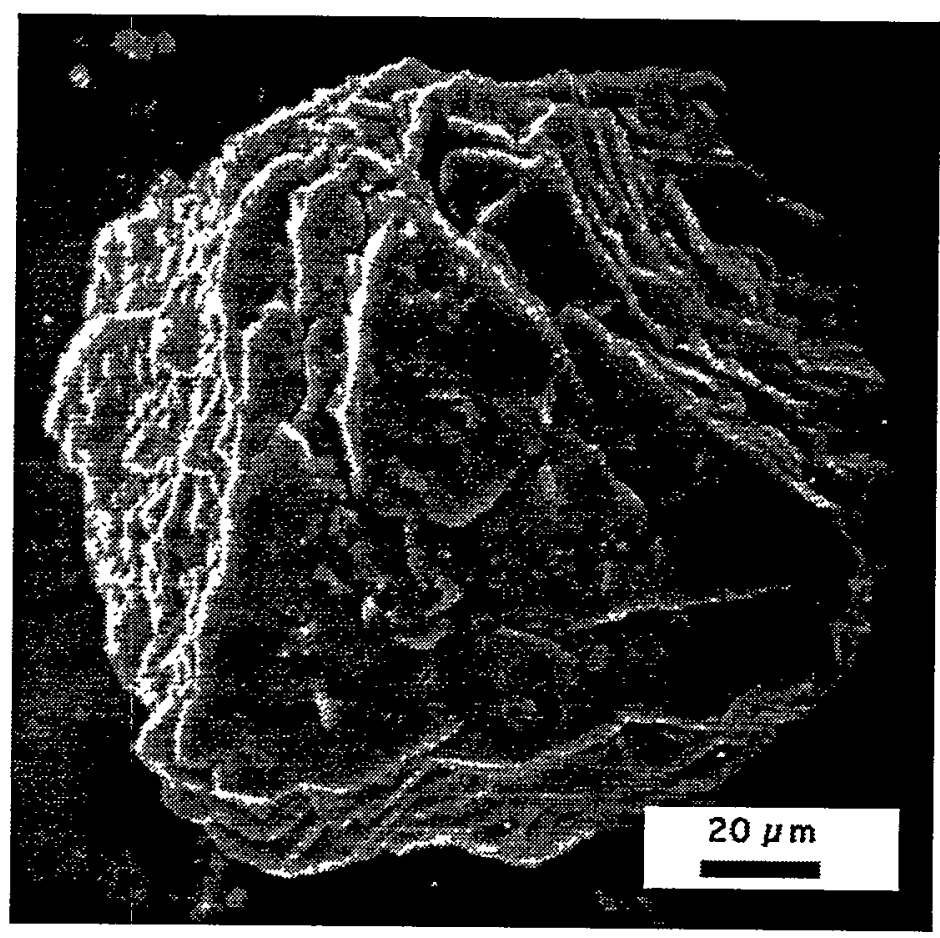

Figure 7. SEM Photomicrograph of Sodium Aluminum Silicate Hydrate Phase Formed in Tests at $2000 \mathrm{~m}^{-1}$ Conducted 313 days and Longer. 


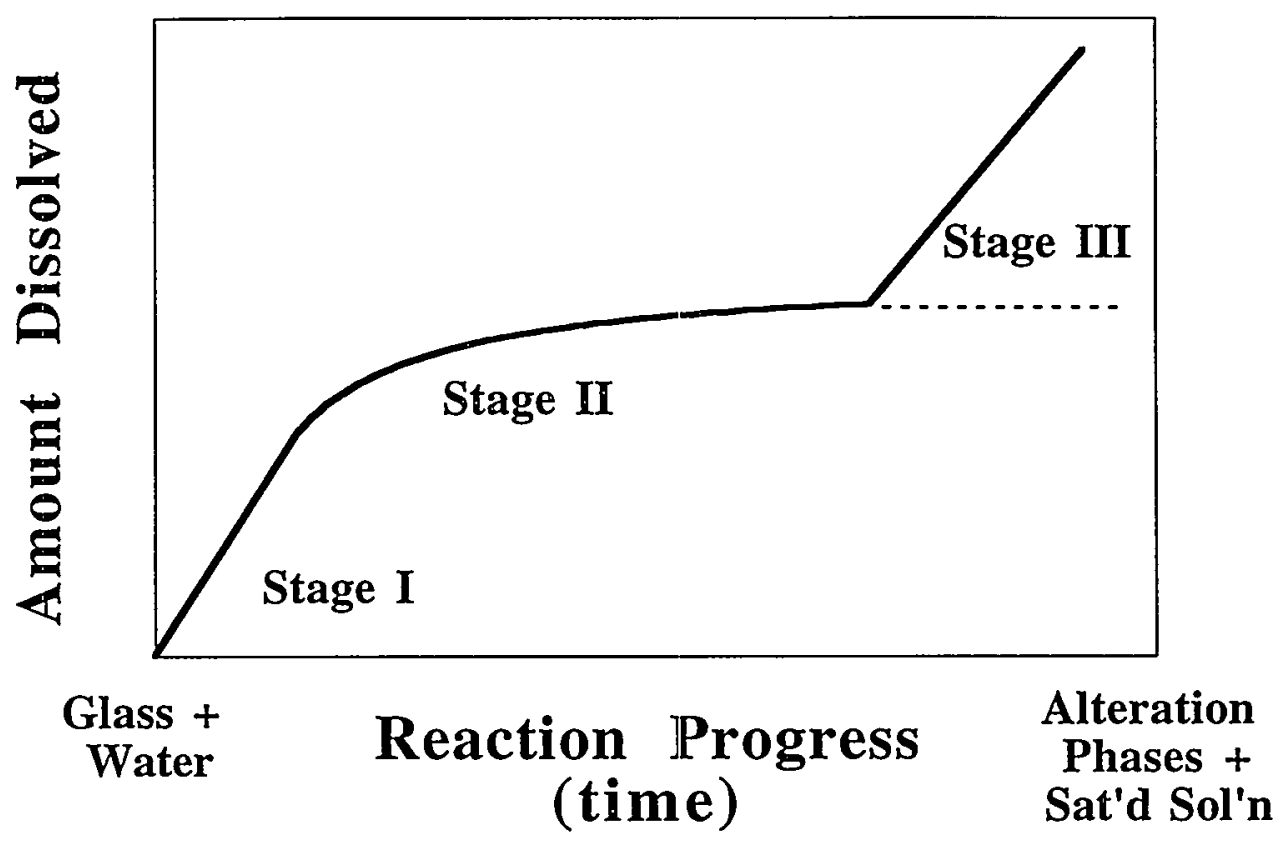

Figure 8. Reaction Progress Plot. 


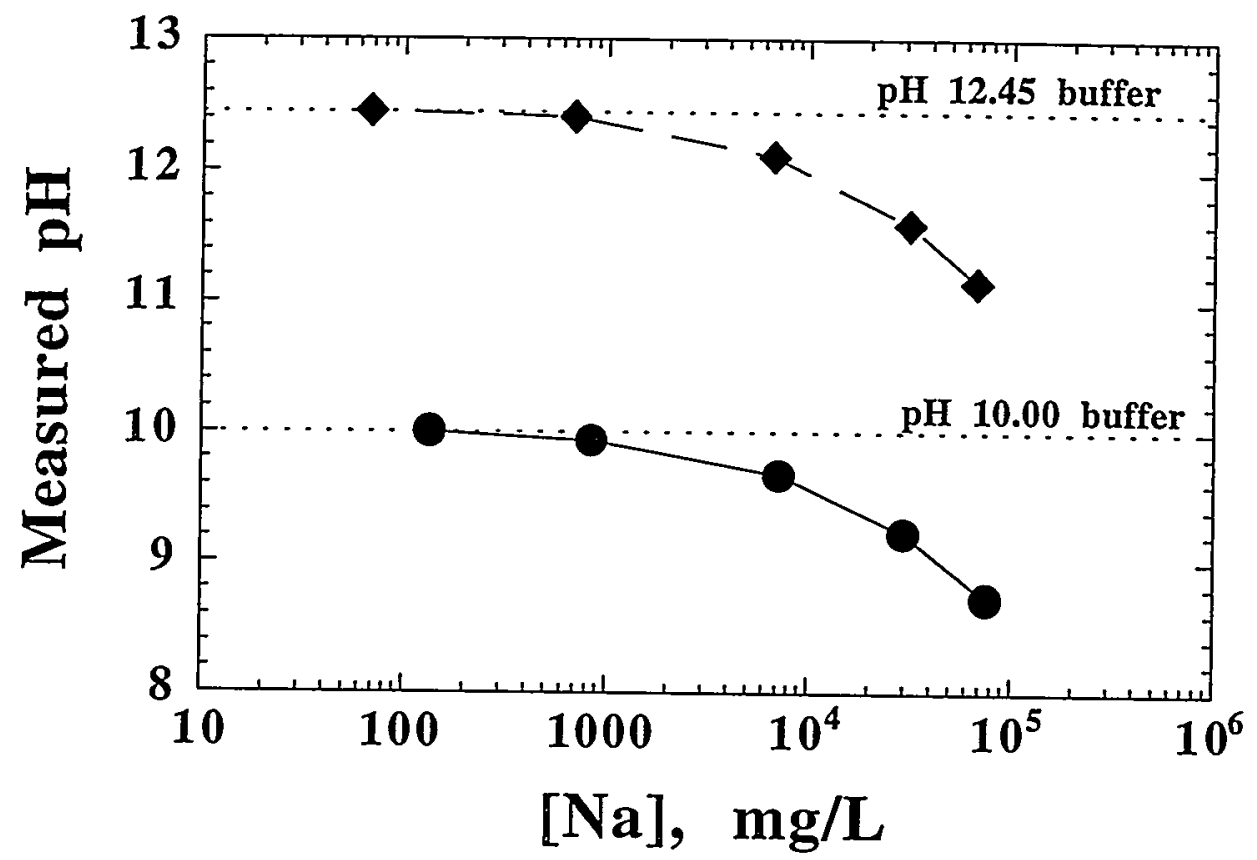

Figure 9. Effect of $\mathrm{Na}$ Concentration on Measured $\mathrm{pH}$ of Two Buffer Solutions. 

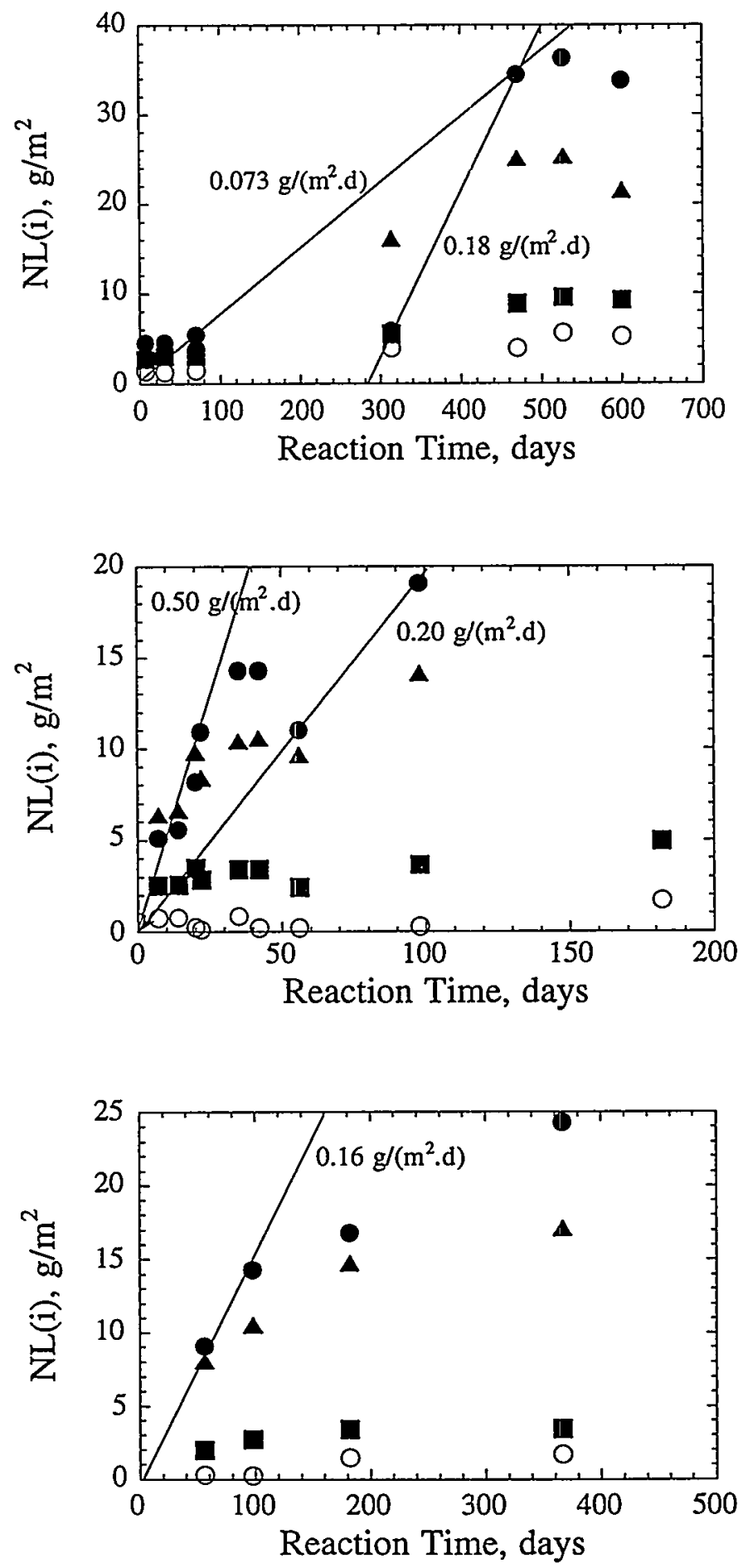

Figure 10. Measured Rates for Tests at (a) $2000 \mathrm{~m}^{-1}$, (b) $20,000 \mathrm{~m}^{-1}$ with $-100+200$ mesh glass, and (c) $20,000 \mathrm{~m}^{-1}$ with $-200+325$ mesh glass. NL(B)-(•), NL(Li)-(II), NL(Na)$(\mathbf{\Delta})$, and $\mathrm{NL}(\mathrm{Si})-(\mathrm{o})$. 


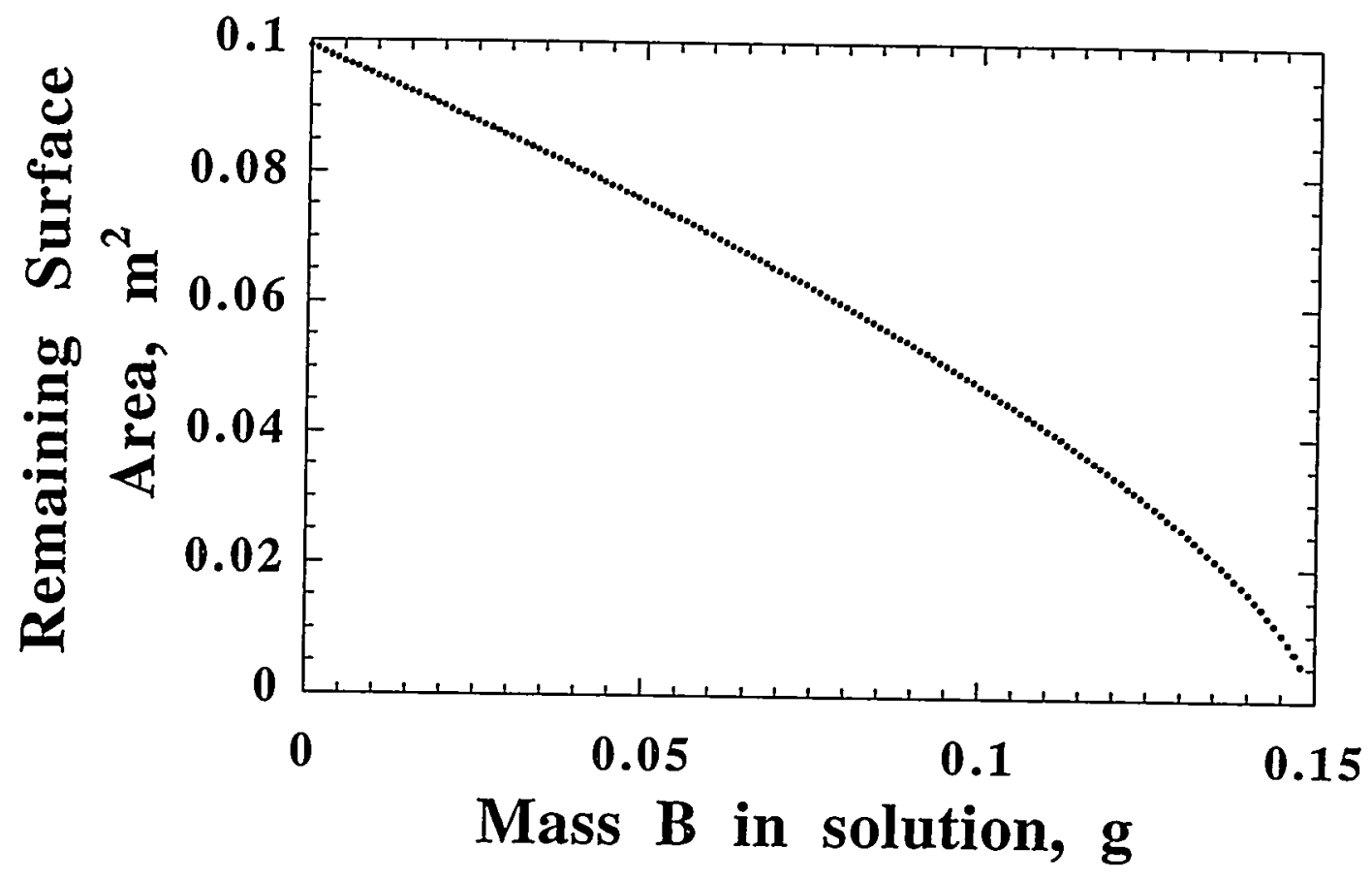

Figure 11. Calculated Surface Area, in $\mathrm{m}^{2}$, vs. Amount of Boron in Solution, in $\mathrm{g}$. 


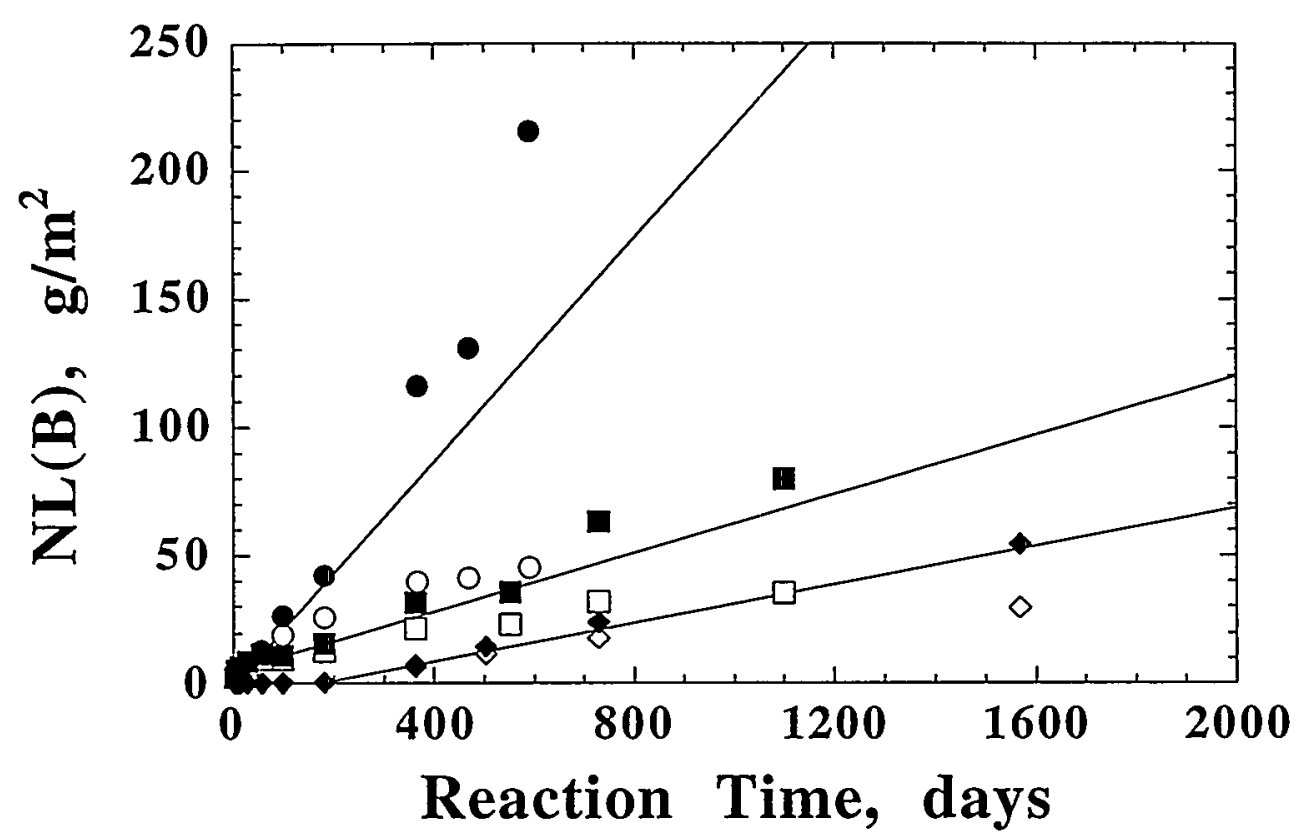

Figure 12. $\quad$ NL(B) for Tests at $20,000 \mathrm{~m}^{-1}$ with SRL EA glass (•), SRL 131A glass $(\square)$, and SRL 202A glass $(\downarrow)$. Open symbols were calculated using the initial surface area, filled symbols were calculated using the surface area remaining at the end of the test. Lines are drawn through the average of open and filled symbols to show the estimated dissolution rate for each glass (see text). 


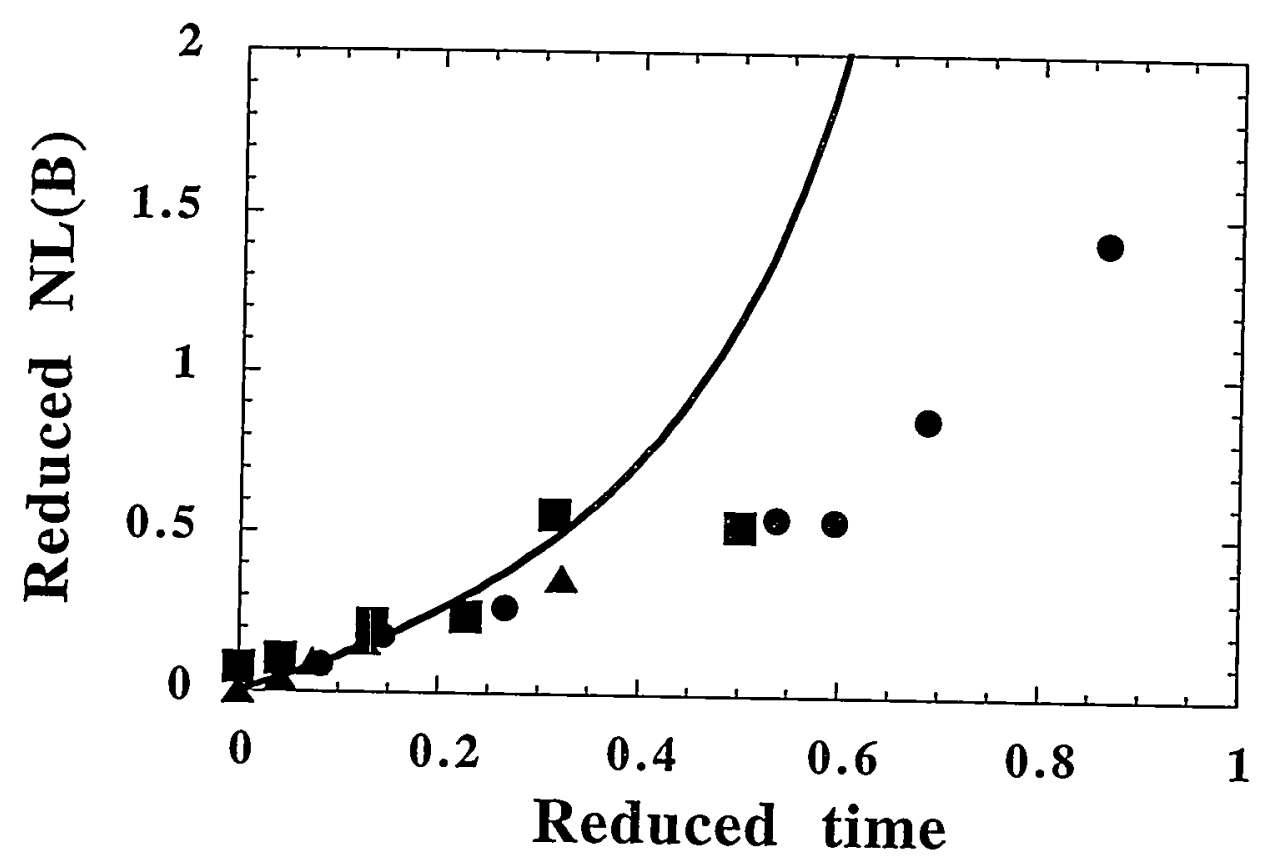

Figure 13. Theoretical Curve and Results of Tests at 20,000 $\mathrm{m}^{-1}$ with SRL EA glass $(\bullet)$, SRL 131A glass $(\square)$, and SRL 202A glass $(\bullet)$. In dimensionless units. 
Appendix I. Test Matrix and Test Data

TEST NO. Test number

TIME, $d$

Test duration, in days

DATE $\mathbb{N}$

Date on which test was initiated

DATE OUT

Date on which test was terminated

VESSEL

Vessel number

GLASS, $g$

mass of glass added to test vessel, in $\mathrm{g}$

LEACHANT, $\mathrm{g}$

mass of leachant (demineralized water or EJ-13 water)

added to test vessel, in $\mathrm{g}$

MASS RATIO glass/leachant mass ratio, in $\mathrm{g} / \mathrm{g}$

$\mathrm{S} / \mathrm{V}, \mathrm{m} \quad \mathrm{S} / \mathrm{N}$ ratio, in $\mathrm{m}^{-1}$

TOTAL IN, $g$ mass of assembled vessel at initiation of test, in $\mathrm{g}$

TOTAL OUT, $g$ mass of assembled vessel at termination of test, in $g$

CHANGE, $g$ difference in vessel mass, termination - initiation, in $\mathrm{g}$

$\mathrm{pH} \quad$ leachate $\mathrm{pH}$ measured at end of test with solution at room temperature

LPE(F.45), g mass of empty solution bottle used to collect aliquot of filtrate solution from $450 \mathrm{~m}$ filtration step, in $\mathrm{g}$

$+\mathrm{F} .45, \mathrm{~g}$

mass of aliquot of filtrate solution from $450 \mathrm{~nm}$ filtrate step, in $\mathrm{g}$

$+\mathrm{DIW}, \mathrm{g}$

mass of demineralized water and nitric acid added to aliquot of filtrate solution, in $\mathrm{g}$

DIL. FACTOR dilution factor for aliquot; calculated as

(mass solution aliquot + mass $\left.\mathrm{DIW} / \mathrm{HNO}_{3}\right) /($ mass solution aliquot)

LPE(F50), g mass of empty solution bottle used to collect aliquot of filtrate solution from $50 \mathrm{~nm}$ filtration step, in $\mathrm{g}$

Sample Calculations for Test EA-21:

MASS RATIO $=$ GLASS, $\mathrm{g} /$ LEACHANT, $\mathrm{g}=1.05 \mathrm{~g} / 10.50 \mathrm{~g}=0.100$

$\mathrm{S} / \mathrm{V}=$ MASS RATIO $\bullet$ specific surface area $\left(0.02 \mathrm{~g} / \mathrm{m}^{2}\right.$ for $\left.-100+200 \mathrm{mesh}\right)=$

$0.100 \mathrm{~g}$ glass $/ \mathrm{g}$ water $\bullet 0.02 \mathrm{~g} / \mathrm{m}^{2} \bullet 1 \mathrm{~g}$ water $/ \mathrm{mL}$ water $\bullet 1 \mathrm{~mL} / 1 \times 10^{-6} \mathrm{~m}^{3}=2000 \mathrm{~m}^{-1}$

CHANGE, $\mathrm{g}=$ TOTAL OUT - TOTAL $\mathbb{I N}=327.25 \mathrm{~g}-327.26 \mathrm{~g}=-0.01 \mathrm{~g}$

DIL. FACTOR $=\{(+F .45)+(+$ DIW $)\} /(+$ F.45 $)=\{8.76+9.99\} /(8.76)=2.1404$ 
Appendix I. (Cont.)

\begin{tabular}{|c|c|c|c|c|c|c|c|c|c|c|c|c|c|c|c|c|}
\hline TESTNO. & TIME, d & DATEIN & DATEOUT & VESSEL & GLASS, 9 & LEACHANT, $g$ & MASS RATO & $S N, / m$ & TOTALIN, $\mathrm{g}$ & TOTAL OUT. 9 & CHANGE, 9 & PH & LPE(F45), g & $+F .45 .9$ & $+D W, g$ & DILFACTOR \\
\hline EA.21 & 7 & 021694 & $02 / 23 / 94$ & 405 & 1.05 & 10.50 & 0.1000 & 2000 & 327.26 & 327.25 & -0.01 & 18.81 & 119.03 & 8.76 & 9.99 & 2.1404 \\
\hline EA-22 & 7 & $02 / 16 / 94$ & $02 / 23 / 94$ & 406 & 1.10 & 11.00 & 0.1000 & 2000 & 328.34 & 328.33 & -0.01 & 11.72 & 11.02 & 10.19 & 10.08 & 1.9892 \\
\hline EA-23 & 7 & $02 / 16 / 94$ & $02 / 23 / 94$ & 407 & 1.13 & 11.29 & 0.1001 & 2000 & 328.22 & 328.21 & -0.01 & 11.73 & 11.10 & 9.56 & 10.01 & 2.0471 \\
\hline EA.21X & 7 & $05 / 48 / 94$ & $05 / 25 / 94$ & 412 & 1.50 & 15.00 & 0.1000 & 2000 & 331.81 & 331.79 & -0.02 & 11.91 & 10.98 & 9.34 & 18.87 & 3.0203 \\
\hline EA.22X & 7 & $05 / 18 / 94$ & $05 / 25 / 94$ & 449 & 1.49 & 14.90 & 0.1000 & 2000 & 333.78 & 333.77 & -0.01 & 11.91 & 10.93 & 9.65 & 18.65 & 2.9326 \\
\hline EA.23X & 7 & $05 / 18 / 94$ & 05/25/94 & 450 & 1.51 & 15.11 & 0.0999 & 2000 & 331.82 & 331.78 & .0 .03 & 11.91 & 11.11 & 9.92 & 17.84 & 2.7984 \\
\hline EA.24 & 7 & $02 / 6 / 94$ & $02 / 23 / 94$ & 408 & 1.11 & 11.09 & 0.1001 & 2000 & 328.16 & 328.17 & 0.01 & 11.61 & 10.92 & 9.52 & 10.19 & 2.0704 \\
\hline EA-25 & 7 & $02 / 16 / 94$ & $02 / 23 / 94$ & 409 & 1.12 & 11.21 & 0.0999 & 2000 & 327.32 & 327.31 & -0.01 & 11.62 & 11.00 & 9.60 & 10.10 & 2.0521 \\
\hline EA.26 & 30 & $04 / 06 / 94$ & $05 / 06 / 94$ & 411 & 1.17 & 11.72 & 0.0998 & 2000 & 328.27 & 328.28 & 0.01 & 11.66 & 10.97 & 4.52 & 9.96 & 3.2035 \\
\hline EA.27 & 30 & \begin{tabular}{|l|l|}
$04 / 06 / 94$ \\
\end{tabular} & \begin{tabular}{|l|l|}
$05 / 06 / 94$ \\
\end{tabular} & 412 & 1.11 & 11.09 & 0.1001 & 2000 & 327.80 & 327.80 & 0.00 & 11.94 & 10.91 & 6.58 & 10.46 & 2.5897 \\
\hline EA-28 & 70 & 03/23/94 & 06/01/94 & 439 & 1.09 & 10.89 & 0.1001 & 2000 & 329.29 & 329.28 & -0.01 & 11.74 & 8.22 & 6.79 & 10.27 & 2.5125 \\
\hline EA-29 & 70 & \begin{tabular}{|l|l}
$03 / 23 / 94$ \\
\end{tabular} & $06 / 01 / 94$ & 440 & 1.05 & 10.49 & 0.1001 & 2000 & 228.99 & 328.98 & -0.01 & 11.71 & 10.95 & 7.13 & 10.06 & 2.4109 \\
\hline$E A \cdot 30$ & 367 & $04 / 20 / 94$ & $02 / 27 / 95$ & 460 & 1.14 & 11.41 & 0.0999 & 2000 & 327,90 & 327.90 & 0.00 & 12.07 & 11.03 & 8.00 & 10.01 & 2.2513 \\
\hline EA-31 & 470 & $04 / 20 / 94$ & $08 / 03 / 95$ & 461 & 1.22 & 12.20 & 0.1000 & 2000 & 329.21 & 329.21 & 0.00 & 12.04 & 11.02 & 8.97 & 10.17 & 2.1338 \\
\hline EA-32 & 527 & $04 / 20 / 94$ & $09 / 27 / 95$ & 462 & 1.25 & 12.50 & 0.1000 & 2000 & 329.06 & 329.02 & .0 .04 & 11.97 & 8.33 & 8.79 & 9.95 & 2.1320 \\
\hline EA-33 & 600 & $04 / 20 / 94$ & $12 / 11 / 95$ & 463 & 1.12 & 11.20 & 0.1000 & 2000 & 328.40 & 328.38 & .0 .02 & 12.05 & 10.96 & 9.38 & 9.93 & 2.0586 \\
\hline EA-41 & 56 & $04 / 06 / 94$ & 06/01/94 & 413 & 7.07 & 7.07 & 1.0000 & 20000 & 330.48 & 330.47 & -0.01 & 12.27 & 11.00 & 2.18 & 10.42 & 5.7798 \\
\hline EA-42 & 56 & $04 / 06 / 94$ & $06 / 01 / 94$ & 445 & 7.03 & 7.05 & 0.9972 & 20000 & 330.69 & 330.68 & -0.01 & 12.25 & 8.23 & 2.11 & 10.47 & 5.9621 \\
\hline$E A \cdot 43$ & 98 & $03 / 23 / 94$ & 06/29/94 & 441 & 7.13 & 7.13 & 1.0000 & 20000 & 332.48 & 332.47 & -0.01 & 12.39 & 10.14 & 2.62 & 14.92 & 6.6947 \\
\hline EA-44 & 98 & $03 / 23 / 94$ & $06 / 29 / 94$ & 442 & 7.07 & 7.09 & 0.9972 & 20000 & 329.69 & 329.67 & -0.02 & $\begin{array}{l}12.35 \\
\end{array}$ & 11.03 & 1.68 & 14.93 & 9.8869 \\
\hline$E A-45$ & 182 & $02 / 25 / 94$ & $08 / 26 / 94$ & 424 & 7.05 & 7.04 & 1.0014 & 20000 & 330.45 & 330.43 & -0.02 & $\begin{array}{l}12.23 \\
\end{array}$ & 11.92 & 2.56 & 15.09 & 6.8945 \\
\hline$E A-46$ & 182 & $02 / 25 / 94$ & $08 / 26 / 94$ & 425 & 7.08 & 7.07 & 1.0014 & 20000 & 330.87 & 330.86 & -0.01 & 12.22 & 11.99 & 2.98 & 15.35 & 6.1510 \\
\hline EA-47 & 367 & $02 / 25 / 94$ & $02 / 27 / 95$ & 426 & 7.10 & 7.09 & 1.0014 & 20000 & 330.35 & 330.35 & 0.00 & 12.07 & 11.12 & 0.40 & 10.01 & 26.0250 \\
\hline EA-48 & 367 & $02 / 25 / 94$ & $02 / 27 / 95$ & 427 & 7.15 & 7.16 & 0.9986 & 20000 & 330.16 & 330.16 & 0.00 & 11.31 & 10.90 & 1.33 & 10.02 & 8.5338 \\
\hline EA-19 & 470 & $04 / 20 / 94$ & 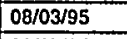 & 464 & 7.18 & 7.17 & 1.0014 & 20000 & 332.53 & 332.50 & -0.03 & & $\begin{array}{l}11.09 \\
\end{array}$ & 0.40 & 15.05 & 38.6250 \\
\hline EA-50 & 527 & $04 / 20 / 94$ & $09 / 27 / 95$ & 465 & 7.02 & 7.04 & 0.9972 & 20000 & 330.04 & 330.05 & 0.01 & 11.41 & 8.29 & 0.57 & 5.01 & 9.7895 \\
\hline EA.51 & 407 & $06 / 22 / 94$ & $08 / 03 / 95$ & 411 & 7.24 & 7.24 & 1.0000 & 20000 & 329.53 & 329.51 & -0.02 & 11.58 & 10.95 & 1.84 & 15.08 & 9.1957 \\
\hline$E A \cdot 52$ & 1155 & $06 / 22 / 94$ & $08 / 19 / 97$ & 412 & 7.04 & 7.04 & 1.0000 & 20000 & 329.25 & 329.23 & .0 .02 & & 11.02 & 0.49 & 10.15 & 21.7143 \\
\hline EA-53 & 1155 & $06 / 22 / 94$ & $08 / 19 / 97$ & 413 & 7.03 & 7.03 & 1.0000 & 20000 & 330.64 & 330.64 & 0.00 & & 10.96 & 0.38 & 10.43 & 28.4474 \\
\hline EA.54 & 1155 & 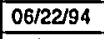 & 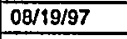 & 439 & 7.07 & 7.07 & 1.0000 & 20000 & 329.61 & 329.61 & 0.00 & & 11.03 & 0.38 & 10.10 & 27.5789 \\
\hline EA-71 & 56 & $04 / 06 / 94$ & $06 / 01 / 94$ & 446 & 3.75 & 7.52 & 0.4987 & 20000 & 326.18 & 326.17 & -0.01 & 12.24 & 8.30 & 3.71 & 10.36 & 3.7925 \\
\hline EA-72 & 56 & $04 / 06 / 94$ & 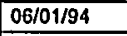 & 447 & 3.60 & 7.20 & 0.5000 & 20000 & 326.49 & 326.48 & -0.01 & 12.25 & 8.22 & 3.50 & 14.99 & 5.2829 \\
\hline EA-73 & 98 & $03 / 23 / 94$ & \begin{tabular}{|l|l|l|} 
\\
\end{tabular} & 443 & 3.70 & 7.40 & 0.5000 & 20000 & 328.24 & 328.23 & -0.01 & 12.29 & 10.95 & 5.17 & 14.89 & 3.8801 \\
\hline EA.74 & 98 & $03 / 23 / 94$ & 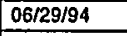 & 444 & 3.68 & 7.35 & 0.5007 & 20000 & 326.25 & 326.24 & -0.01 & 12.28 & 10.91 & 3.56 & 14.87 & 5.1770 \\
\hline EA-75 & 182 & $02 / 25 / 94$ & \begin{tabular}{|l|l|l|}
$086 / 94$ \\
\end{tabular} & 428 & 3.68 & 7.37 & 0.4993 & 20000 & 326.99 & 326.97 & -0.02 & 12.24 & 11.97 & 5.00 & 16.23 & 4.2460 \\
\hline EA-76 & 182 & $02 / 25 / 94$ & 08/26/94 & 429 & 3.63 & 7.26 & 0.5000 & 20000 & 326.22 & 326.22 & 0.00 & 12.22 & 11.52 & 4.76 & 17.22 & 4.6176 \\
\hline EA-77 & 367 & $02 / 25 / 94$ & $02 / 27 / 95$ & 430 & 3.54 & 7.08 & 0.5000 & 20000 & 327.03 & 327.01 & -0.02 & 11.78 & 11.04 & 4.18 & 9.89 & 2.8555 \\
\hline EA-78 & 367 & $02 / 25 / 94$ & \begin{tabular}{|l|l|}
$02 / 27 / 95$ \\
\end{tabular} & 436 & 3.74 & 7.48 & 0.5000 & 20000 & 329.78 & 329.78 & 0.00 & 11.75 & 10.93 & 4.54 & 9.87 & 3.1740 \\
\hline EA-79 & 527 & $04 / 20 / 94$ & $09 / 27 / 95$ & 466 & 3.78 & 7.57 & 0.4993 & 20000 & 327.12 & 327.12 & 0.00 & $\begin{array}{l}11.61 \\
\end{array}$ & 8.26 & 4.03 & 5.00 & 2.2407 \\
\hline$E A \cdot B 0$ & 527 & $04 / 20 / 94$ & 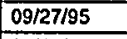 & 467 & 3.71 & 7.42 & 0.5000 & 20000 & 327.62 & 327.59 & -0.03 & 11.60 & 8.21 & 4.13 & 9.94 & 3.4068 \\
\hline EA-81 & 1155 & $06 / 22 / 94$ & $08 / 19 / 97$ & 445 & 3.71 & 7.42 & 0.5000 & 20000 & 327.48 & 327.47 & 0.01 & 11.71 & 10.82 & 3.35 & 10.17 & 4.0358 \\
\hline EA-82 & 1155 & $06 / 22 / 94$ & \begin{tabular}{|l|l|}
$08 / 19 / 97$ \\
\end{tabular} & 449 & $\begin{array}{l}3.76 \\
\end{array}$ & 7.52 & 0.5000 & 20000 & 328.38 & 328.38 & 0.00 & 11.68 & 10.94 & 3.43 & 10.14 & 3.9563 \\
\hline EA.91 & 22 & $09 / 18 / 96$ & \begin{tabular}{|l|l}
$10 / 10 / 96$ \\
\end{tabular} & 453 & 5.07 & 5.07 & 1.0000 & 20000 & \begin{tabular}{|c|}
327.38 \\
\end{tabular} & 327.38 & 0.00 & 11.96 & 10.88 & 2.67 & 23,33 & 4.6629 \\
\hline EA.92 & 35 & $09 / 18 / 96$ & \begin{tabular}{|l}
$10 / 23 / 96$ \\
\end{tabular} & 456 & 5.02 & 5.02 & 1.0000 & 20000 & 331.37 & 331.35 & -0.02 & 11.91 & 9.92 & 2.82 & 23.10 & 4.6738 \\
\hline EA.93 & 42 & $09 / 18 / 96$ & \begin{tabular}{|l|}
$10 / 30 / 96$ \\
\end{tabular} & 463 & 5.01 & 5.00 & 1.0020 & 20000 & 326.76 & 326.75 & -0.01 & 11.92 & 10.92 & 2.66 & 27.73 & 6.3195 \\
\hline EA-94 & 20 & $10 / 10 / 96$ & \begin{tabular}{|l|}
$10 / 30 / 96$ \\
\end{tabular} & 453 & 5.05 & 5.05 & 1.0000 & 20000 & 327.21 & 327.18 & -0.03 & 11.87 & 10.98 & 2.03 & 25.48 & 7.1429 \\
\hline EA.95 & 7 & \begin{tabular}{|l|l|}
$11 / 4 / 96$ \\
\end{tabular} & \begin{tabular}{|l|}
$11 / 11 / 96$ \\
\end{tabular} & 453 & 5.00 & 5.00 & 1.0000 & 20000 & 327.03 & 327.02 & -0.01 & 11.86 & 9.98 & 2.69 & 23.43 & 5.0000 \\
\hline EA-96 & 14 & $11 / 4 / 96$ & $11 / 18 / 96$ & 463 & 5.01 & 5.01 & 1.0000 & 20000 & 326.90 & 326.92 & 0.02 & 11.71 & 8.22 & 2.80 & 23.85 & 4.5821 \\
\hline
\end{tabular}


Appendix II. Solution Analytical Results for Cations in PCT-A Tests

TEST NO. Test number

TIME, $\mathrm{d} \quad$ Test duration, in days

$\mathrm{pH} \quad$ measured solution $\mathrm{pH}$

(a blank indicates that the $\mathrm{pH}$ was not measured because not enough solution could be recovered from the test)

DIL. FACTOR dilution factor for aliquot analyzed

$\mathrm{S} / \mathrm{V}, / \mathrm{m} \quad \mathrm{S} / \mathrm{V}$ ratio of test, in $\mathrm{m}^{-1}$

METHOD technique used to analyze the solution (ICP-AES or ICP-MS)

FLEE solution sample identification number

$\mathrm{i}, \mathrm{ACL} \quad$ raw concentration of element i from analysis, in $\mathrm{mg} / \mathrm{L}$

$\mathrm{i}, \mathrm{mg} / \mathrm{L} \quad$ concentration corrected for dilution, in $\mathrm{mg}(\mathrm{i}) / \mathrm{L}$

NC(i), normalized elemental concentration, in g(glass)/L

NL(i), normalized elemental mass loss, in $\mathrm{g} / \mathrm{m}^{2}$

BKGND concentration of element i measured in EJ-13 solution, in $\mathrm{mg} / \mathrm{L}$

$\mathrm{f}(\mathrm{i}) \quad$ mass fraction of element $\mathrm{i}$ in EA glass, in $\mathrm{g} / \mathrm{g}$

note: negative values give detection limit values

Sample Calculations for Test EA-21:

$\mathrm{B}, \mathrm{mg} / \mathrm{L}=\mathrm{B}, \mathrm{ACL} \bullet \mathrm{DIL} . \mathrm{FACTOR}=208 \mathrm{mg} / \mathrm{L} \cdot 2.1404=445 \mathrm{mg} / \mathrm{L}$

$\mathrm{NC}(\mathrm{B})=\mathrm{B}, \mathrm{mg} / \mathrm{L} / \mathrm{f}_{\mathrm{B}}=445 \mathrm{mg} / \mathrm{L} / 0.0347=12800 \mathrm{mg} / \mathrm{L}=12.8 \mathrm{~g} / \mathrm{L}$

$\mathrm{NL}(\mathrm{B})=\{\mathrm{B}, \mathrm{mg} / \mathrm{L}-\mathrm{BKGND}(\mathrm{B})\} /\left\{(\mathrm{S} / \mathrm{V}) \bullet \mathrm{f}_{\mathrm{B}}\right\}$

$=\{445 \mathrm{mg} / \mathrm{L}-0.00\} /\left\{2000 \mathrm{~m}^{-1} \bullet 0.347\right\}=6.41 \mathrm{~g} / \mathrm{m}^{2}$ 
Appendix II. (Cont.)

\begin{tabular}{|c|c|c|c|c|c|c|c|c|c|c|c|c|c|c|c|c|c|c|}
\hline TESTNO. & TIME. d & $\mathrm{pH}$ & DR.FACTOR & $\mathrm{SN}, \mathrm{Im}$ & \begin{tabular}{|l|l|} 
METH \\
\end{tabular} & FILE & $\mathrm{A}, \mathrm{ACL}$ & Al, mgl & $\mathrm{NL}(A), g^{\prime} \mathrm{m} 2$ & $\mathrm{~B}, \overline{\mathrm{ACL}}$ & B. $\mathrm{mgl}$ & $N C(B), g \Omega$ & $N L(B), g^{\prime} / m 2$ & $\mathrm{Ba}, \mathrm{ACl}$ & $\mathrm{Ba}, \mathrm{mgh}$ & $\mathrm{Ca}, \mathrm{ACZ}$ & $\mathrm{Ca}, \mathrm{mgl}$ & $\mathrm{NL}(\mathrm{Ca}), g^{\prime} \mathrm{m}^{2}-$ \\
\hline$E A \cdot 21$ & 7 & 11.81 & 2.1404 & 2000 & ICP-MS & PACKET 2 & 0.71 & 1.5 & 0.04 & 208 & 445 & 12.8 & 6.41 & 0.0003 & 0.0006 & 3.46 & 7.41 & 0.43 \\
\hline EA-22 & 7 & 11.72 & 1.9892 & 2000 & ICP-MS & PACKET.2 & 0.74 & 1.5 & 0.039 & 175 & 349 & 10.1 & 5.02 & 0.0003 & 0.0006 & 2.89 & 5.75 & 0.33 \\
\hline$\frac{E A-23}{E A-21}$ & $\frac{7}{7}$ & 11.73 & 2.0471 & 2000 & ICP.MS & \begin{tabular}{|l} 
PACKET. 2 \\
\end{tabular} & 0.84 & 1.7 & 0.04 & 172 & 352 & 10.1 & 5.07 & 0.0004 & 0.0008 & 2.66 & 5.45 & 0.31 \\
\hline$\frac{E A-21}{E A-22}$ & $\frac{7}{7}$ & 11.81 & 2.1404 & 2000 & ICP-AES & $94-0288-01$ & 0.86 & 1.8 & & 213 & 456 & 13.1 & & & & & & \\
\hline$\frac{E A \cdot 22}{E A \cdot 23}$ & $\frac{7}{7}$ & 11.72 & 1.9892 & 2000 & ICP.AES & $94-0288-02$ & 0.89 & 1.8 & & 178 & 354 & 10.2 & & & & & & \\
\hline$\frac{E A \cdot 23}{E A \cdot 21 X}$ & $\frac{7}{7}$ & 11.73 & 2.0471 & 2000 & ICP.AES & 94.0288.03 & 0.86 & 1.8 & & 185 & 379 & 10.9 & & & & & & \\
\hline$\frac{E A \cdot 21 x}{E A \cdot 22 X}$ & $\frac{7}{7}$ & 11.91 & 3.0203 & 2000 & ICP.AES & 94-0396-14 & 0.34 & 1 & 0.027 & 187 & 565 & 16.3 & 8.14 & -0.05 & -0.2 & -0.01 & -0.03 & -0.002 \\
\hline$\frac{E A \cdot 22 X}{E A \cdot 23 X}$ & $-\frac{7}{7}$ & 11.91 & 2.9326 & 2000 & ICP-AES & 94-0396-15 & 0.32 & 0.94 & 0.025 & 225 & 660 & 19.0 & 9.51 & -0.05 & -0.2 & -0.01 & -0.03 & -0.002 \\
\hline EA.23X & 7 & 11.91 & 2.7984 & 2000 & ICP-AES & $94.0396-16$ & 0.26 & 0.73 & 0.019 & 239 & 669 & 19.3 & 9.64 & -0.05 & -0.2 & -0.01 & -0.03 & -0.002 \\
\hline (1) & & & & & & & 0.019 & 0.019 & & 0.0347 & 0.0347 & & & 0 & 0 & 0.0087 & 0.0087 & \\
\hline
\end{tabular}

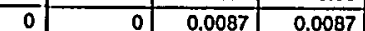

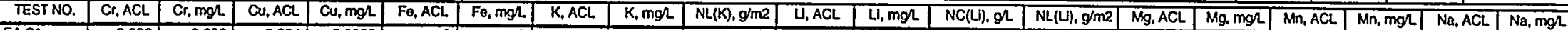

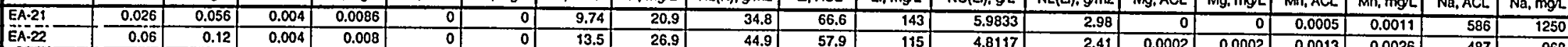

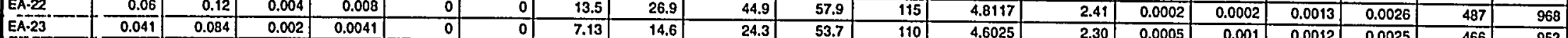

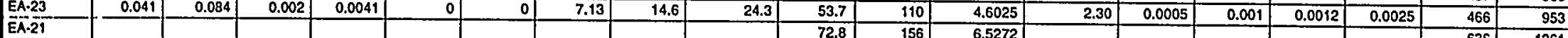

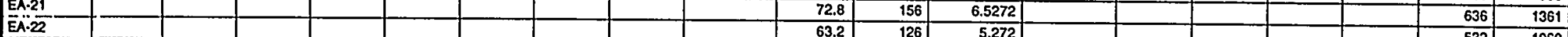

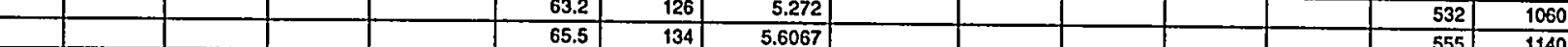

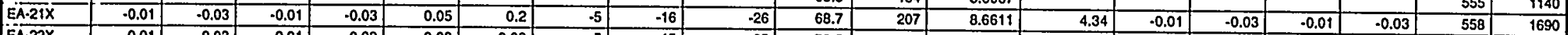

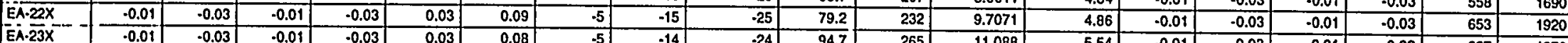

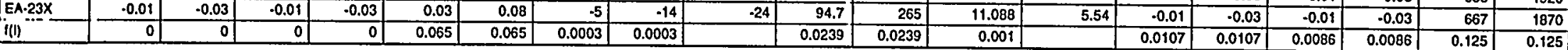

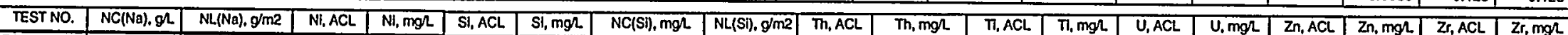

\begin{tabular}{|c|c|c|c|c|c|c|c|c|c|c|c|c|c|c|c|c|c|c|}
\hline & & & & & & & & & & & & & & & & & & \\
\hline$E A \cdot 21$ & $\frac{10.00}{774}$ & 5.01 & 0.0006 & 0.0013 & 361 & 773 & 3.39 & 1.7 & 30.05 & 6.42120 .05 & 0.0019 & 0.0041 & 0.0003 & 0.00064 & 0.0044 & 0.0094 & 0.0002 & 0.00021 \\
\hline EA.22 & 7.74 & 3.87 & 0.0018 & 0.0036 & 328 & 653 & 2.86 & 1.43 & $7 e-05$ & 0.00013924 & 0.0017 & 0.0034 & 0.0002 & 0.0002 & 0.0084 & 0.017 & 0.0004 & 0.0008 \\
\hline EA-23. & 7.62 & 3.81 & 0.002 & 0.0041 & 344 & 705 & 3.09 & 1.55 & 10.05 & $\begin{array}{l}.0471 \mathrm{e}-05 \\
\end{array}$ & 0.0017 & 0.0035 & 0.0002 & 0.00041 & 0.0052 & 0.011 & 0.0004 & 0.00082 \\
\hline EA-21 & 10.89 & & & & $3 \pi$ & 807 & 3.54 & & & & & & & & & & & \\
\hline EA-22 & 8.48 & & & & 337 & 670 & 2.94 & & & & & & & & & & & \\
\hline EA.23 & 9.12 & & & & 352 & 721 & 3.16 & & & & & & & & & & & \\
\hline$E A \cdot 21 x$ & 13.52 & 6.74 & 0.03 & 0.091 & 316 & 954 & 4.18 & 2.09 & & & -0.02 & -0.06 & & & -0.01 & -0.03 & -0.02 & -0.06 \\
\hline EA-22X & 15.36 & 7.66 & 0.02 & 0.059 & 361 & 1060 & 4.65 & 2.32 & & & -0.02 & -0.06 & & & -0.01 & .0 .03 & -0.02 & -0.06 \\
\hline EA-23X & $\frac{14.96}{0.00}$ & 7.47 & 0.03 & 0.084 & 390 & 1090 & 4.78 & 2.39 & & & $\begin{array}{r}.0 .02 \\
\end{array}$ & $\begin{array}{r}-0.06 \\
\end{array}$ & & & -0.01 & -0.03 & -0.02 & -0.06 \\
\hline (III) & 0.00 & & 0.00417 & 0.00417 & 0.2279 & 0.2279 & & & 0 & 0 & 0.00389 & 0.00389 & 0 & 0 & 0.0021 & 0.0021 & 0.0356 & 0.0356 \\
\hline
\end{tabular}


Appendix III. Solution Analytical Results for Cations in PCT-B Tests

$\begin{array}{ll}\text { TEST NO. } & \text { Test number } \\ \text { TME, } d & \text { Test duration, in days } \\ \mathrm{pH} & \text { measured solution } \mathrm{pH}\end{array}$

(a blank indicates that the $\mathrm{pH}$ was not measured because not enough solution could be recovered from the test)

DIL. FACTOR dilution factor for aliquot analyzed

$\mathrm{S} / \mathrm{V}, \mathrm{m} \quad \mathrm{S} / \mathrm{V}$ ratio of test, in $\mathrm{m}^{-1}$

SIZE $\quad$ size fraction of glass used in test

FILE Solution sample identification number

i, $\mathrm{ACL} \quad$ raw concentration of element i from analysis, in $\mathrm{mg} / \mathrm{L}$

$\mathrm{i}, \mathrm{mg} / \mathrm{L} \quad$ concentration corrected for dilution, in $\mathrm{mg} / \mathrm{L}$

NL(i), normalized elemental mass loss, in $\mathrm{g} / \mathrm{m}^{2}$

BKGND concentration of element i measured in EJ-13 solution, in $\mathrm{mg} / \mathrm{L}$

$\mathrm{f}(\mathrm{i}) \quad$ mass fraction of element $\mathrm{i}$ in EA glass, in $\mathrm{g} / \mathrm{g}$

note: negative values give detection limit values

Sample Calculations for Test EA-24:

$\mathrm{B}, \mathrm{mg} / \mathrm{L}=\mathrm{B}, \mathrm{ACL} \cdot \mathrm{DIL} . \mathrm{FACTOR}=150 \mathrm{mg} / \mathrm{L} \cdot 2.0704=311 \mathrm{mg} / \mathrm{L}$

$\mathrm{NL}(\mathrm{B})=\{\mathrm{B}, \mathrm{mg} / \mathrm{L}-\mathrm{BKGND}(\mathrm{B})\} /\left\{(\mathrm{S} / \mathrm{V}) \bullet \mathrm{f}_{\mathrm{B}}\right\}$

$=\{150 \mathrm{mg} / \mathrm{L}-0.23\} /\left\{2000 \mathrm{~m}^{-1} \bullet 0.347\right\}=4.48 \mathrm{~g} / \mathrm{m}^{2}$ 


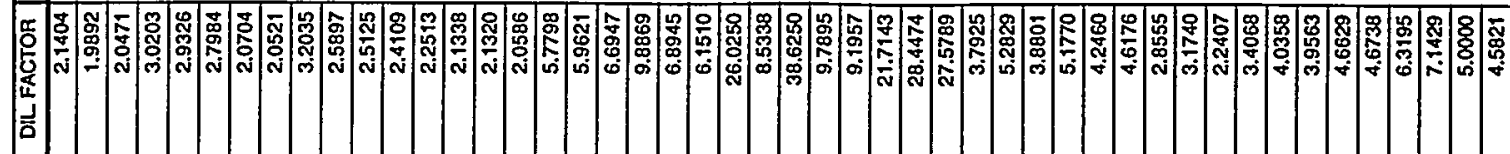

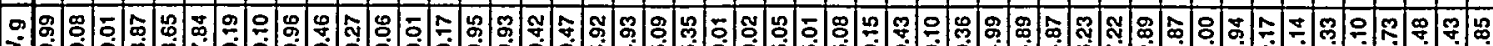

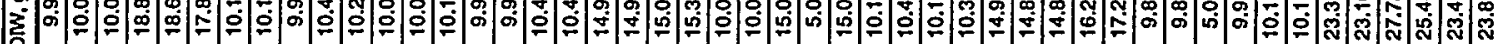

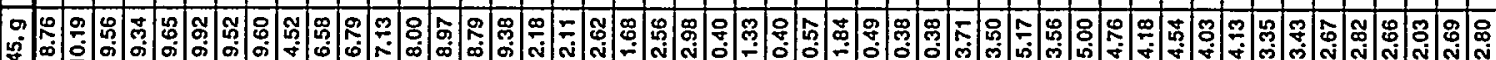
实

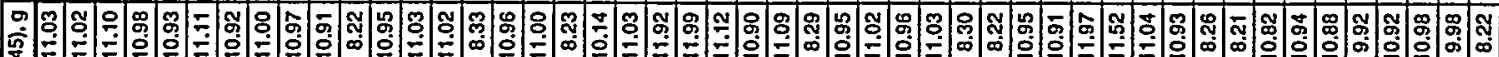
言

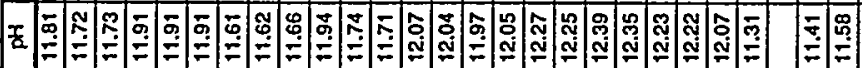

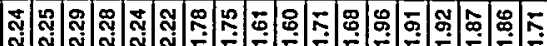

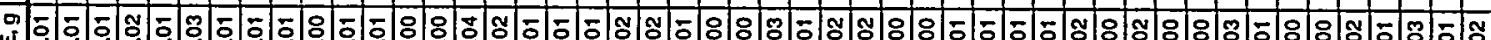

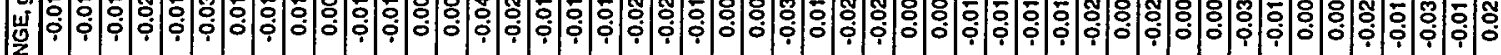

预

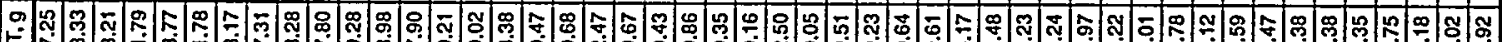

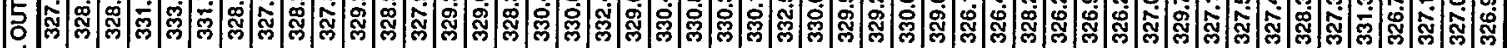

站

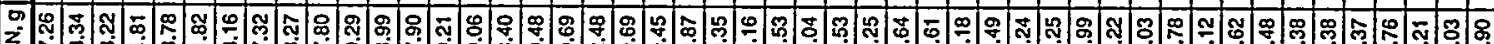

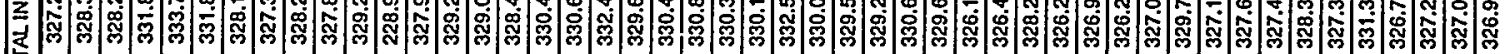

占

草

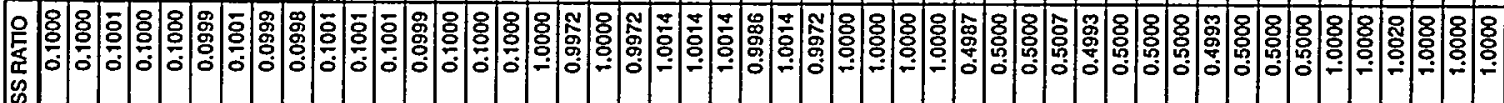

空

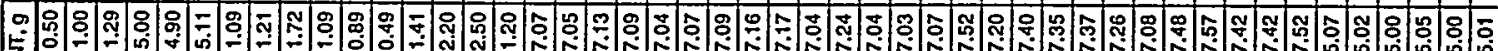
这

⿶凵్

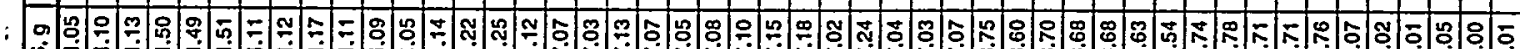

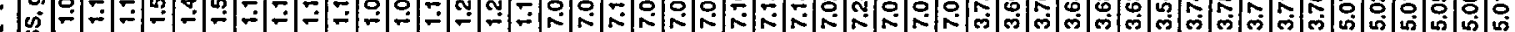

过

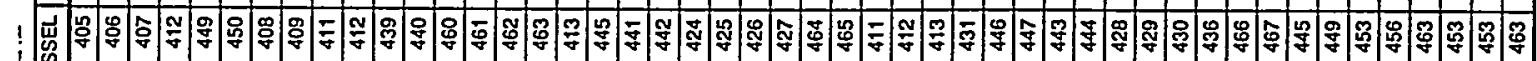

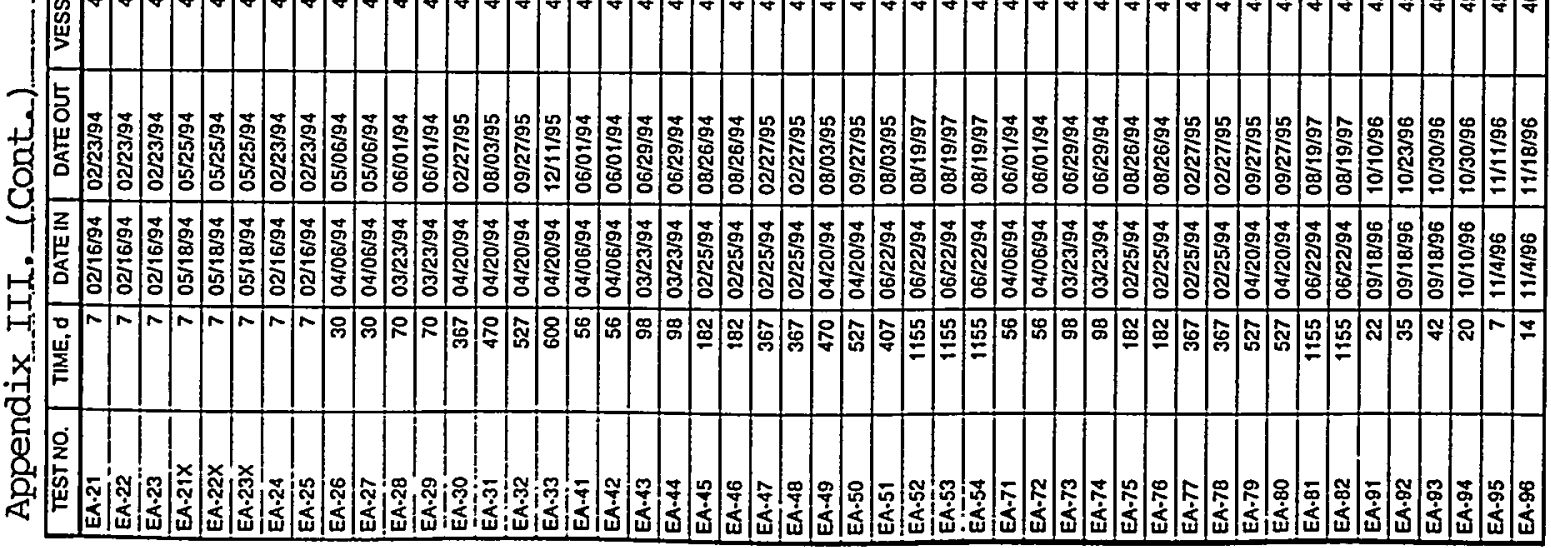


Appendix III. (Cont.)

\begin{tabular}{|c|c|c|c|c|c|c|c|c|c|c|c|c|c|c|c|c|c|}
\hline TEST NO. & TIME, d & pH & DILFACTOR & SN. Im & SIZE & FILE & $\overline{A 1}, \mathrm{ACL}$ & $A t_{1}, m g / h$ & $\mathrm{NL}(\mathrm{AL}) . \mathrm{g} / \mathrm{m} 2$ & $\overline{B, A C L}$ & $B, m g h$ & $N L(B), g / m 2$ & $B a, A C L$ & $\mathrm{Ba}, \mathrm{mgl}$ & $\overline{C a, A C L}$ & Ca, mgh & $\mathrm{NL}$ (Ca), $g / \mathrm{m} 2$ \\
\hline EA.24 & 7 & 11.61 & 2.0704 & 2000 & \begin{tabular}{|l|}
$-100+200$ \\
\end{tabular} & PACKET.2 & 0.727 & 1.51 & 0.0025 & 150 & 311 & 4.49 & 0.0002 & 0.00043 & 2.36 & 4.88 & 0.0956 \\
\hline EA.25 & 7 & 11.62 & 2.0521 & 2000 & $.100+200$ & \begin{tabular}{|l|} 
PACKET.2 \\
\end{tabular} & 0.738 & 1.51 & 0.0028 & 154 & 316 & 4.56 & 0.0002 & 0.00046 & 2.77 & 5.69 & 0.141 \\
\hline EA.26 & 30 & 11.66 & 3.2035 & 2000 & $-100+200$ & \begin{tabular}{|c|}
$94.0396 \cdot 17$ \\
\end{tabular} & 0.33 & 1.06 & -0.01 & 218 & 698 & 10.1 & .0 .05 & -0.2 & -0.01 & .0 .04 & .0 .2 \\
\hline EA.27 & 30 & 11.94 & 2.5897 & 2000 & $-100+200$ & \begin{tabular}{|c|}
$94-0396-18$ \\
\end{tabular} & 0.47 & 1.22 & .0 .006 & 120 & 310 & 4.47 & .0 .05 & .0 .2 & .0 .01 & .0 .03 & .0 .2 \\
\hline$E A \cdot 28$ & 70 & 11.74 & 2.5125 & 2000 & $.100+200$ & \begin{tabular}{|c|}
$94-0476 \cdot 14$ \\
\end{tabular} & 1.65 & 4.15 & 0.072 & 149 & 374 & 5.39 & .0 .3 & .0 .8 & -0.05 & .0 .2 & .0 .2 \\
\hline$\overline{E A \cdot 29}$ & 70 & 11.71 & 2.4109 & 2000 & $-100+200$ & \begin{tabular}{|l|}
$94-0396-19$ \\
\end{tabular} & 0.63 & 1.52 & 0.0029 & 139 & 335 & 4.83 & $\begin{array}{r}.0 .05 \\
\end{array}$ & $\cdot 0.2$ & -0.01 & .0 .03 & .0 .2 \\
\hline EA.30 & 313 & 12.07 & 2.2513 & 2000 & $-100+200$ & WE950342b & 0.378 & 0.85 & .0 .02 & 179 & 402 & 5.8 & 0.0009 & 0.0021 & 8.42 & 19 & 0.896 \\
\hline$E A \cdot 3 i$ & 470 & 12.04 & 2.1338 & 2000 & $-100+200$ & WE950823 & 0.417 & 0.89 & .0 .02 & 1120 & 2390 & 34.4 & 0.0018 & 0.0039 & 5.75 & 12.3 & 0.516 \\
\hline$E A \cdot 32$ & 527 & 11.97 & 2.132 & 2000 & $-100+200$ & WLE951013b & 0.287 & 0.61 & .0 .03 & 1180 & 2520 & 36.3 & 0.0016 & 0.0034 & 7.7 & 16.4 & 0.752 \\
\hline$E A .33$ & 600 & 12.05 & 2.0586 & 2000 & $-100+200$ & WLE960118a & 0.547 & 0.13 & .0 .008 & 1140 & 2350 & 33.8 & & & 11.9 & 24.5 & 1.21 \\
\hline EA-Ai & 56 & 12,27 & 5.7798 & 20000 & \begin{tabular}{|l|}
$.100+200$ \\
\end{tabular} & \begin{tabular}{|l|}
$94-0476-15$ \\
\end{tabular} & 0.8 & 4.62 & 0.0085 & 1320 & 7630 & 11 & .0 .3 & -2 & 0.14 & 0.809 & .0 .02 \\
\hline EA.42 & 56 & 12,25 & 5.9621 & 20000 & $-100+200$ & \begin{tabular}{|l|}
$94-1476-16$ \\
\end{tabular} & 0.6 & 3.58 & 0.0057 & 1280 & 7630 & 11 & .0 .3 & -2 & 0.15 & 0.894 & .0 .02 \\
\hline$\overline{E A \cdot 43}$ & 98 & 12.39 & 6.6947 & 20000 & $-100+200$ & \begin{tabular}{|c|}
$94-0396-20$ \\
\end{tabular} & -0.1 & .0 .8 & -0.006 & 1360 & 9100 & 13.1 & .0 .05 & -0.4 & 0.06 & 0.402 & .0 .02 \\
\hline EA-4A & 98 & 12.35 & 9.8869 & 20000 & $-100+200$ & \begin{tabular}{|c|}
$94-0396-21$ \\
\end{tabular} & -0.1 & -1 & .0 .007 & 1340 & 13250 & 19.1 & .0 .05 & .0 .5 & 0.08 & 0.791 & .0 .02 \\
\hline$\overline{E A}-44-F 50$ & & & 12.075 & & & \begin{tabular}{|l|}
$94-0396-22$ \\
\end{tabular} & $\cdot 0.1$ & -2 & & 1050 & 12680 & & .0 .05 & -0.6 & 0.15 & 1.81 & \\
\hline$E A \cdot 45$ & 182 & 12.23 & 6.8945 & 20000 & $-100+200$ & \begin{tabular}{|l|}
$94-0476-06$ \\
\end{tabular} & 1.36 & 9.38 & 0.021 & 2430 & 16750 & 24.1 & .0 .3 & .2 & 0.16 & 1.1 & .0 .02 \\
\hline$E A-46$ & 182 & 12.22 & 6.151 & 20000 & $-100+200$ & \begin{tabular}{|c|}
$94-0476-07$ \\
\end{tabular} & 2.23 & 13.7 & 0.032 & 2910 & 17900 & 25.8 & $\cdot 0.3$ & -2 & 0.22 & 1.35 & .0 .02 \\
\hline$\overline{E A \cdot 47}$ & 367 & 12.07 & 26.025 & 20000 & \begin{tabular}{|l|}
$-100+200$ \\
\end{tabular} & WE9503420 & 1.61 & 41.9 & 0.11 & 767 & 19960 & 28.8 & 0.0066 & 0.17 & 8.73 & 227 & 1.27 \\
\hline$E A \cdot 48$ & 367 & 11.31 & 8.5338 & 20000 & $-100+200$ & WE950342b & 3.46 & 29.5 & 0.074 & 3240 & 27650 & 39.8 & 0.021 & 0.18 & 5.3 & 45.2 & 0.239 \\
\hline$\overline{E A-49}$ & 470 & & 38.625 & 20000 & $-100+200$ & \begin{tabular}{|l|} 
WE950823 \\
\end{tabular} & 0.779 & 30.1 & 0.076 & 738 & 28500 & 41.1 & 0.0044 & 0.17 & 2.5 & 96.6 & 0.531 \\
\hline EA-50 & 527 & 11.41 & 9.7895 & 20000 & $-100+200$ & WLE951013b & 2.02 & 19.8 & 0.048 & 3200 & 31330 & 45.1 & 0.0181 & 0.18 & 1.99 & 19.5 & 0.0926 \\
\hline$\overline{E A-51}$ & 407 & 11.58 & 9.1957 & 20000 & $-100+200$ & WE950823 & 0.86 & 7.91 & 0.017 & 2690 & 24740 & 35.6 & 0.0025 & 0.023 & $\overline{6.95}$ & 63.9 & 0.345 \\
\hline$\overline{E A-52}$ & 1155 & & 21.714 & 20000 & $-100+200$ & WLE971222b & 0.812 & 17.6 & 0.043 & 1180 & 25620 & 36.9 & 0.0038 & 0.083 & 5.47 & 119 & 0.657 \\
\hline$E A \cdot 53$ & 1155 & & 28.447 & 20000 & $-100+200$ & WLE971222b & 0.902 & 25.7 & 0.064 & 907 & 25800 & 37.2 & 0.0034 & 0.097 & 4.7 & 134 & 0.742 \\
\hline EA-54 & 1155 & & 27.579 & 20000 & $-100+200$ & WLE971222b & 0.91 & 25.1 & 0.062 & 917 & 25290 & 36.4 & 0.0036 & 0.1 & 4.73 & 130 & 0.724 \\
\hline$\overline{E A .71}$ & 56 & 12.24 & 3.7925 & 20000 & $-200+325$ & \begin{tabular}{|l|}
$94 \cdot 0476 \cdot 17$ \\
\end{tabular} & 0.85 & 3.22 & 0.0048 & 1660 & 6290 & 9.07 & -0.3 & .2 & 0.25 & 0.948 & -0.02 \\
\hline$\overline{E A-72}$ & 56 & 12,25 & 5.2829 & 20000 & $-200+325$ & \begin{tabular}{|l|}
$94-0396-23$ \\
\end{tabular} & 0.13 & 0.687 & .0 .002 & 1220 & 6440 & 9.29 & -0.05 & .0 .3 & -0.01 & -0.06 & -0.02 \\
\hline EA-73 & 98 & 12.29 & 3.8801 & 20000 & $-200+325$ & \begin{tabular}{|l|}
$94-0396-24$ \\
\end{tabular} & .0 .1 & -0.4 & .0 .005 & 2420 & 9390 & 13.5 & -0.05 & -0.2 & 0.08 & 0.31 & -0.02 \\
\hline EA-74 & 98 & 12.28 & 5.177 & 20000 & \begin{tabular}{|l|}
$-200+325$ \\
\end{tabular} & \begin{tabular}{|c|}
$94-0396-25$ \\
\end{tabular} & -0.1 & -0.6 & .0 .005 & 1910 & 9890 & 14.3 & .0 .05 & -0.3 & 0.07 & 0.362 & -0.02 \\
\hline EA-74.F50 & & & 2.6899 & & & \begin{tabular}{|l|}
$94-0396-26$ \\
\end{tabular} & 0.3 & 0.81 & & 737 & 1980 & & -0.05 & -0.2 & 0.23 & 0.619 & \\
\hline EA.75 & 182 & 12.24 & 4.246 & 20000 & $-200+325$ & 94.0476 .08 & 1.35 & 5.73 & 0.011 & 2590 & 11000 & 15.9 & -0.3 & .2 & 0.13 & 0.552 & -0.02 \\
\hline EA.76 & 182 & 12.22 & 4.6176 & 20000 & $-200+325$ & $94-0476-09$ & 1.62 & 7.48 & 0.016 & 2530 & 11680 & 16.8 & $\cdot 0.3$ & .2 & 0.15 & 0.693 & -0.02 \\
\hline EA-77 & 367 & 11.78 & 3.366 & 20000 & $.200+325$ & WE950342b & 5.9 & 19.9 & 0.049 & 4950 & 16660 & 24 & 0.0086 & 0.029 & 31.4 & 106 & 0.583 \\
\hline EA.78 & 367 & 11.75 & 3.174 & 20000 & $-200+325$ & WE950342b & 4.67 & 14.8 & 0.035 & 5320 & 16890 & 24.3 & 0.0119 & 0.038 & 10.9 & 34,6 & 0.179 \\
\hline EA-79 & 527 & 11.61 & 2.2407 & 20000 & $-200+325$ & WLE951013b & 4.13 & 9.25 & 0.021 & 7680 & 17210 & 24.8 & 0.0228 & 0.051 & 18.2 & 40.8 & 0.214 \\
\hline EA-BO & 527 & 11.60 & 3.4068 & 20000 & $-200+325$ & WLE951013b & 1.86 & 6.34 & 0.013 & 4920 & 16760 & 24.2 & 0.0093 & 0.032 & 16.5 & 56.2 & 0.302 \\
\hline EA.81 & 1155 & 11.71 & 4.0358 & 20000 & $.200+325$ & WLE971222b & 1.51 & 6.09 & 0.012 & 3460 & 13960 & 20.1 & 0.0037 & 0.01 & 11.8 & 47.6 & 0.253 \\
\hline EA-82 & 1155 & 11.68 & 3.9563 & 20000 & $-200+325$ & WLE971222b & 1.93 & 7.64 & 0.016 & 3380 & 13370 & 19.3 & 0.0037 & 0.015 & 12.4 & 49.1 & 0.261 \\
\hline$E A-91$ & 22 & 11.96 & 4.6629 & 20000 & $-100+200$ & wo.970110 & -4 & -19 & -0.06 & 1620 & 7550 & 10.9 & & & & & \\
\hline EA.92 & 35 & 11.91 & 4.6738 & 20000 & $-100+200$ & \begin{tabular}{|l|l|} 
W 0.970110 \\
\end{tabular} & -4 & -19 & -0.06 & 2120 & 9910 & 14.3 & & & & & \\
\hline$\overline{E A \cdot 93}$ & 42 & 11.92 & 6.3195 & 20000 & $-100+200$ & \begin{tabular}{|l|l|} 
we.970110 \\
\end{tabular} & -4 & -26 & -0.07 & 1570 & 9920 & 14.3 & & & & & \\
\hline EA-94 & 20 & 11.87 & 7.1429 & 20000 & $-100+200$ & we.970110 & -4 & -29 & -0.08 & 793 & 5660 & 8.16 & & & & & \\
\hline \begin{tabular}{|l|}
$E A \cdot 95$ \\
\end{tabular} & 7 & 11.86 & 5 & 20000 & $-100+200$ & we. 970110 & -4 & -20 & -0.06 & 710 & 3550 & 5.11 & & & & & \\
\hline EA-96 & 14 & 11.71 & 4.5821 & 20000 & $-100+200$ & W6.970110 & -4 & -19 & -0.06 & 844 & 3870 & 5.57 & & & & & \\
\hline BKGND & & & 1 & & & & & 1.41 & & & 0.231 & & & 0 & & 3.2 & \\
\hline$i(1)$ & & & 1 & & & & & 0.019 & & & 0.0347 & & & 0 & & 0.0088 & \\
\hline
\end{tabular}




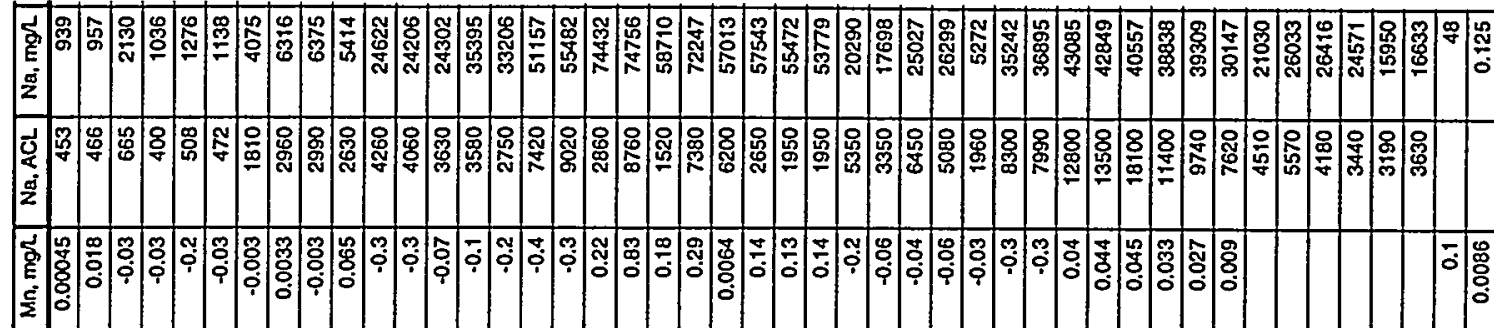

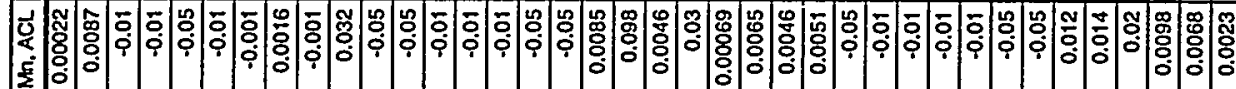

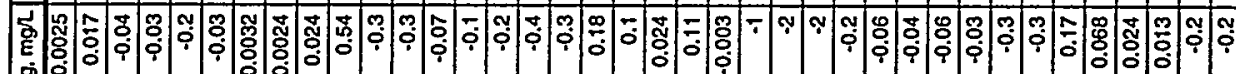

$\frac{5}{2}$

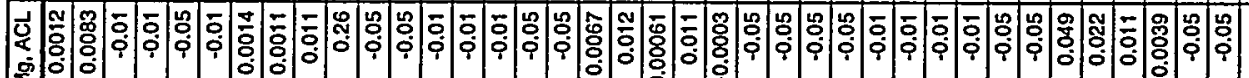

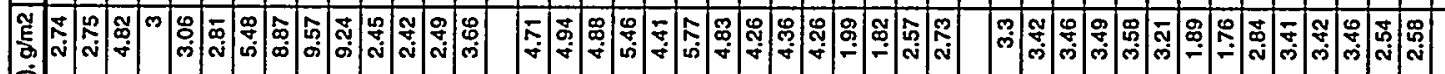

产

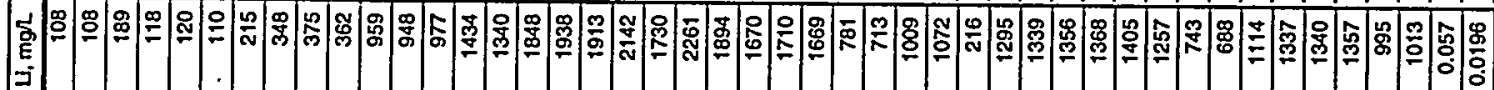

$\exists$

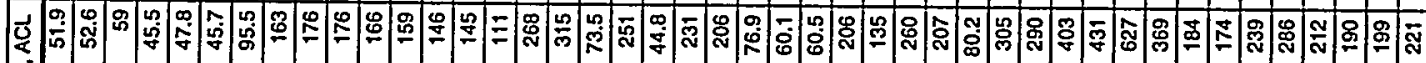

כ

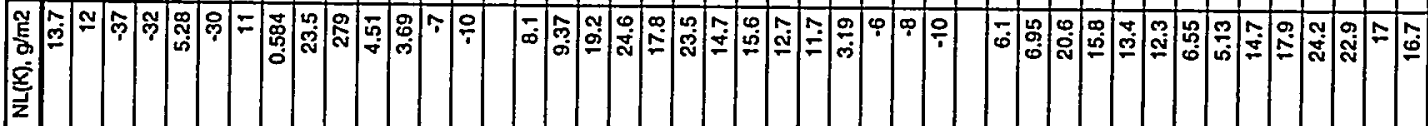

Б)

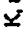

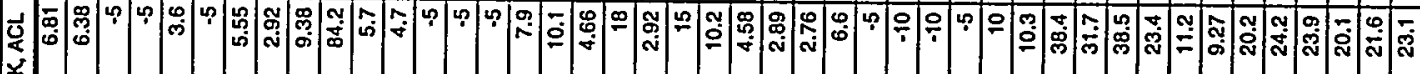

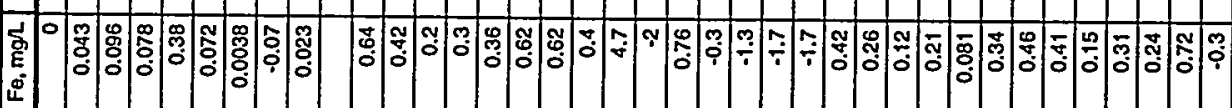

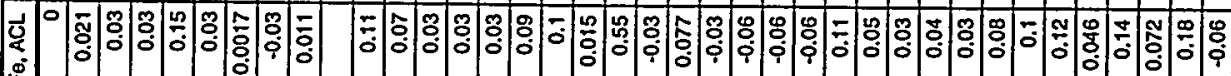

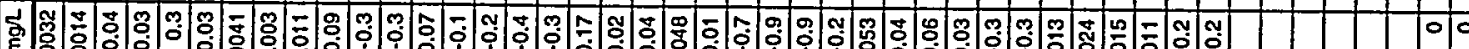
它

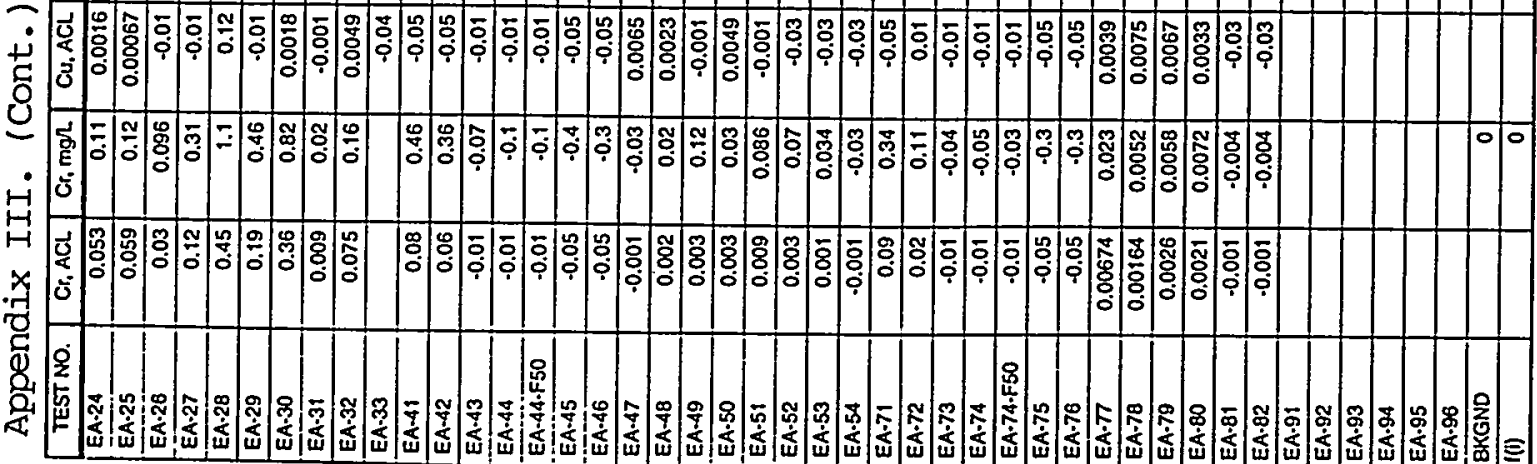


Appendix III (Cont.)

\begin{tabular}{|c|c|c|c|c|c|c|c|c|c|c|c|c|}
\hline TEST NO. & $\mathrm{NL}(\mathrm{Na}), \mathrm{g} / \mathrm{m} 2$ & $\mathrm{Ni}, \mathrm{ACl}$ & $\mathrm{Ni}, \mathrm{mgl}$ & $\overline{S I}, \mathbf{A C L}$ & $S 1, m g h$ & NL(SI), g/m2 & $\pi, A C L$ & $\pi, m g h$ & $\mathrm{Zn,ACL}$ & $Z n, m g l$ & $Z \pi, A C L$ & $2 r_{1} \mathrm{mg} / \mathrm{l}$ \\
\hline EA.24 & 3.56 & 0.002 & 0.0042 & 308 & 637 & 1.31 & 0.0029 & 0.006 & 0.0048 & 0.0099 & 0.00046 & 0.00095 \\
\hline EA.25 & 3.64 & 0.0053 & 0.011 & 307 & 629 & 1.29 & 0.0073 & 0.015 & 0.0042 & 0.0086 & 0.00065 & 0.0013 \\
\hline EA-26 & 8.33 & 0.02 & 0.064 & 323 & 1040 & 2.18 & -0.02 & .0 .07 & $\begin{array}{r}-0.01 \\
\end{array}$ & -0.04 & .0 .02 & .0 .07 \\
\hline EA.27 & 3.95 & 0.03 & 0.078 & 242 & 627 & 1.28 & -0.02 & .0 .06 & 0.01 & 0.026 & -0.02 & -0.06 \\
\hline EA-28 & 4.91 & 0.37 & 0.93 & 269 & 676 & 1.39 & .0 .1 & $\cdot 0.3$ & -0.05 & -0.2 & 0.11 & 0.28 \\
\hline EA-29 & 4.36 & 0.04 & 0.096 & 275 & 663 & 1.36 & .0 .02 & -0.05 & -0.01 & -0.03 & -0.02 & .0 .05 \\
\hline EA-30 & 16.11 & 0.0024 & 0.0054 & 809 & 1820 & 3.9 & 0.0025 & 0.0056 & 0.012 & 0.024 & 0.0012 & 0.0026 \\
\hline EA-31 & 25.07 & 0.0051 & 0.011 & 861 & 1840 & 3.94 & 0.0015 & 0.0033 & & & 0.0044 & 0.0093 \\
\hline EA-32 & 25.31 & 0.0032 & 0.0067 & 1210 & 2580 & 5.57 & 0.0017 & 0.0036 & 0.0097 & 0.021 & 0.0034 & 0.0073 \\
\hline EA-33 & 21.46 & -0.5 & -1 & 1170 & 2410 & 5.19 & & & 0.87 & 1.8 & -0.1 & -0.2 \\
\hline EA-41 & 9.83 & 0.24 & 1.4 & 153 & 884 & 0.185 & -0.1 & -0.6 & -0.05 & .0 .3 & .0 .05 & .0 .3 \\
\hline EA.42 & 9.66 & 0.13 & 0.78 & 172 & 1030 & 0.216 & .0 .1 & .0 .6 & -0.05 & -0.3 & .0 .05 & .0 .3 \\
\hline EA-43 & 9.7 & -0.02 & .0 .2 & 154 & 1030 & 0.217 & -0.02 & -0.2 & -0.01 & -0.07 & .0 .02 & .0 .2 \\
\hline EA-44 & 14.14 & .0 .02 & -0.2 & 136 & 1340 & 0.286 & -0.02 & -0.2 & -0.01 & -0.1 & -0.02 & -0.2 \\
\hline EA-44-F50 & & 0.02 & 0.24 & 136 & 1640 & & -0.02 & .0 .3 & .0 .01 & .0 .2 & -0.02 & -0.3 \\
\hline EA-45 & 20.44 & 0.17 & 12 & 1050 & 7240 & 1.58 & .0 .1 & -0.7 & -0.05 & -0.4 & .0 .1 & -0.7 \\
\hline EA-46 & 22.17 & 0.19 & 9.2 & 1280 & 7870 & 1.72 & .0 .1 & -0.7 & -0.05 & -0.3 & -0.1 & -0.7 \\
\hline$E A-47$ & 29.75 & 0.002 & 0.051 & 780 & 20300 & 4.44 & 0.0093 & 0.24 & 0.018 & 0.46 & 1.3 & 33 \\
\hline EA-48 & 29,88 & 0.039 & 0.33 & 436 & 3720 & 0.807 & 0.05 & 0.43 & 0.04 & 0.34 & 8.5 & 72 \\
\hline EA-49 & 23.46 & 0.0026 & 0.1 & 452 & 17460 & 3.82 & 0.0044 & 0.17 & 0.029 & 1.1 & 0.76 & 30 \\
\hline EA-50 & 28.88 & 0.011 & 0.11 & 1240 & 12140 & 2.65 & 0.0077 & 0.076 & & & 0.024 & 0.24 \\
\hline EA.51 & 22.79 & 0.0064 & 0.059 & 1040 & 9560 & 2.09 & 0.0026 & 0.024 & & & 0.054 & 0.5 \\
\hline$\overline{E A-52}$ & 23 & -0.005 & $\begin{array}{c}0.1 \\
\end{array}$ & 546 & 11860 & 2.59 & 0.0083 & 0.18 & -0.007 & -0.2 & 1.2 & 26 \\
\hline$E A \cdot 53$ & 22.17 & -0.005 & -0.2 & 545 & 15500 & 3.39 & 0.0046 & 0.13 & -0.007 & -0.2 & 1.1 & 30 \\
\hline EA-54 & 21.49 & -0.005 & -0.2 & 604 & 16660 & 3.64 & 0.0051 & 0.14 & -0.007 & .0 .2 & 1.1 & 30 \\
\hline EA-71 & 8.1 & 0.21 & 0.8 & 331 & 1260 & 0.266 & -0.1 & -0.4 & -0.05 & -0.2 & -0.05 & $\cdot 0.2$ \\
\hline EA.72 & 7.06 & 0.07 & 0.37 & 95.9 & 506 & 0.102 & -0.02 & -0.1 & -0.01 & -0.06 & -0.02 & .0 .1 \\
\hline EA-73 & 9.99 & -0.02 & -0.08 & 731 & 2840 & 0.613 & -0.02 & -0.08 & 0.01 & 0.039 & -0.02 & -0.08 \\
\hline EA.74 & 10.5 & -0.02 & -0.1 & 220 & 1140 & 0.241 & -0.02 & .0 .1 & 0.01 & 0.052 & -0.02 & .0 .1 \\
\hline EA-74-F50 & & -0.02 & .0 .06 & 396 & 1070 & & -0.02 & -0.06 & 0.02 & 0.054 & -0.02 & .0 .06 \\
\hline EA-75 & 14.08 & 0.12 & 0.51 & 1550 & 6580 & 1.43 & .0 .1 & -0.5 & -0.05 & $\begin{array}{c}-0.3 \\
\end{array}$ & 0.23 & 0.98 \\
\hline EA-78 & 14.74 & 0.18 & 0.83 & 1450 & 6700 & 1.46 & .0 .1 & -0.5 & -0.05 & -0.3 & 0.27 & 1.3 \\
\hline EA-77 & 17.21 & 0.025 & 0.085 & 1700 & 5720 & 1.25 & 0.01 & 0.034 & 0.06 & 0.2 & 0.49 & 1.7 \\
\hline EA-78 & 17.12 & 0.024 & 0.076 & 2420 & 7680 & 1.68 & 0.0084 & 0.027 & 0.03 & 0.096 & 0.55 & 1.7 \\
\hline EA-79 & $\begin{array}{ll}16.2 \\
\end{array}$ & 0.01 & 0.023 & 2350 & 5270 & 1.15 & 0.0063 & 0.014 & 0.015 & 0.033 & 0.0064 & 0.014 \\
\hline EA-80 & 15.52 & 0.011 & 0.036 & 2120 & 7220 & 1.58 & 0.0034 & 0.011 & 0.0062 & 0.021 & 0.12 & 0.41 \\
\hline$E A-81$ & 15.7 & 0.013 & 0.051 & 1610 & 6500 & 1.42 & 0.0068 & 0.027 & -0.007 & -0.03 & 0.31 & 1.2 \\
\hline EA-82 & 12.04 & -0.005 & -0.02 & 1480 & 5850 & 1.28 & 0.0023 & 0.009 & -0.007 & -0.03 & 0.45 & 1.8 \\
\hline EA-91 & 8.39 & & & 113 & 527 & 0.107 & & & & & & \\
\hline EA-92 & 10.39 & & & 839 & 3920 & 0.851 & & & & & & \\
\hline EA.93 & 10.55 & & & 154 & 973 & 0.204 & & & & & & \\
\hline EA-94 & 9.81 & & & 167 & 1190 & 0.253 & & & & & & \\
\hline EA-95 & 6.36 & & & 694 & 3470 & 0.752 & & & & & & \\
\hline EA-96 & 6.63 & & & 787 & 3610 & $\begin{array}{l}0.782 \\
\end{array}$ & & & & & & \\
\hline BKGND & & & 0.024 & & 41.1 & & & 0.015 & & 0.01 & & 0 \\
\hline (i) & & & 0.004 & & 0.228 & & & 0.0039 & & 0.0021 & & 0.0036 \\
\hline
\end{tabular}


Appendix IV. Solution Analytical Results for Carbon and Anions

TEST NO. Test number

TIME, $d$

Test duration, in days

$\mathrm{pH}$

measured solution $\mathrm{pH}$

(a blank indicates that the $\mathrm{pH}$ was not measured because not enough solution could be recovered from the test)

$\mathrm{S} / \mathrm{V}, \mathrm{m} \quad \mathrm{S} / \mathrm{V}$ ratio of test, in $\mathrm{m}^{-1}$

CARBON DF dilution factor for aliquot analyzed for organic and total carbon

TC, ACL concentration of total carbon from analysis, $\mathrm{mg} / \mathrm{L}$ elemental carbon

TOC, ACL concentration of total organic carbon from analysis, $\mathrm{mg} / \mathrm{L}$ elemental carbon

$\mathrm{TC}, \mathrm{mg} / \mathrm{L} \quad$ concentration of total carbon corrected for dilution, $\mathrm{mg} / \mathrm{L}$ elemental carbon

TOC, $\mathrm{mg} / \mathrm{L} \quad$ concentration of total carbon organic carbon corrected for dilution,

$\mathrm{TIC}, \mathrm{mg} / \mathrm{L} \quad$ concentration of total inorganic carbon calculated as TC-TOC, $\mathrm{mg} / \mathrm{L}$ elemental carbon

ACL NO. sample number assigned by analytical chemistry laboratory

ANION DF dilution factor for aliquot analyzed for anions

i, ACL raw concentration measured for species $i$, in $\mathrm{mg} / \mathrm{L}$

i, $\mathrm{mg} / \mathrm{L}$ concentration of $i$ corrected for dilution, in $\mathrm{mg} / \mathrm{L}$

EJ-13-1/4/94 concentration of element i measured in EJ-13 solution used, in $\mathrm{mg} / \mathrm{L}$ 
Appendix IV. (Cont.)

\begin{tabular}{|c|c|c|c|c|c|c|c|c|c|c|c|c|}
\hline TEST NO. & ACL NO. & ANIONDF & $\mathrm{F}=\mathrm{ACL}$ & $F_{-}, m g h$ & CL-, ACL & $\mathrm{Cl}-\mathrm{mg} / \mathrm{L}$ & NO3-, ACL & NO3-, mgl & $\mathrm{HPO} 4=, \mathrm{ACL}$ & $\mathrm{HPO} 4=, m g h$ & $\mathrm{SO} 4=\mathrm{ACL}$ & $\mathrm{SO} 4=, \mathrm{mg} h$ \\
\hline \multicolumn{13}{|l|}{ EA-21 } \\
\hline \multicolumn{13}{|l|}{$\overline{E A-22}$} \\
\hline \multicolumn{13}{|l|}{ EA-23 } \\
\hline EA-21X & $94-0365-12$ & 1.5652 & -0.1 & -0.157 & 0.75 & 1.17 & 0.35 & 0.548 & 1.7 & 2.66 & 2.1 & 3.29 \\
\hline EA-22X & 94-0365-13 & 1.6837 & & & 0.76 & 1.28 & 0.27 & 0.455 & 1.6 & 2.69 & 2.8 & 4.71 \\
\hline EA-23X & $94-0365-14$ & 1.7685 & & & 1 & 1.77 & 0.29 & 0.513 & 1.6 & 2.83 & 2.4 & 4.24 \\
\hline & & & & & & & & & & & & \\
\hline \multicolumn{13}{|l|}{ EA-24 } \\
\hline \multicolumn{13}{|l|}{ EA-25 } \\
\hline EA-26 & $94-0365-15$ & 1.8632 & 0.72 & 1.34 & 4.5 & 8.38 & 5.3 & 9.87 & 1.7 & 3.17 & 12.7 & 23.7 \\
\hline EA-27 & $94-0365-16$ & 2.3557 & 0.64 & 1.51 & 3.6 & 8.48 & 4.4 & 10.4 & 0.96 & 2.26 & 9.4 & 22.1 \\
\hline EA-28 & $94-0365-21$ & 2.0704 & & & 4 & 8.28 & 5 & 10.4 & 1.5 & 3.11 & 11.8 & 24.4 \\
\hline EA-29 & 94-0365-22 & 2.1789 & & & 3.9 & 8.5 & 4.7 & 10.2 & 1.1 & 2.4 & 12 & 26.1 \\
\hline EA-30 & 95-0168-03 & 2.92 & & & 3.3 & 9.6 & 3.8 & 11 & 2.6 & 7.6 & 11.2 & 32.7 \\
\hline \multicolumn{13}{|l|}{ EA-31 } \\
\hline \multicolumn{13}{|l|}{ EA-32 } \\
\hline & & & & & & & & & & & 202 & \\
\hline$\frac{E A-41}{E A-42}$ & $\frac{94-0365-17}{94-0365-18}$ & $\begin{array}{l}3.2519 \\
3.1069\end{array}$ & & & $\begin{array}{l}6.1 \\
4.8\end{array}$ & $\frac{19.8}{14.9}$ & $\begin{array}{l}4.4 \\
3.5\end{array}$ & $\frac{14.3}{10.9}$ & $\begin{array}{r}11.7 \\
9.3\end{array}$ & $\begin{array}{r}38 \\
28.9\end{array}$ & \begin{tabular}{|l|}
20.2 \\
17.3
\end{tabular} & $\frac{65.7}{53.7}$ \\
\hline \multicolumn{13}{|l|}{ EA-43 } \\
\hline$\overline{E A-44}$ & $94-0438-05$ & 1 & -10 & -10 & 46 & 46 & 51 & 51 & 58 & 58 & 125 & 125 \\
\hline EA-45 & 94-2121-05 & 1 & -10 & -10 & 85 & 85 & 16 & 16 & 128 & 128 & 215 & 215 \\
\hline EA-46 & $94-2121-06$ & 1 & -10 & -10 & 50 & 50 & 12 & 12 & 99 & 99 & 151 & 151 \\
\hline \multicolumn{13}{|l|}{ EA-47 } \\
\hline \multicolumn{13}{|l|}{ EA-48 } \\
\hline & & & & & & & & & & & & \\
\hline EA-71 & $94-0365-19$ & 3.1406 & & & 4.8 & 15.1 & 3.5 & 11 & 9.3 & 29.2 & 17.3 & 54.3 \\
\hline EA-72 & $94-0365-20$ & 2.9854 & & & 5.3 & 15.8 & 3.6 & 10.7 & 9.3 & 27.8 & 19.3 & 57.6 \\
\hline \multicolumn{13}{|l|}{ EA-73 } \\
\hline \begin{tabular}{|l|} 
EA-74 \\
\end{tabular} & 94-0438-06 & 1 & -10 & -10 & 35 & 35 & 24 & 24 & 61 & 61 & 112 & 112 \\
\hline EA-75 & $94-2121-07$ & 1 & -10 & -10 & 31 & 31 & 15 & 15 & 60 & 60 & 110 & 110 \\
\hline EA-76 & $94-2121-08$ & 1 & -10 & -10 & 67 & 67 & 22 & 22 & 59 & 59 & 116 & 116 \\
\hline EA-77 & 95-2039-05 & 1 & -1 & -1 & 46 & 46 & 22 & 22 & 17 & 17 & 36 & 36 \\
\hline EA-78 & $95-2039 \cdot 06$ & 1 & -1 & -1 & 31 & 31 & 8.8 & 8.8 & 14 & 14 & 28 & 28 \\
\hline EJ13-1/4/94 & 94-2037-01 & 1 & 3.8 & 3.8 & 11 & 11 & 16 & 16 & -0.5 & -0.5 & 30 & 30 \\
\hline
\end{tabular}




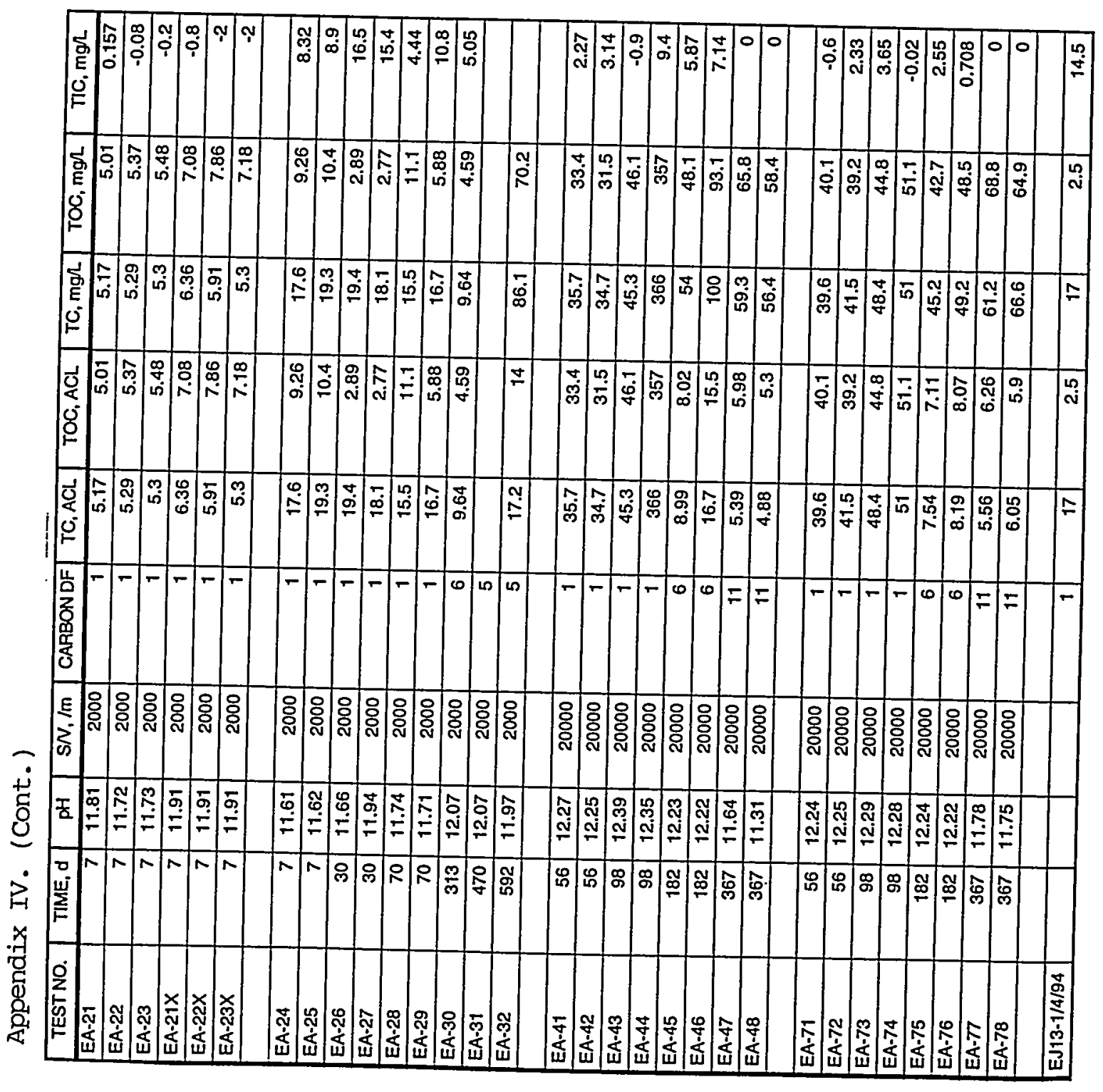


Distribution for ANL-98/27

Internal:
A. J. Bakel
M. M. Goldberg
L. R. Morss
E. C. Buck
J. E. Harmon
L. Nuñez
D. B. Chamberlain
M. C. Hash
J. C. Cunnane
J. E. Helt
T. P. O'Holleran
W. L. Ebert (25)
S. Johnson
R. A. Olson
R. E. Einziger
J. J. Laidler
S.-W. Tam
R. J. Finch
M. A. Lewis
S. F. Wolf
P. A. Finn
J. S. Luo
V. N. Zyryanov
J. Fortner
C. J. Mertz
TIS Files

\section{External:}

DOE-OSTI (2)

ANL-E Library

ANL-W Library

A. Bindokas, DOE-CH

J. C. Haugen, DOE-CH

Chemical Technology Division Review Committee Members:

H. U. Anderson, University of Missouri-Rolla, Rolla, MO

E. R. Beaver, Monsanto Company, St. Louis, MO

A. L. Bement, Purdue University, West Lafayette, IN

M. V. Koch, University of Washington, Seattle, WA

R. A. Osteryoung, North Carolina State University, Raleigh, NC

V. P. Roan, University of Florida, Palm Beach Gardens, FL

G. R. St. Pierre, Ohio State University, Columbus, $\mathrm{OH}$

T. A. Abrajano, Rensselaer Polytechnic Institute, Troy, NY

H. Adkins, TRW Environmental Safety Inc., Las Vegas, NV

T. Ahn, U.S. Nuclear Regulatory Commission, Washington, DC

D. H. Alexander, USDOE, Civilian Radioactive Waste Management, Washington, DC

M. K. Andrews, Westinghouse Savannah River Company, Aiken, SC

J. K. Bates, Plainfield, IL

R. W. Benedict, Idaho National Engineering and Environmental Laboratory, Idaho Falls, ID

H. A. Benton, Framatome Cogema Fuels, Las Vegas, NV

N. E. Bibler, Westinghouse Savannah River Company, Aiken, SC

W. L. Bourcier, Lawrence Livermore National Laboratory, Livermore, CA

N. R. Brown, USDOE, Richland Operations Office, Richland, WA

K. A. Chacey, USDOE, Office of Environmental Management, Germantown, MD

Y. Chen, Framatome Cogema Fuels, Las Vegas, NV

P. Cloke, Science Applications International Corp., Las Vegas, NV

R. C. Ewing, University of Michigan, Ann Arbor, MI

$\mathrm{X}$. Feng, Ferro Corp., Cleveland, $\mathrm{OH}$

K. M. Goff, Idaho National Engineering and Environmental Laboratory, Idaho Falls, ID 
S. E. Gomberg, USDOE, Office of Civilian Radioactive Waste Management, Washington, DC

W. G. Halsey, Lawrence Livermore National Laboratory, Livermore, CA

J. Harbor, Westinghouse Savannah River Company, Aiken, SC

J. H. Holbrook, Pacific Northwest National Laboratory, Richland, WA

E. W. Holtzscheiter, Westinghouse Savannah River Company, Aiken, SC

P. R. Hrma, Pacific Northwest National Laboratory, Richland, WA

C. G. Interrante, U.S. Nuclear Regulatory Commission, Rockville, MD

W. S. Ketola, USDOE, West Valley Project Office, West Valley, NY

D. A. Knecht, Idaho National Engineering and Environmental Laboratory, Idaho Falls, ID

P. E. LaMont, USDOE, Richland Operations Office, Richland, WA

F. M. Mann, Lockheed Martin Hanford Company, Richland, WA

B. P. McGrail, Pacific Northwest National Laboratory, Richland, WA

G. B. Mellinger, Pacific Northwest National Laboratory, Richland, WA

R. Palmer, West Valley Nuclear Services, West Valley, NY

D. K. Peeler, Westinghouse Savannah River Company, Aiken, SC

I. L. Pegg, Vitreous State Laboratory, The Catholic University of America, Washington, DC

$\mathrm{K}$. Picha, USDOE, Office of Environmental Management, Germantown, MD

G. F. Piepel, Pacific Northwest National Laboratory, Richland, WA

J. Plodinec, Mississippi State University, Mississippi State, MS

D. C. Sassani, Framatome Cogema Fuels, Las Vegas, NV

G. L. Smith, Pacific Northwest National Laboratory, Richland, WA

D. Stahl, Framatome Cogema Fuels, Las Vegas, NV

B. Staples, Lockheed Martin Idaho Technology Company, Idaho Falls, ID

C. Stockman, Framatome Cogema Fuels, Las Vegas, NV

R. B. Stout, Lawrence Livermore National Laboratory, Livermore, CA

D. M. Strachan, Pacific Northwest National Laboratory, Richland, WA

T. A. Thornton, Framatome Cogema Fuels, Las Vegas, NV

J. D. Vienna, Pacific Northwest National Laboratory, Richland, WA

G. G. Wicks, Westinghouse Savannah River Company, Aiken, SC

M. Aertsens, Centre d'Etude de L'Energie Nucleaire, Boeretang, BELGIUM

R. Baschwitz, Cogema, Velizy Cedex, FRANCE

E. Curti, Paul Scherrer Institute, Villigen, SWITZERLAND

B. Grambow, Kernforschungszentrum Karlsruhe Institut, Karlsruhe, GERMANY

L. Johnson, Atomic Energy of Canada, Ltd., Pinawa, Manitoba, CANADA

S. Luo, China Institute of Atomic Energy, Beijing, CHINA

P. Van Iseghem, Centre d'Etude de L'Energie Nucleaire, Boeretang, BELGIUM

E. R. Vance, Australian Nuclear Science \& Technology Org., Lucas Heights, AUSTRALIA

E. Vernaz, Centre d'Etudes Nucleares de la Valle du Rhone, Marcoule, FRANCE

C. M. Veyer, Commissariat a L'Energie Atomique - SCD, Saint Waast La Vallee, FRANCE 